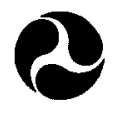

U.S. Department of Transportation National Highway

Traffic Safety

Administration

\title{
Understanding Youthful Risk Taking and Driving
}


This publication is distributed by the U.S. Department of Transportation, National Highway Traffic Safety Administration, in the interest of information exchange. The opinions, findings and conclusions expressed in this publication are those of the author(s) and not necessarily those of the Department of Transportation or the National Highway Traffic Safety Administration. The United States Government assumes no liability for its contents or use thereof. If trade or manufacturers' name or products are mentioned, it is because they are considered essential to the object of the publication and should not be construed as an endorsement. The United States Government does not endorse products or manufacturers. 
Technical Report Documentation Page

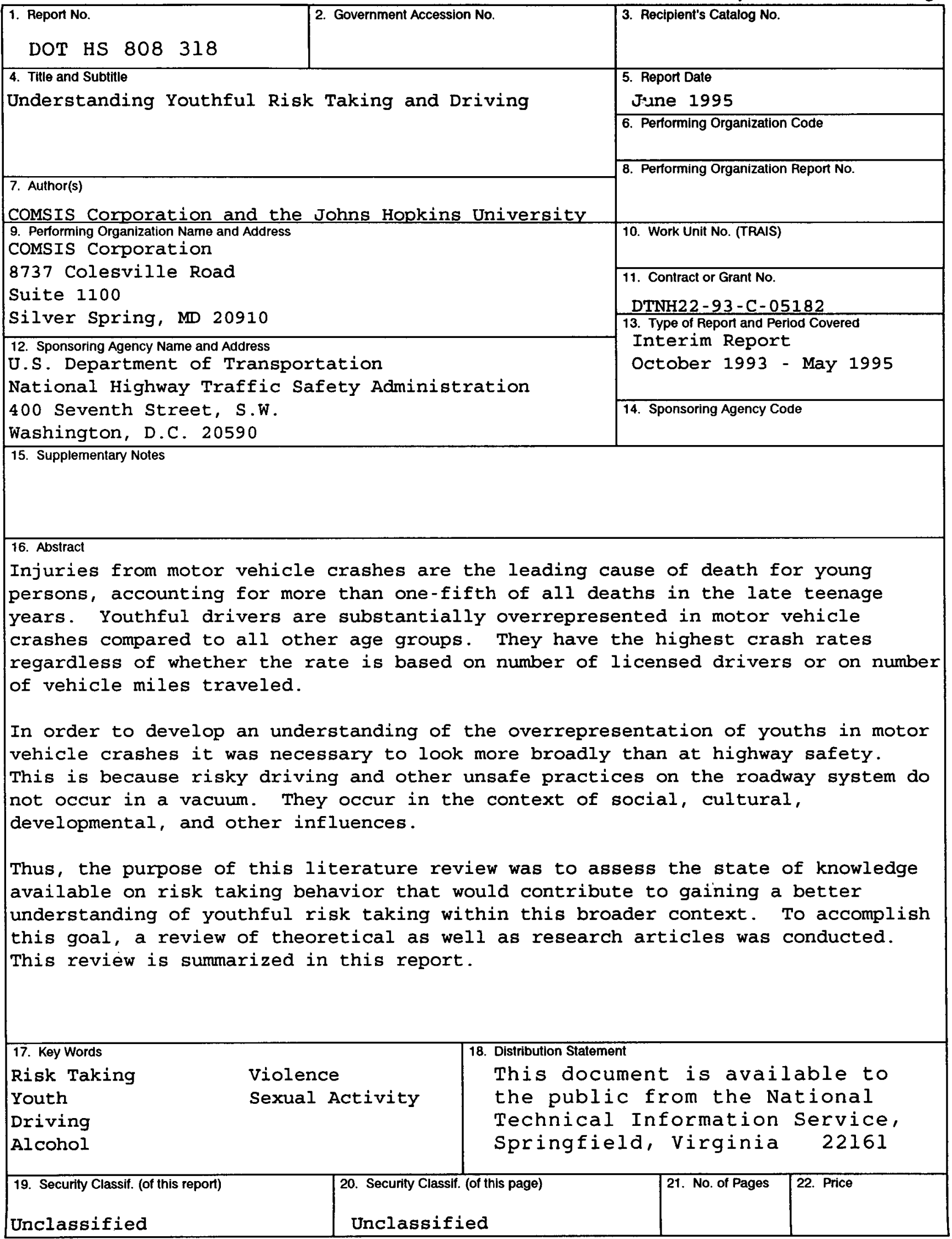

Form DOT F 1700.7 (8-72) Reproduction of completed page authorized 


\section{ACKNOWLEDGMENTS}

The Causal Model of Adolescent Risk Taking (Figure 2) was reprinted by permission of Elsevier Science Inc. from Biopsychosocial correlates of risk-taking behavior during adolescence by $\mathrm{C}$. E. Irwin and S.G. Millstein, Joumal of Adolescent Health Care, 7(Suppl), pp. 82S-96S. Copyright 1986 by the Society for Adolescent Medicine.

The figure of Zero Risk Theory (Figure 3) was reprinted by permission of North-Holland, Elsevier Science Book Division from Road-user behavior and traffic accidents by $R$. Naatanen and H. Summala. Copyright 1976 Elsevier Science.

The Threat Avoidance Model (Figure 4) was reprinted by permission of Taylor and Francis from A conceptualization of driving behavior as threat avoidance by R. Fuller, Ergonomics, 27(11), 1139-1155. Copyright 1984 Taylor \& Francis.

The Model of Behavior Feedback (Figure 5) was reprinted by permission of Leonard Evans, Ph.D. from Traffic Safety and the Driver (p. 285). Copyright 1991 Van Nostrand Reinhold, New York.

The Hierarchical Risk Model (Figure 6) was reprinted by permission of Taylor and Francis. A hierarchical risk model for traffic participants by $H$. Van Der Molen and $A$. Botticher, Ergonomics. 


\section{TABLE OF CONTENTS}

TABLE OF CONTENTS $\ldots \ldots \ldots \ldots \ldots \ldots \ldots \ldots$

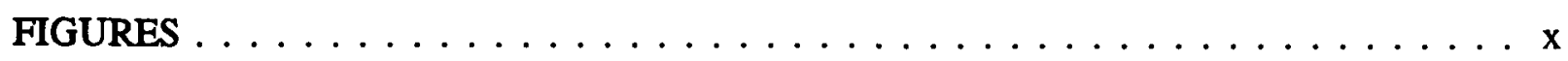

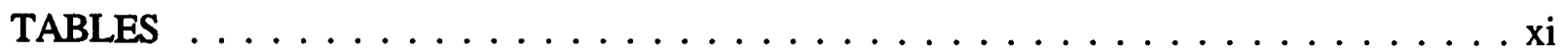

EXECUTIVE SUMMARY $\ldots \ldots \ldots \ldots \ldots \ldots \ldots \ldots \ldots \ldots \ldots \ldots \ldots \ldots \ldots$

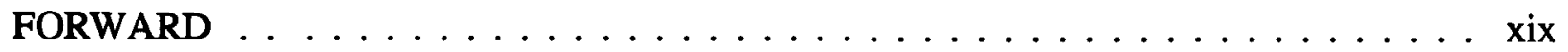

PART I. YOUTHFUL RISK TAKING BEHAVIORS . . . . . . . . . . . . . 1

1. INTEGRATED THEORIES OF YOUTHFUL RISK TAKING . . . . . . . . . 2

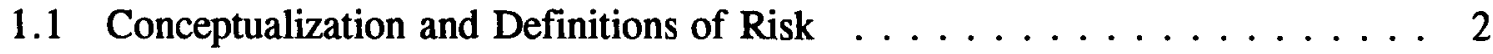

1.1.1 Biomedical Concepts of Risk ................ . 3

1.1.2 Social Developmental Concepts of Risk . . . . . . . . . . . 3

1.1.3 Cognitive Developmental Concepts of Risk . . . . . . . . . . . 6

1.1.4 Social Learning Theory Concept of Risk . . . . . . . . . . . . . . 7

1.2 Common Versus Unique Behaviors $\ldots \ldots \ldots \ldots \ldots$

1.3 Intra Versus Inter-individual Determinants of Risk Taking . . . . . . . . . 9

1.4 Volitional Versus Non-volitional Risk Taking . . . . . . . . . . . . . . 12

1.5 Developmental Versus Stationary Framework for Understanding Youthful

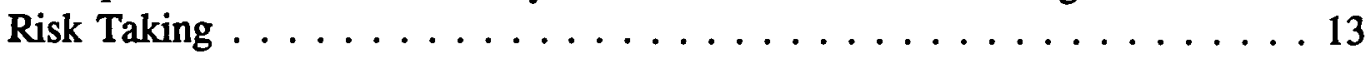

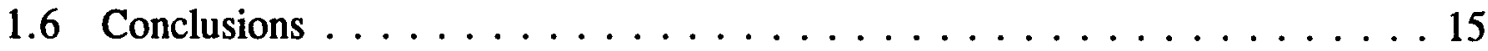

2. SUBSTANCE USE . . . . . . . . . . . . . . . . . . . 16

2.1 The Prevalence and Major Trends of Substance Use Among Youths . . . . 16

2.1.1 National Household Survey on Drug Abuse . . . . . . . . . . . 17

2.1.2 Monitoring the Future . . . . . . . . . . . . . . . 19

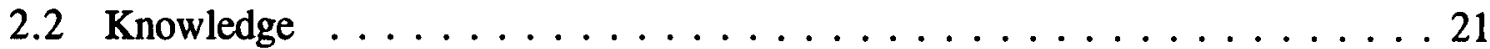

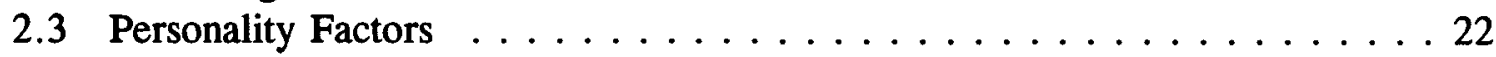

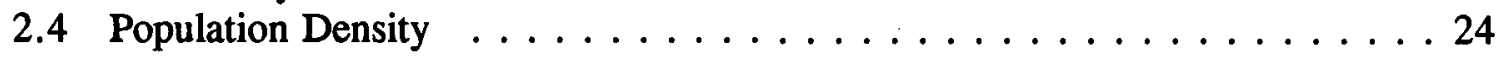

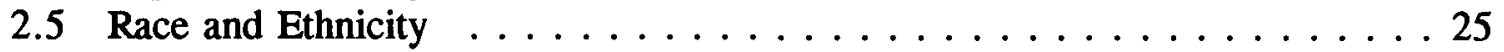

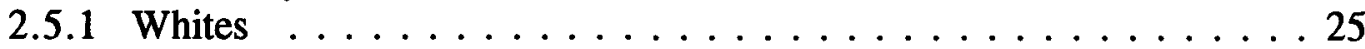

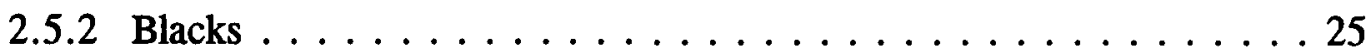

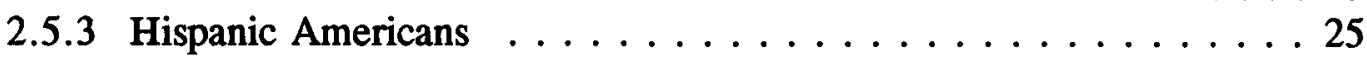

2.5 .4 Native Americans . . . . . . . . . . . . . . . 26

2.5 .5 West Indians and Asians . . . . . . . . . . . . 27

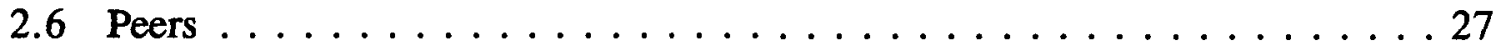

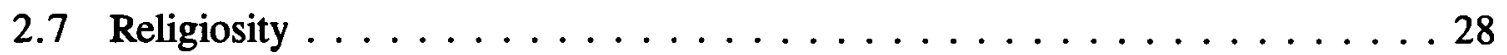

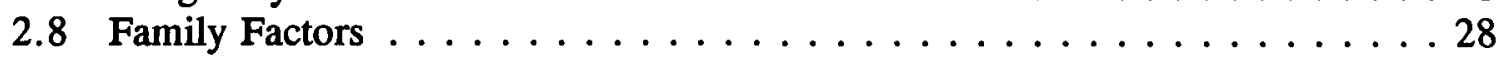




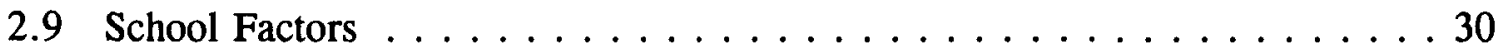

2.10 The Relationship Among High Risk Behaviors . . . . . . . . . . 30

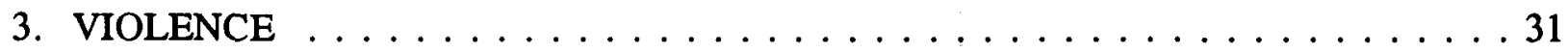

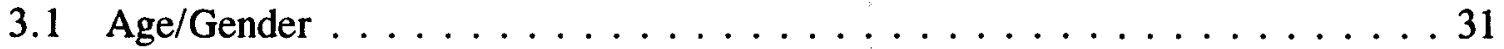

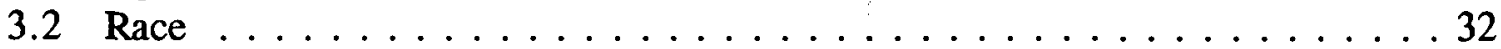

3.3 Violence as a Learned Behavior . . . . . . . . . . . . . 32

3.3.1 The Relationship of Moral Development to Juvenile Delinquency . . 33

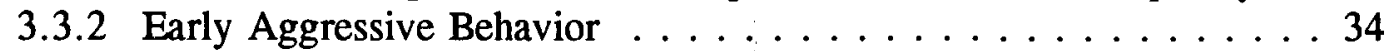

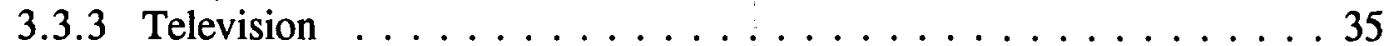

3.3.4 Victim-offender Patterns . . . . . . . . . . . . . 36

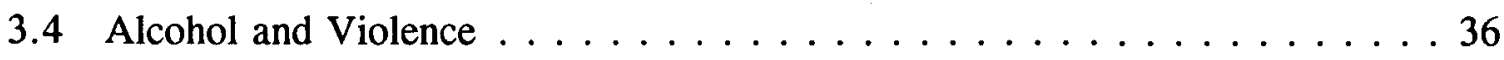

3.5 Illegal Drug Use and Violence . . . . . . . . . . . . . 37

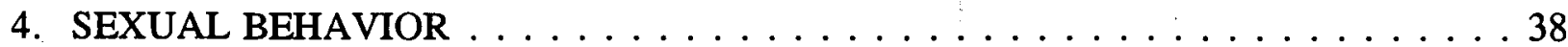

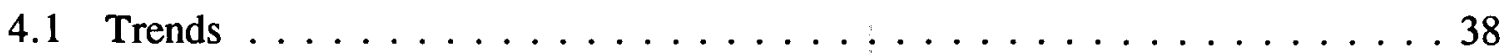

4.2 Demographics . . . . . . . . . . . . . . . . . . . . 39

4.2.1 Younger Versus Older Adolescents . . . . . . . . . . . . 39

4.2.2 Timing of Initial Sexual Intercourse . . . . . . . . . . . 39

4.2.3 Male/Female Differences . . . . . . . . . . . . . . 40

4.3 Knowledge, Attitudes, Beliefs and Patterns of Sexual Behavior . . . . . 41

4.3.1 Relationship of the Mechanics of Safe Sex to Changes in Behavior .....................41

4.3.2 Beliefs and Attitudes about Contraception, and Patterns of

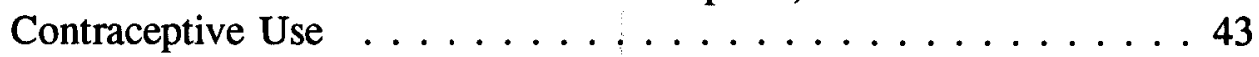

4.3.3 Coital Frequency . . . . . . . . . . . . . . 44

4.3.4 Number of Sexual Partners . . . . . . . . . . . . . . . . . 44

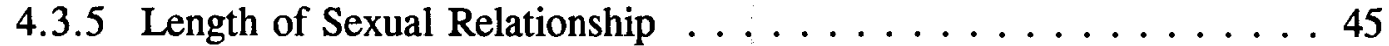

4.4 Psychological and Personality Factors . . . . . . . . . . . . 45

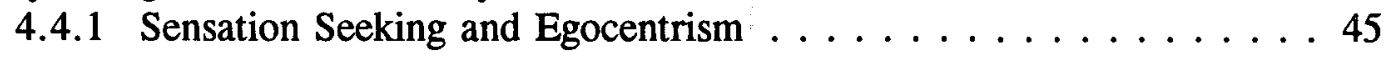

4.4.2 Self-directed Decision-making and Autonomy . . . . . . . . . 45

4.4 .3 Self-esteem . . . . . . . . . . . . . . . . . . 46

4.4 .4 Self-efficacy $\ldots \ldots \ldots \ldots \ldots \ldots \ldots \ldots \ldots \ldots$

4.4 .5 Communication Skills . . . . . . . . . . . . . . 46

4.4.6 The Belief that Pregnancy is a Mark of Maturity . . . . . . . 446

4.5 Peer Influence . . . . . . . . . . . . . . . . . . . . 47

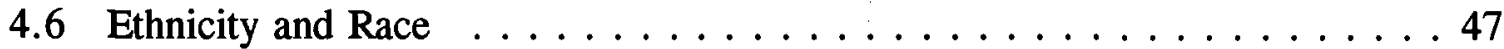

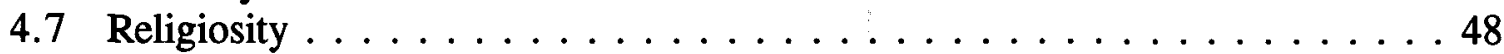

4.8 School Factors $\ldots \ldots \ldots \ldots \ldots \ldots \ldots \ldots \ldots \ldots \ldots \ldots \ldots \ldots$

4.9 Family Factors . . . . . . . . . . . . . . . . . . . . 48

4.9.1 Communication Between Parents and Children . . . . . . . . 48

4.9 .2 Marital Status of Parents . . . . . . . . . . . . . . 49

4.9.3 Parental Supervision and Control . . . . . . . . . . 49

4.9.4 Parental Attitudes and Norms . . . . . . . . . . . 50 
4.9.5 Parental Education $\ldots \ldots \ldots \ldots \ldots \ldots \ldots \ldots \ldots$

4.9.6 Parental Income . . . . . . . . . . . . . . . . . 50

4.9.7 Family Structure and the Behavior of Siblings $\ldots \ldots \ldots \ldots 51$

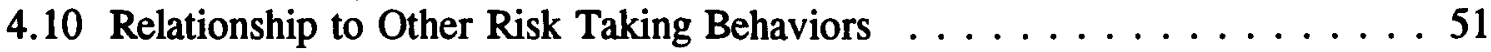

PART II: $\quad$ RISK TAKING AND DRIVING AMONG YOUTH $\ldots \ldots \ldots \ldots 2$

1. INTRODUCTION TO DRIVING $\ldots \ldots \ldots \ldots \ldots \ldots \ldots \ldots \ldots \ldots \ldots \ldots \ldots$

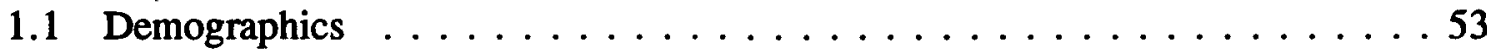

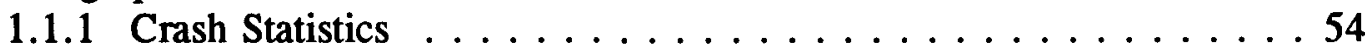

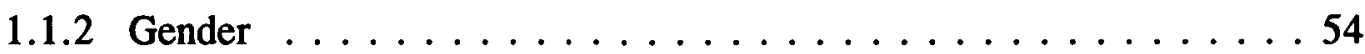

1.1.3 Race/Ethnicity . . . . . . . . . . . . . . . . 54

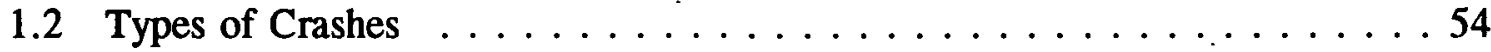

1.3 Experience . . . . . . . . . . . . . . . . 58

1.4 Driver Performance and Driver Behavior . . . . . . . . . . . . 59

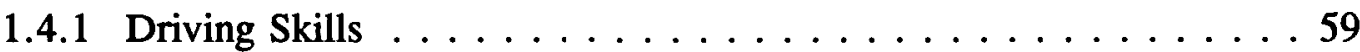

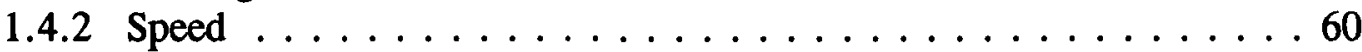

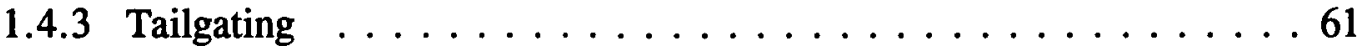

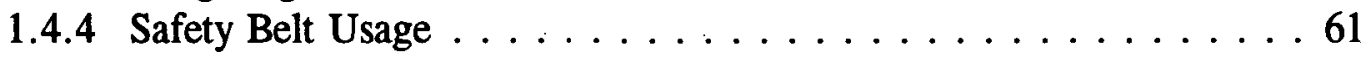

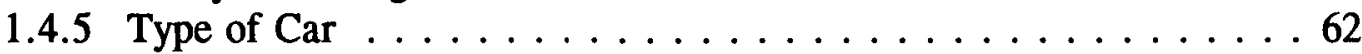

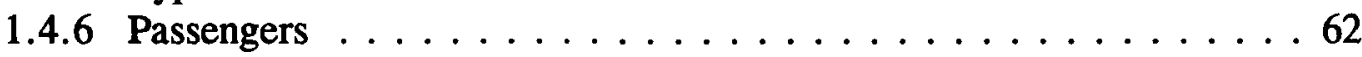

2. THEORIES OF RISK AND DRIVING $\ldots \ldots \ldots \ldots \ldots \ldots \ldots \ldots \ldots \ldots \ldots$

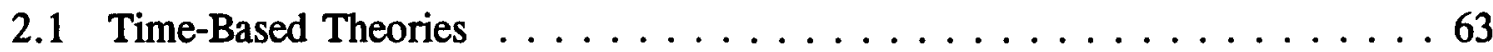

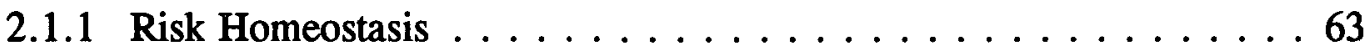

2.2 Spatial Theories . . . . . . . . . . . . . . . . 64

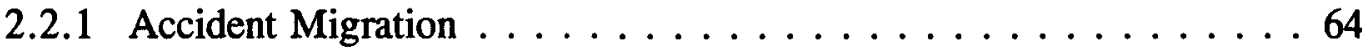

2.3 Motivational Theories . . . . . . . . . . . . . . 66

2.3.1 Zero Risk Theory . . . . . . . . . . . . . .66

2.3.2 Threat Avoidance Model . . . . . . . . . . . . 68

2.3.3 Behavior Feedback . . . . . . . . . . . . . . . . 70

2.3.4 Utility Maximization Model . . . . . . . . . . . . . 73

2.3.5 Problem Behavior Theory . . . . . . . . . . . . . 74

2.4 Decision Making Theories . . . . . . . . . . . . . . . 76

2.4.1 General Decision Making and Information Processing . . . . . 76

2.4.2 Hierarchical Risk Model . . . . . . . . . . . . . . . 77

2.4.3 Bounded Rationality . . . . . . . . . . . . . . 79

2.5 Social Context Theories . . . . . . . . . . . . . . 80

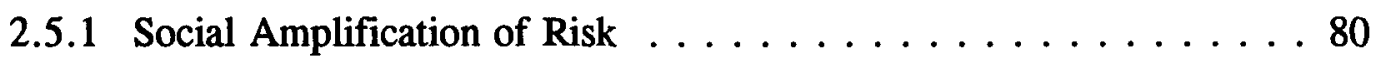

2.5.2 Other General Traffic Sociology Theories . . . . . . . . . 81

3. RISK PERCEPTION AND DRIVING $\ldots \ldots \ldots \ldots \ldots \ldots$

4. PERSONALITY FACTORS AND RISKY DRIVING $\ldots \ldots \ldots \ldots 7$ 


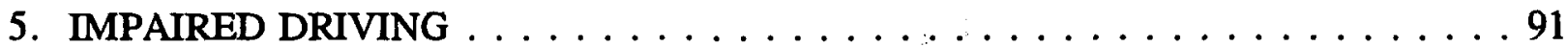

5.1 Demographics . . . . . . . . . . . . . . . .91

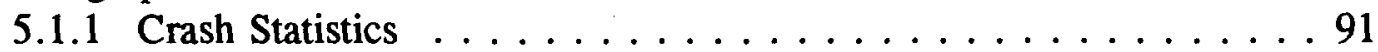

5.1 .2 Gender . . . . . . . . . . . . . . . .91

5.2 Unequal Effects of Alcohol on Crash Risk . . . . . . . . . . . .93

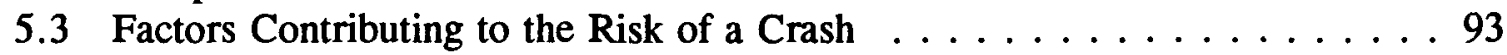

5.3.1 Personality Factors $\ldots \ldots \ldots \ldots \ldots \ldots \ldots \ldots \ldots$

5.3 .2 Social Factors $\ldots \ldots \ldots \ldots \ldots \ldots \ldots \ldots \ldots \ldots \ldots \ldots$

PART III: INTERVENTIONS $\ldots \ldots \ldots \ldots \ldots \ldots \ldots \ldots \ldots \ldots \ldots \ldots \ldots . \ldots \ldots$

1. INTRODUCTION/COMMON THEMES $\ldots \ldots \ldots \ldots \ldots \ldots$

2. INTERVENTIONS: SUBSTANCE USE . . . . . . . . . . . . . . . . 97

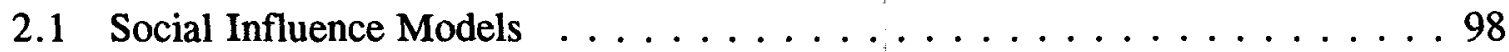

2.1.1 Project Model Health $\ldots \ldots \ldots \ldots \ldots \ldots \ldots$

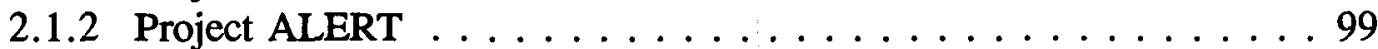

2.2 Skills Training Models . . . . . . . . . . . . . . . . . 100

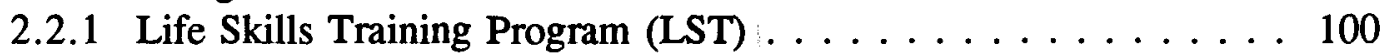

2.3 School-Based Programs . . . . . . . . . . . . . . . . . . . . . 100

2.4 Communications and Mass Media Based Programs . . . . . . . . . 101

2.4.1 Public Service Announcements (PSAs) . . . . . . . . . . 102

3. INTERVENTIONS: RISKY ADOLESCENT SEXUAL BEHAVIOR . . . . . 103

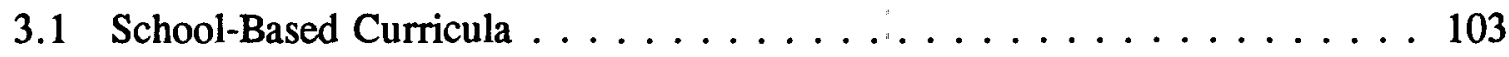

3.1 .1 Reducing the Risk . . . . . . . . . . . . . 103

3.1 .2 Postponing Sexual Involvement . . . . . . . . . . . . 104

3.1.3 Family-Life Education . . . . . . . . . . . . . . . . . . 104

3.2 School-Based Clinics . . . . . . . . . . . . . . . . . . . . . 105

3.3 Community-Based/Multicomponent $\ldots \ldots \ldots \ldots \ldots \ldots \ldots$

4. INTERVENTIONS: RISKY DRIVING . . . . . . . . . . . . . . . . . . . 107

4.1 Overview of Countermeasures $\ldots \ldots \ldots \ldots \ldots \ldots \ldots \ldots$

4.1.1 Graduated Licensing . . . . . . . . . . . . . . 107

4.1 .2 Other Licensing Issues . . . . . . . . . . . . . . . . . . 109

4.1 .3 Driver Education . . . . . . . . . . . . . . . . . 109

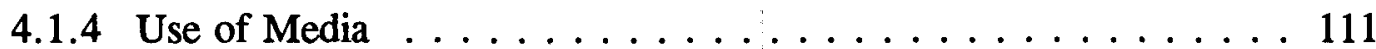

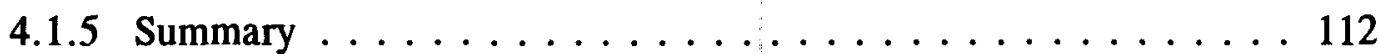

4.2 DRINKING AND DRIVING $\ldots \ldots \ldots \ldots \ldots \ldots \ldots \ldots \ldots$

4.2.1 Minimum Drinking Age Laws . . . . . . . . . . . . 113

4.2.2 Lowering Blood Alcohol Concentration (BAC) limits . . . . . . 114

4.2.3 Enforcement of DWI Laws . . . . . . . . . . . . . . . . . 114

4.2.4 Developing Planning Strategies $\ldots \ldots \ldots \ldots \ldots \ldots \ldots$ 
4.2 .5 Mass Media Campaigns . . . . . . . . . . . . . 116

4.2.6 Educational Campaigns $\ldots \ldots \ldots \ldots \ldots \ldots$

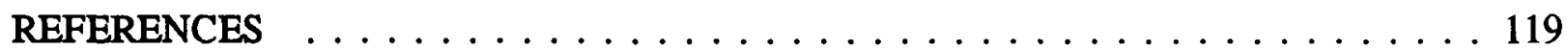




\section{FIGURES}

Figure 1: Epidemiological Model of Risk Taking Behaviors.

Figure 2: Causal Model of Adolescent Risk Taking Behavior. 5

Figure 3: Zero Risk Theory.

Figure 4: Threat Avoidance Model.

Figure 5: Behavior Feedback.

Figure 6: Hierarchical Risk Model. 


\section{TABLES}

Table 1: $\quad$ Percentages Reporting Substance Use During The

Past Month: Preliminary Estimates For 1993 By Age.

Table 2: $\quad$ Percentages Reporting Substance Use During The

Past Month 1985-1993: Preliminary Estimates for 1993.

Table 3: $\quad$ Percentages Reporting Monthly And Weekly Substance

Use 1985-1993: Preliminary Estimates for 1993.

Table 4: $\quad$ Occupant Fatality and Injury Rates per Population by Age Group, 1975-1993.

Table 5: $\quad$ Persons Killed or Injured and Fatality and Injury

Rates per 100,000 Population by Age and Sex.

Table 6: Drivers in Fatal Crashes by Blood Alcohol Concentration (BAC) and Age, 1982-1993. 


\section{EXECUTIVE SUMMARY}

\section{Introduction}

Injuries from motor vehicle collisions are the leading cause of death for young persons, accounting for more than one-fifth of all deaths in the late teenage years. Youthful drivers are substantially overrepresented in motor vehicle crashes compared to all other age groups. They have the highest crash rates regardless of whether the rate is based on number of licensed drivers or on number of vehicle miles traveled.

Increasingly, risk taking among youth appears to be a critical factor in explaining the high crash incidence. Risk taking may be defined in varied ways, and different disciplines hold different perspectives of risk taking. In general, risk taking refers to behaviors that can potentially lead to some form of loss, and the processes involved in making those behavioral choices.

To make major inroads in the youth crash problem, countermeasures are needed that can deal effectively with youthful risk taking. Developing such countermeasures requires an understanding of the mechanisms underlying risk taking. This project is part of a broader effort by NHTSA to develop that understanding, and those countermeasures.

In order to develop this understanding, risk taking needs to be looked at more broadly than highway safety. This is because risky driving and other unsafe practices on the roadway system do not occur in a vacuum. They occur in the context of social, cultural, developmental and other influences. Focusing exclusively on risky driving can misdirect efforts for addressing the problem.

The purpose of this literature review was to gain a better understanding of youthful risk taking within this broader context. To accomplish this goal, a review of theoretical as well as research articles was conducted.

\section{Theories}

Contemporary theories of youthful risk taking take into consideration the interplay between individual characteristics and social environmental contexts. Theories generally differ in their specific notions of risk and in the relative weight they attribute to inter- versus intra-individual differences in behavior. Theories vary as well by the degree to which they embrace a common behavior versus unique behavior hypothesis, volitional versus non-volitional model of decision making, and a developmental versus a stationary framework for investigating risk taking behaviors.

For practitioners, program planners, and policy makers, the question is often "which theory is best?" Unfortunately, there is no clear answer. There are, however, some elements that are common to most theories and should be taken into consideration when selecting a theoretical framework for an intervention program. Increasingly, contemporary theories of youthful risk 
taking consider both biological and psychosocial factors as important in predicting risk taking. Pubertal timing, hormonal fluctuations, and genetics are being studied in combination with self perceptions, peer relationships, parenting styles, and other psychosocial factors in assessments of risk taking behavior. Theories which only emphasize one aspect of human development fail to explain the complexity of risk taking behavior.

\section{Risk taking involving substance use}

Estimates from the 1993 National Household Survey on Drug Abuse showed that 16.8 million 18- to 25-year-olds had consumed alcohol in the past month, representing 59.3 percent of that age group. Among persons 12 to 17, 3.8 million or 18.0 percent had consumed alcohol in the past month. The percentages of youth reporting substance use in the past month have dropped significantly since 1985 . However, the data suggest that the momentum may have stalled somewhat in recent years. No statistically significant differences emerge when comparing 1992 and 1993 percentages except for alcohol use among youth ages 12 to 17, with the percentage of users actually increasing in 1993.

Data indicate that the younger the initiation of alcohol use, the greater the likelihood of heavy drinking in later years. Moreover, age at which a participant first became drunk has been found to be a predictor of current alcohol consumption, with those who first got drunk at younger ages having higher levels of current alcohol consumption.

Knowledge of the consequences associated with substance use has typically not been found to be an effective deterrent to drug use among adolescents. In fact, adolescents tend to display little concern over the impact of psychoactive substances despite warnings from parents, teachers, and health care professionals. Adolescents like to feel they are in control, and tend to overestimate their own ability to avoid or discontinue use of harmful substances.

Other factors, such as peer influence, personality, religiosity, family, and school, have been found to be predictive of substance use. For example, peers encourage ongoing use of substances by tolerating use, providing emotional support and furnishing education about drugs. Peers who use a particular type of drug have been found to associate with others using that drug. Adolescents who attend religious services more frequently are less likely to have problems with substance use. Biological correlates of substance use have also been found; adoption studies suggest children with an alcoholic biological parent may have as much as 2.5 times the risk of alcoholism than children without alcoholic parents. Finally, adolescent substance use has been linked directly to academics and school involvement, with substance users being less involved in extracurricular activities, and having lower levels of academic orientation.

\section{Risk taking involving violence}

Victimization and criminal offender data show violence most heavily concentrated among younger age groups, and among males. Data on homicide victims indicate that homicide rates are highest between ages twenty and thirty-four. Homicide rates are five to ten-fold higher for 
males than for females. Firearms are used in 80 percent of teenage homicides. However, this is in part a reflection of the lethality of firearms compared to other weapons.

A theme that pervades much of the literature on violence is that it is a learned behavior or response. For instance, the more offenders are victimized by routine family violence the more violent crimes they commit. There also is considerable literature identifying histories of sexual or physical abuse as risk factors for later violence. In addition, since 1970 there has been considerable interest in the impact of violence portrayed on television on children's behavior. Many of the studies are correlation-based -- indicating that an increased amount of televised violence was correlated with an increased amount of aggression among children. There are five processes that may explain the relationship of watching TV to increased violent behavior in children: observational learning, catharsis, physical arousal, attitude changes, and justification processes. A review of research found strong support for observational learning, as there was "a solid body of research evidence suggesting that children who see someone rewarded for a particular kind of behavior are more likely to imitate this behavior." This review also indicated that children's attitudes toward aggressive behavior are affected by the kinds of television programs they watch.

Review of studies on alcohol and violence indicated that binge drinking is the feature of alcohol consumption primarily related to increased risk of violence. One hypothesis is binge drinking may turn an argument into a fight. It may also turn the possession of a weapon into using it; i.e., alcohol may lesson inhibitions that restrain violent behavior. Use of illicit drugs has also been linked with violence, such as gang fights and other fighting.

\section{Risk taking involving sexual behavior}

Risky sexual activity includes having unprotected sex, having sex more often, with more partners, and initiating sexual activity earlier in life. Risky adolescent sexual activity shows many of the same patterns as adolescent substance use. For example, the earlier sexual activity is initiated, the more likely it is that risky sexual activity will take place in later adolescence. In addition, high levels of knowledge about the risks of sexual activity and the ways of minimizing risk do not seem to translate into behavior changes. Success in school, educational aspirations, and membership in prosocial groups predict a lower likelihood of sexual risk taking. Certain psychological characteristics, such as sensation seeking and egocentrism, are related to sex without contraception, while self-efficacy has been found to predict condom use. Selfesteem, however, has not been shown to have a strong relationship with safer sexual practices.

There are significant behavioral and attitudinal differences between males and females. One striking finding is that although girls are less likely to believe their partner is responsible for contraception, boys are actually more likely than girls to feel positive about condoms and to insist on condom use. The marital status of parents has more of an effect on girls than boys. There are also ethnic differences. For example, white female adolescents are more likely to have friends with similar sexual habits than are black female adolescents. Coital onset is about 2.5 years younger among black males than among whites. 
The factors most associated with the use of condoms appear to be beliefs and attitudes about the short-term costs of engaging in safe sex, such as embarrassment, or the perceived benefits of engaging in risky sex, such as it is more spontaneous. Lesser condom use and greater number of sexual partners have been found to be related to difficulties in communication skills.

\section{Risk taking involving driving}

Youth, especially males, are substantially overrepresented in motor vehicle crashes and fatalities. Experiential, developmental, psychosocial, and personality factors all likely contribute. Novice drivers quickly attain proficiency in such skills as steering and braking. Over a period of months, they learn to concentrate their visual fixations in the vehicle's projected path, and to use peripheral vision to locate the vehicle in the lane. Lagging behind acquisition of motor skills is development of decisional skills. Studies show youth more likely to engage in riskier behaviors such as faster driving, tailgating, and refraining from safety belt use. Youth often overestimate their driving skills, and tend to perceive themselves as less vulnerable to a crash than their peers. They also may attach priority to social interaction within the vehicle to the detriment of the driving task at hand. Adding to potential risks for selected youth are intrapersonal traits that some studies have associated with riskier driving or crashes, such as sensation seeking (heightened among teenagers) and behavior disorders.

\section{Interventions}

Intervention approaches for reducing risk taking include: (1) teaching about the negative consequences of risk taking behavior; (2) enhancing self-esteem and self-concept; (3) teaching communication and decision making skills; and (4) providing opportunities for leisure-time activities. In general, the public health sector has shown greater evidence of a social influences orientation to addressing problem behavior than has the highway safety field.

Meta-analysis of secondary school drug prevention programs showed "Peer Programs" superior to other program modalities in affecting drug-specific knowledge, attitudes, substance use, and avoidance-related skills among average problem-free teens. These programs expose youth to "positive peer influences" while building competencies and skills important to resisting drugs. For adolescents exhibiting serious problems such as delinquency or substance use, the metaanalysis identified "Alternatives" programs as an effective modality for building skills and changing behavior. Here, at-risk youth undergo compensatory and other activities tailored towards their special needs.

Sexual risk taking behavior is one of the costliest risk taking behaviors among adolescents. To be successful, intervention programs should consider the situations in which adolescent sex takes place and be attentive to the influence of family, peers, and schools, as well as cultural influences. Intervention programs include: school-based clinics, school-based curricula, and community-wide/multicomponent programs. One objective of intervention is pregnancy prevention. Dryfoos notes that the objectives of a good pregnancy prevention program should 
be to promote responsible decision-making, to increase contraception use, and to prevent unwanted pregnancy. In addition, pregnancy prevention programs should begin early (no later than middle school) and provide comprehensive, multicomponent services including school, community, and parental input.

The predominant highway safety interventions directed toward youth involve educational efforts, and controls or negative incentives to deter unsafe behaviors. Driver education was first introduced into the schools more than 50 years ago. Though recent findings concerning the effectiveness of high school driver education have been disappointing, there remains a sense that novice driver education can be effective in reducing crashes involving youth. NHTSA is initiating efforts to develop an improved driver education program that is an integral part of a graduated licensing system. A graduated licensing system gradually integrates novice drivers into the traffic environment in a manner that enables them to gain knowledge, skill, and experience over a period of time under controlled conditions. The system divides the licensing process into a series of stages, with requirements attached to each stage that can be protective, motivational, and/or educational. Protective components may include night-time driving restrictions, lower legal blood alcohol concentration (BAC) limits, requirements for adult supervision when driving, mandatory use of safety restraints by all vehicle occupants, and limits on the number of passengers in the vehicle. Motivational components for safe driving revolve around making acquisition of the regular drivers license contingent on demonstrated safe driving performance (e.g., crash and conviction free record). No state has implemented a graduated licensing system containing all recommended components. However, partial systems have been implemented and found to be effective.

Raising the minimum drinking age during the 1980s produced significant reductions in crash fatalities among youth. More recently, states have been legislating lower BAC limits for youth when driving. These too have corresponded with significant crash reductions. Linked to the laws are enforcement efforts that bolster their effectiveness. However, data show youth being arrested for DWI (driving while intoxicated) less frequently than would be expected based on their incidence in alcohol-related crashes.

\section{Conclusions}

Many parallels can be observed between youthful risk taking on the road and other domains of risk taking. This underscores the importance of exploring these other areas to identify countermeasure approaches that have been successful and may beneficially apply to highway safety. An important lesson to be learned from such review is the value of early intervention to postpone the onset of risk behavior -- the younger the initiation of unhealthy behaviors, the more likely the unhealthy behaviors will persist over time. 


\section{FORWARD}

Injuries from motor vehicle collisions are the leading cause of death for young persons, accounting for more than one-fifth of all deaths in the late teenage years. Youthful drivers are substantially overrepresented in motor vehicle crashes compared to all other age groups. They have the highest crash rates regardless of whether the rate is based on number of licensed drivers or on number of vehicle miles traveled.

Research has examined a variety of possible contributing causes for these elevated crash rates. Such explanations as lack of driving experience, more dangerous types of driving exposure, and operation of less safe vehicles have been explored. Yet while some of these factors clearly contribute to the problem, they still fail to account for the magnitude of the difference in crash risk (e.g., Jonah, 1986). Increasingly, risk taking among youth appears to be a critical factor in explaining the high crash incidence. Risk taking may be defined in varied ways, and different disciplines hold different perspectives of risk taking. In general, risk taking refers to behaviors that can potentially lead to some form of loss, and the processes involved in making those behavioral choices. To make major inroads in the youth crash problem, countermeasures are needed that can deal effectively with youthful risk taking. Developing such countermeasures requires an understanding of the mechanisms underlying risk taking. This project is part of a broader effort by NHTSA to develop that understanding, and those countermeasures.

In order to develop this understanding, risk taking needs to be looked at more broadly than highway safety. This is because risky driving and other unsafe practices on the roadway system do not occur in a vacuum. They occur in the context of social, cultural, developmental, and other influences. In fact, there is a burgeoning amount of research literature showing risky driving activities to be related to other types of unsafe behaviors. Focusing exclusively on risky driving can misdirect efforts for addressing the problem. For example, studies suggest that adolescents misread the level of risk in certain driving situations. Yet isolating the countermeasure to informational attacks directed at educating adolescents about the risk will likely fail as research shows youth misreading risk in many other areas as well. Other underlying factors would likely need to be addressed by the countermeasure for it to succeed.

Thus, the purpose of this literature review was to gain a better understanding of youthful risk taking within this broader context. To accomplish this goal, a review of theoretical as well as research articles was conducted. This review is summarized in this report. The overarching goal was to identify common themes that cut across domains of risky behaviors.

This literature review is organized into three parts. The first part begins with a discussion of models of risk taking behavior among youth. Subsequent chapters in this section review the literature in specific areas of risk taking behavior: substance use, sexual behavior, and violence. These sections are organized around antecedents of risk taking behavior such as demographic, personal, and social factors. The second part of this report presents an overview of research 
related to risky driving among youth. It summarizes theories of risk and driving, current research in risk perception and driving, and the relationship of personality to risky driving. The third part of this report highlights countermeasures for risky driving, substance use, and risky sexual behavior. The report concludes with a chapter discussing key issues for program practitioners. 
PART I. YOUTHFUL RISK TAKING BEHAVIORS 


\section{INTEGRATED THEORIES OF YOUTHFUL RISK TAKING}

The period of adolescence is often considered synonymous with risk taking. In the face of rising mortality among young people that has a behavioral basis (e.g. injuries, homicide, suicide), researchers have turned their attention to considerations of what defines and determines youthful risk taking. For some, risk taking is seen as a set of volitional behaviors initiated during the teenage years that have major negative health and social consequences (Irwin \& Millstein, 1986; Jessor \& Jessor, 1977; Donovan, Jessor \& Costa, 1991; Jessor, 1992). For others, risk taking is perceived more generally, often as a way by which individuals meet their biological needs for stimulation and sensation (e.g. mountain climbing, sky diving, race car driving, heavy drinking, gambling) (Hovarth \& Zuckerman, 1993; Zuckerman, 1979) For example, individuals with high needs for stimulation have been shown to be more likely than low sensation seekers to engage in novel or reckless behaviors in order to experience intense feelings of arousal (Hovarth \& Zuckerman, 1993). While adolescents, as a group, may manifest high levels of sensation seeking, Hovarth and Zuckerman (1993) contend that risk taking behaviors are not confined to a particular life stage but are more related to individual needs for stimulation.

Risk taking has also been viewed as normative and adaptive for identity and social competence development (Baumrind, 1991). Individuals who emerge from adolescence with strong positive self concepts are often those individuals who have experimented with various life styles and life style behaviors (Baumrind,19911). For individuals who live in adverse social environments, risk taking is thought to reflect a way of coping with the loss of personal control (Lyng, 1993).

Contemporary theories of youthful risk taking take into consideration the interplay between individual characteristics and social environmental contexts. Theories generally differ in their specific notions of risk and in the relative weight they attribute to inter-versus intra-individual differences in behavior. Theories vary as well by the degree to which they embrace a common behavior versus unique behavior hypothesis, volitional versus non-volitional model of decision making, and a developmental versus a stationary framework for investigating risk taking behaviors. In this section, we will examine these cross-cutting themes regarding youthful risk taking and will review some of the major theories that frame risk taking discussions.

\subsection{Conceptualization and Definitions of Risk}

Traditionally, definitions of risk reflect the disciplinary orientation of the researcher. Those in the biomedical fields often view risk as a set of factors which increase the probability of adverse or negative health outcomes. Risk taking in adolescence is equated with behaviors which directly or indirectly lead to mortality or morbidity (Irwin, 1993; Tonkin, 1987). Behaviors like engaging in unprotected sexual intercourse, substance use, and reckless driving are considered risk taking since they can be linked with specific morbidity and mortality (e.g., sexually transmitted disease, unplanned pregnancy, and death due to injuries) (Irwin, 1993). Biomedical models of risk taking tend to use epidemiological approaches in which environmental 
characteristics (e.g., conditions of roads, access to alcohol) and individual characteristics (e.g., gender, race, SES) are classified as risk factors and then assessed in terms of their relative contribution to specific health outcomes (e.g., motor vehicle injury). The focus is on the identification of risk factors and the predictive power of these factors in explaining the occurrence of negative health outcomes.

\subsubsection{Biomedical Concepts of Risk}

One biomedical model used to describe adolescent risk taking behavior is the classic epidemiological host-agent-environment model. Although this model traditionally has been applied to studies of infectious disease processes, some researchers have adapted it to investigations of risk factors in the social environment and behavior arenas. For example, characteristics of the host (e.g., level of cognitive development of the adolescent) interact with the agent (e.g., automobile) and environment (e.g., poor lighted highway) to produce a death or disability due to automobile injuries. This approach tends to reduce all possible interactions to three domains; those occurring between the host, agent, and environment. It fails to consider the interplay among a variety of host, agent, or environmental factors. For example, the cognitive resources applied to the driving task may vary according to the social context in which the driving occurs.

Other biomedical researchers (Irwin, 1993) define risk as involving both biological as well as psychosocial factors. These researchers emphasize puberty as a triggering force for adolescent risk behaviors. The timing of puberty influences the individual's perceptions of the social environment, self perceptions, cognitive development, and personal values (Irwin, 1993). Effects vary by gender and by the adolescent's pubertal status relative to that of his/her peers. Thus, early maturers are expected to experience the strongest effects of biological changes on behavior since their physical development is in sharp contrast to the development of other young people. The concept of "off time," that is, development which is asynchronous with the development of the majority of adolescents, has been used in studies of pubertal timing and depressive feelings among adolescent girls in which early maturing girls are more vulnerable to depressive symptoms and psychological distress (Petersen et al., 1992). Alcohol and other drug use has been linked to early maturation in girls (Magnusson et. al., 1985)

\subsubsection{Social Developmental Concepts of Risk}

For social developmental psychologists, risk incorporates a wide range of personal development and social adaptive behaviors. Risk taking according to Jessor (1992) transcends physical health outcomes and refers to behaviors that can compromise the normal psychosocial development of the individual. Thus, adolescent risk taking behavior is important not simply because it may lead to illness or death but because it can severely compromise a young person's mastery of normal developmental tasks and ability to fulfill social roles. For example, alcohol and other drug use may lead to withdrawal from school, thereby restricting future opportunities for education and employment (Jessor, 1992). 


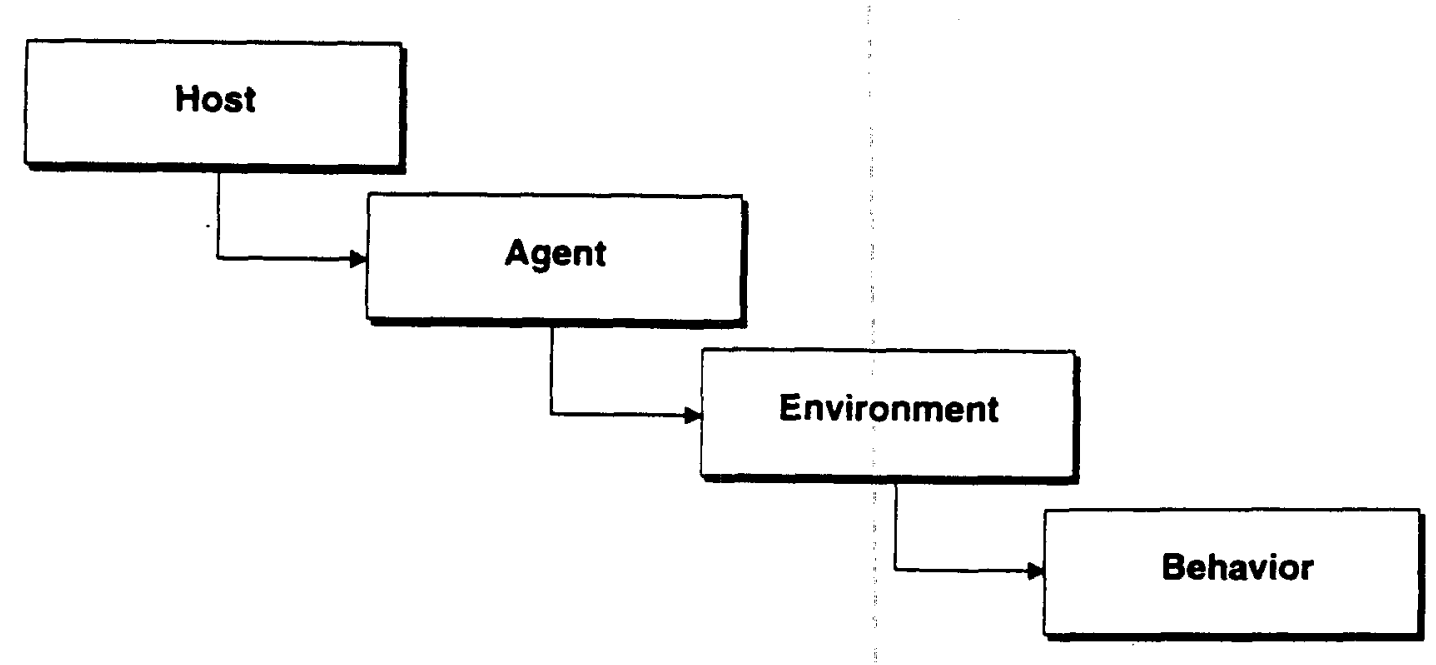

Figure 1: Epidemiological Model of Risk Taking Behaviors 
A psychosocial formulation of risk recognizes the contributions of the social context to adolescent behaviors. Furthermore, it stresses the need to examine the meaning of the outcomes for the adolescent. Some risk taking behaviors, like drinking, may be fulfilling needs for peer approval and for feelings of autonomy and independence (Jessor, 1992). This emphasis on the role of motivation in risk taking provides insight into why programs that simply stress sexual abstinence or focus on lung cancer as a consequence of smoking fail in reducing sexual activity or cigarette smoking.

The framework posed by Jessor and his colleagues attempts to understand behavior, its antecedents and consequences, by considering a series of domains consisting of proximal and distal factors that taken together influence behavior ("a web of causation"). The domains include the social environment, the perceived environment, personality, behavior, and biology/genetics.

Added to Jessor's domains are a set of protective factors, that is, those factors which enable a young person to avoid involvement in risk taking and develop a sense of personal adequacy and competence despite exposure to an adverse social environment (Jessor, 1992). Protective factors are important to Jessor's concept of the person-situation model of risk taking behaviors because they help explain why not all adolescents who seemingly are at high risk for problem behaviors succumb; so called "resilient youth."

This theory is a cross-sectional snap-shot of relationships which to be fully appreciated must be considered within the framework of historical and developmental change. Changes are occurring in each domain, which have implications for adolescent behavior. For example, role models for deviant behavior, a risk factor for perceived environment, may change as a young person moves from early to middle to late adolescence.

For Jessor and his colleagues, understanding contextual changes is as important as understanding individual changes. The dynamic quality of changing environments, and the frequent limitations that researchers experience in quantifying environmental change, make this a formidable task.

\subsubsection{Cognitive Developmental Concepts of Risk}

Risk as defined by cognitive psychologists and decision making theorists refers to the perceived chance of loss (Furby \& Beyth-Marom, 1992; von Winterfeldt \& Edwards, 1986; Yates, 1992). Risk taking behaviors represent acts which may or may not be volitional but involve some probability of loss. Behaviors may be undertaken consciously or unconsciously. Risk perception, a construct not found in the biomedical or psychosocial theories of risk taking, refers to an individuals's conscious assessment of the probability of loss associated with engaging in (or not engaging in) a specific behavior (Furby \& Beyth-Marom, 1992).

Decision making theory charts the course by which individuals determine whether or not to engage in a particular behavior. This theory assumes that individuals seek to satisfy their own needs and goals by making rational choices regarding which behaviors will minimize loss and maximize gains given environmental constraints (Gardner 1993). According to Furby and Beyth- 


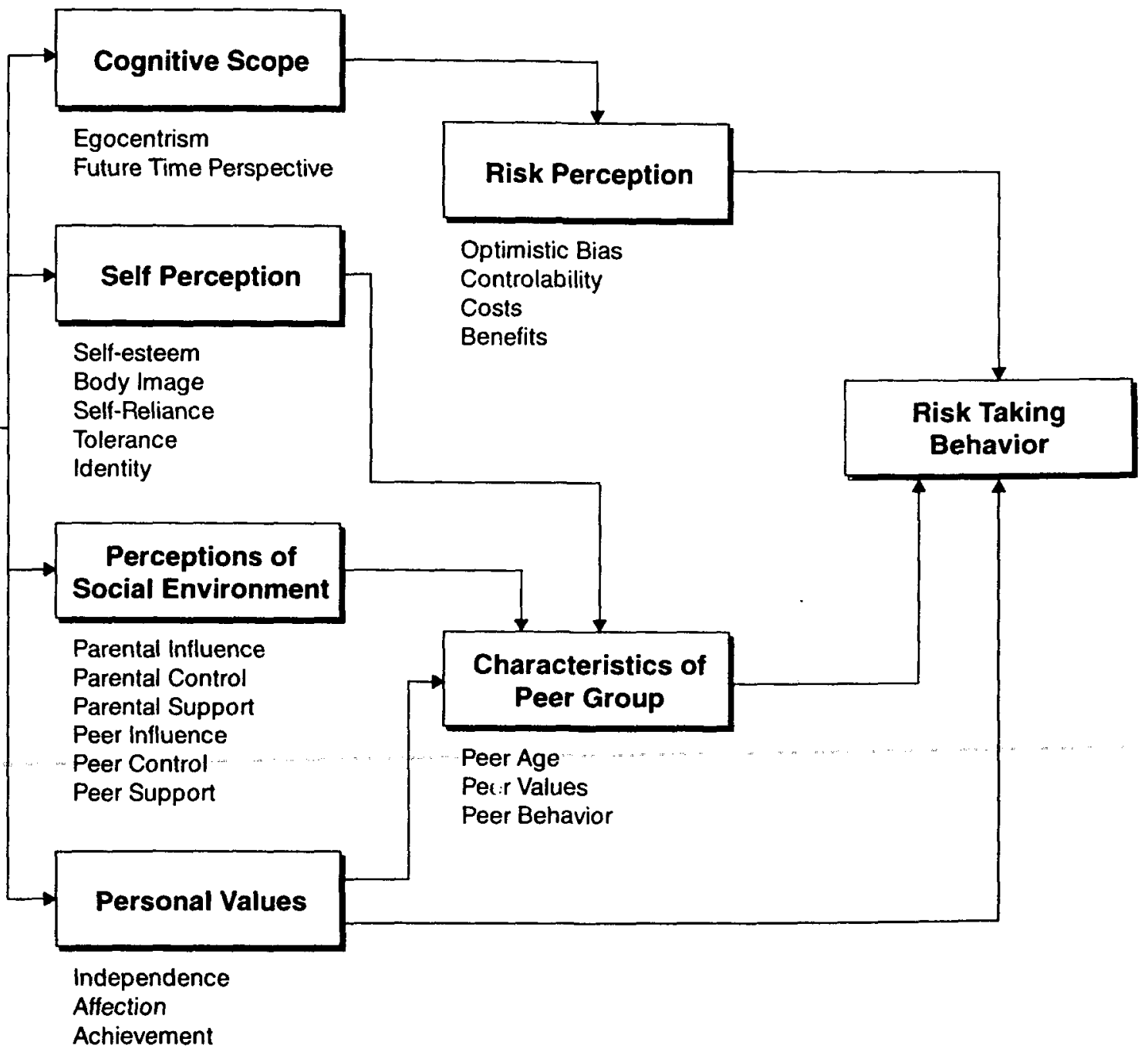


Marom the decision making process involves a series of steps in which the individual first identifies possible options. The individual then assesses the consequences that may follow from each option, the desirability of each consequence, the likelihood of each consequence, and ultimately creates a decision rule which draws upon some combination of the above (Furby \& Beyth-Marom, 1992). A key component of this process is the use of expected utility theory which mathematically models the valences individuals place on anticipated consequences (Luce \& Raiffla, 1957).

From a decision making perspective, all behaviors are risky in the sense that they involve some loss. Obviously, the potential loss associated with some behaviors (e.g., dying as a consequence of driving when drunk) is greater than for others (e.g., getting a ticket for parking in a fire zone). Furthermore, the perception of loss may vary widely across individuals and situations. Because risk perception is closely tied to risk taking behavior, interventions directed at this cognitive decision making process might seek to alter the perceptions of risk associated with a given behavior.

Unlike other conceptualizations of risk taking, decision making theory considers the consequences of both engaging or not engaging in a risk taking behavior. Differences between adolescents and adults in involvement in risk taking behavior may reflect differences in the values placed on the consequences of not engaging in a behavior such as smoking marijuana (Furby \& Beyth-Marom,1992). Interventions might attempt to reduce risk taking by influencing the relative attractiveness of alternatives to involvement in risk taking behaviors.

\subsubsection{Social Learning Theory Concept of Risk}

Social learning theory has been used to understand the roots of adolescent risk taking behavior and as a theoretical model for developing strategies for prevention. From a social learning theory perspective, adolescents learn behavior through a process of modeling behavior and reinforcement. Repeated exposure to high-status individuals in the environment or in the media who are engaging in risky behavior may influence adolescents to engage in such behavior themselves. The view that engaging in risky behaviors is "standard practice" among age-mates also helps to create norms that are supportive of risky behavior. Personal characteristics modulate the degree to which high status role models influence behavior. For example, adolescents who have goals for the future that are inconsistent with engaging in risky behavior would be less likely to engage in the behavior. In contrast, "low self-esteem, low selfsatisfaction, low self-confidence, greater need for social approval, low sense of personal control, low assertiveness, greater impulsivity, and impatience to assume adult roles" may contribute to adolescents' vulnerability to engage in risky behaviors (Botvin \& Botvin, 1992).

In contrast to stage theories, which view behavior within a developmental context, social learning theory believes that behavior is determined within a "social situational context." Behavior changes are attributed to the interaction between environmental and situational factors (Muss, 1988). The social influences model (derived from social learning theory) posits that peers play a major role in shaping behavior. It has been used as a basis for prevention strategies 
to forestall risky behaviors. An example of a prevention strategy is teaching adolescents skills for dealing with social pressure to engage in risky behaviors. Prevention programs using this model are discussed in Part III of this report.

\subsection{Common Versus Unique Behaviors}

One issue that frequently arises in the literature on youthful risk taking is the extent to which there is an organization and structure among various risk taking behaviors. Some researchers view risk taking behaviors as sharing common causes and argue that they should be considered as reflecting a constellation of behaviors rather than a set of individual behaviors. Others focus on individual behaviors, such as alcohol use, without examining other risk taking behaviors like early unprotected sexual intercourse. Whether one conceptualizes a common structure for risk taking behaviors or focuses on the unique properties of these behaviors has important policy and practice implications.

Observed covariation among such adolescent behaviors as alcohol use, drug use, sexual behavior, and delinquency has led some investigators to focus on mechanisms which could explain the interrelationships among behaviors (Donovan \& Jessor, 1985; Irwin and Millstein, 1987). According to these researchers, behaviors are best considered together as a constellation or syndrome reflecting a singular underlying construct.

In this view, adolescent risk taking behavior is characterized by deviations from a set of socially accepted norms (Donovan, Jessor, \& Costa 1991; Jessor, 1993; Jessor \& Jessor, 1975). Adolescents place less value on conventional societal values such as academic achievement, religiosity, and parental control and greater emphasis on unconventional values including deviance, independence, and peer influence versus parental influence over decision making (Donovan, Jessor \& Costa, 1991). Their unconventionality is reflected in greater involvement in problem behaviors such as alcohol and other drug use, delinquency, and sexual activity and less involvement in conventional behaviors such as school activities, church attendance, and family activities. From a problem behavior perspective, individual behaviors do not make any unique contribution to our understanding of risk, other than the variance shared by the conventionality-unconventionality construct. Problem Behavior Theory directs our attention to the adolescent as a whole rather than to a set of discrete behaviors (Jessor, 1992). It calls into question intervention strategies which are behavior specific, such as smoking, alcohol, or other drug use prevention programs and focuses instead on interventions that address lifestyle change and societal values for conventional behavior.

In contrast, other researchers have argued that risk behaviors manifest unique characteristics that explain deviance which may be masked if the behaviors are treated as a syndrome or a whole (Osgood, Johnston, O'Malley \& Bachman, 1988). In a longitudinal study of 18-24 year olds, Osgood and his colleagues examined the relationships among alcohol,marijuana, other drug use, and reckless driving. They found that much of the variation in these risk behaviors was accounted for by separate rather than common factors. They concluded that theories which stress a general construct will be unable to account for all the variation in individual behaviors. For 
example, in designing a substance abuse intervention, one would need to focus attention on the determinants of alcohol and other drug use as well as a more general approach to risk taking.

\subsection{Intra Versus Inter-individual Determinants of Risk Taking}

While most contemporary theories of youthful risk taking highlight the interaction between individual and social environmental factors, there is considerable variation in the extent to which personal or individual attributes are emphasized compared to attributes of the social environment. For some, "reckless" behavior in adolescence reflects the interplay of developmental changes in sensation seeking and in egocentric thinking with the social environment (Arnett, 1992). These intra-individual features of development are viewed as important motivating sources for adolescent risk taking behavior.

Adolescents are thought by some to engage in risk taking behaviors because of developmental needs for stimulation which increase during puberty. Zuckerman and his colleagues postulated that the need for variety, change, and intensity of stimulation varies by individuals but also varies over the life span (1979). Some individuals have higher needs for stimulation than do others. Furthermore, changes in hormonal production during puberty increase the level of stimulation required to satisfy autonomic needs. As a result, young people attempt to meet their needs for arousal and stimulation through thrill seeking and risk taking behavior. It is not coincidental, according to these researchers, that risk taking behaviors increase during early adolescence and then decline subsequently with age (Hovarth \& Zuckerman, 1993).

Studies of sensation seeking youth indicate that these individuals have high needs for autonomy, exhibitionism, change, and have an "optimistic bias," that is they see themselves less at risk and less likely to have a negative outcome from a risky activity than are others (Zuckerman, 1979; Weinstein, 1980; Arnett, 1990a). Since personality characteristics are relatively fixed, as is the individual's optimal level for arousal, one would expect that youthful risk takers would become adult risk takers, although the type and frequency of risk taking should modulate over time.

Thinking patterns of adolescents represent a second intra-individual trait that explains risk taking behavior. Egocentric thinking, pre-occupation with one's own thoughts and experiences, is theorized to occur as an individual passes from concrete operational thinking to formal operational thinking (Elkind, 1967) or from childhood to adolescence. Adolescent egocentrism is manifested in two constructs, the imaginary audience and the personal fable (Elkind, 1967). The imaginary audience is the belief that others are as preoccupied with the adolescent's behavior as $s /$ he is about her/himself. The personal fable involves an individual's belief in his/her own uniqueness and invulnerability. These beliefs are thought to originate during adolescence, the time in which individuals increase their ability to think hypothetically and focus on self. Risk taking behaviors result from an interaction of these cognitive constructs with the social environment. For example," pregnancy will never happen to me" or "one more drink can't affect my driving" are thought to reflect a personal fable. Drinking at a party because of concerns that everyone in the room will think badly of her/him if s/he doesn't drink is an example of imaginary audience. Egocentric thinking protects adolescents from being concerned 
with the health consequences of their actions by assuring them that bad outcomes will not happen to them because of the uniqueness of their lives.

Cognitive developmental changes impact on adolescent risk taking behavior in a more generic way. For young adolescents, judging the probability of an outcome is mentally challenging. Newly acquired formal operational thought processes do not contain the repertoire of experiences adequate for judging probability. Kahneman and Tversky (1972) described two mental constructs used in developing probabilistic estimations; the representativeness of a possible outcome and the availability of relevant examples. For example, when judging the likelihood of becoming pregnant as a result of engaging in unprotected sexual intercourse, an adolescent may consider the distribution of possible probabilities from 0 to 100 percent and then fix her own likelihood somewhere along that continuum. The point on the continuum will reflect the adolescent's degree of egocentric thinking and her knowledge of the experiences of others with pregnancy. Thus, a younger adolescent might consider the probability of becoming pregnant at 0 percent to 1 percent for herself and 20 percent or greater for someone else. An older adolescent may estimate the likelihood of pregnancy closer to its actual statistical occurrence.

Younger adolescents may not have as many relevant instances of negative outcomes resulting from risk taking behaviors as older adolescents and therefore may make their probability judgements based on a more limited set of examples. With increasing age comes a growing awareness of individuals similar to oneself who have suffered personal disasters as a result of risk taking (e.g., death or severe disability as a result of drunk driving, or pregnancy as a result of engaging in unprotected sexual intercourse).

The interaction of developmental changes (both in thinking and in needs for stimulation) with the social environment are theorized to underlie reckless behavior among adolescents (Arnett, 1992). The social environment determines where and under what circumstances reckless behaviors occur but does not explain the genesis of the behaviors. Social processes are important but the determinants of adolescent risk behaviors lie within the individual.

Similarly, those who embrace a cognitive decision making explanation for adolescent risk taking behavior place greater emphasis on intra-individual processes. Choices regarding whether or not to drive faster than the speed limit, to smoke marijuana, or to engage in unprotected sexual intercourse reflect the instrumental means to attain personal goals in a given context. The venue by which the social environment influences decision making is through the social values assigned to specific outcomes. These values shift over time. For example, peer acceptance seen as a desirable outcome during early adolescence may decline in its influence over the teenage years and subsequently lose some of its influence on behavioral choices.

Researchers who share a common emphasis on the importance of individual attributes in explaining risk taking behaviors often differ in their approaches to interventions. Those who highlight the influence of biologically determined needs for stimulation seek to channel sensation seeking in more controlled and theoretically safer ways. For example, adolescents with high 
needs for stimulation might be encouraged to engage in organized forms of risk taking like backpacking or rock climbing rather than seeking thrills while driving.

Others who see risk taking behavior in adolescence as an outcome of the developmental changes associated with the transition from concrete to formal operational thinking might seek to disabuse young people of the notions of invulnerability by exposing them to age similar peers who have experienced negative health outcomes and who had thought that "it couldn't happen to me" (Jack, 1989). Altering the belief in the uniqueness of one's life should, according to Elkind and his colleagues, raise the awareness of the negative consequences which may result from risk taking.

Researchers who view risk taking as the outcome of the choices individuals make among competing courses of action would focus on the adequacy of various behaviors in meeting the individual's overall goals. Risk taking behaviors, within this context, are potentially modifiable through training in social and thinking skills and specifically through decision making instruction (Beyth-Marom, Fischhoff, Quadrel, \& Furby, 1991). Those who engage in decision making training emphasize the need to promote mastery of skills that are linked to appropriate stages of cognitive development. A common view is that risk taking behaviors result from inadequacies in social competence which can be acquired through decision making training and skills development.

None of these theoretical approaches ignores the role played by the social environment (e.g., family, school, community, larger society) in youthful risk taking behavior. It is rather the perspective that socializing influences of the adolescent's environment shape predispositions to engage in risk taking behaviors and restrict or enhance their expression.

For other researchers, the person-situation interaction forms the basis for considering youthful risk taking (Jessor, 1992; Irwin, 1993; Botvin \& Botvin, 1992) Here emphasis is placed on the role of the social environment in establishing normative beliefs conducive to risk taking behaviors, and in constraining opportunities for success (e.g., poverty, racial/ethnic marginality, limited educational and employment opportunities) (Jessor, 1992; Botvin \& Botvin, 1992).

From a social-psychological perspective, adolescent risk taking behavior is viewed as a product of interactions among several conceptual domains: biology/genetics, social environment, perceived environment, personality, and behavior (Jessor, 1992). The origin of risk taking behavior is considered complex and belies an explanation which stresses one conceptual domain over others. Furthermore, the various domains are hypothesized to have indirect as well as direct effects on risk taking behavior. For example, factors within the social environment such as poverty may influence adolescent involvement in unprotected sexual intercourse largely through the individual's low perceived life-chances in the personality domain (Jessor, 1992). Identification of specific direct and indirect pathways by which domains influence risk behaviors has practical implications for designing interventions to minimize risk taking. 
The inclusion of protective factors, that is, those factors which enable a young person to avoid involvement in risk taking and develop a sense of personal adequacy and competence despite exposure to an adverse social environment (Jessor, 1992), have important implications for interventions. To the extent that protective factors like a cohesive family or high value on academic achievement operate, they mitigate against the impact and effects of risk factors. The inclusion of protective factors in the model provides an alternative strategy for combatting risk taking by strengthening positive characteristics of the individual or environment.

The biopsychosocial model of risk taking as proposed by Irwin and his colleagues (Irwin, 1993) shares many characteristics with Jessor's model. Both emphasize the multi-dimensional nature of the antecedents of risk taking behavior. Both recognize the interplay between the individual and the social environment. The two models differ in the extent to which biological maturation is viewed as a significant force in precipitating risk taking, and in the scope of the social environment.

In the biopsychosocial model of risk taking, the social environment is defined by individual perceptions of parental and peer influences and supports. Absent from the model is any consideration of broader social context such as quality of schools, poverty level, racial composition of the community, or neighborhood resources. In this sense the influence of social environment is captured by the individual's perceptions and attitudes rather than by a broader measure of external structures and organizations.

Interventions based on psychosocial conceptual models are inherently complex. Since the genesis of risk taking behaviors is not viewed as lying within the individual nor within the social environment but at the intercept of both, prevention efforts must be comprehensive in scope. For models like Jessor's which identify both protective and risk factors in each conceptual domain, interventions must be designed to simultaneously enhance protective and minimize risk factors, some of which are more modifiable than others (e.g., increasing neighborhood resources for families versus reducing poverty). These interventions focus explicitly on lifestyle change.

Interventions that use a biopsychosocial model recognize the importance of predisposing endogenous (largely individual) and predisposing exogenous (largely environmental) factors for increasing an adolescent's vulnerability to risk taking situations (Irwin, 1993). Vulnerable adolescents, when faced with a series of precipitating factors (e.g., social pressure, peer initiation of risk behaviors) and limited experience in dealing with them (e.g., lack of social skills and knowledge of the consequences of engaging in risky behavior), tend to engage in risk taking. Effective interventions are those which alter either predisposing or precipitating factors or both. Again, the emphasis is lifestyle change.

\subsection{Volitional Versus Non-volitional Risk Taking}

Researchers differ in the extent to which they consider risk taking behavior to be a volitional activity. Those who embrace a volitional definition of risk taking may exclude behaviors which are viewed as a result of pathology (i.e., eating disorders) or forces of the environment (i.e., 
crime) (Irwin, 1990). Others include behaviors such as delinquency, truancy, and unhealthy eating behaviors but exclude violent behaviors such as suicide or homicide (Jessor, 1992). And some like Arnett (1992) focus only on those behaviors which are not only considered volitional but which have the "potential for immediate and serious consequences" (p.393). Thus, sexual intercourse is not considered to be risk taking unless the individuals fail to use some form of birth control or sexually transmitted disease protection.

Decision making theorists entertain the possibility that risk taking may not be deliberate (Von Winterfeldt \& Edwards, 1986; Furby \& Beyth-Marom, 1992). Individuals may engage in risk taking behaviors without perceiving the potential of loss. Although risk perception is an important ingredient in decision making, it is not required for risk taking to take place.

More recently, sociologists have studied risk taking as a response to stressful environmental conditions (Lyng, 1990). In some sense, behaviors which pose a risk to an individual's health and social well being but represent a means of coping with stressful circumstances can be construed as less than volitional. Lyng (1990) conceived "edgework" as activities engaged in by. an individual which involve the process of negotiating boundaries of experiences such as life and death, order and disorder, etc. Individuals believe that success in edgework activities rests with the ability to exert control over situations. For individuals caught in circumstances for which they have little power to change, such as living in a poverty stricken inner city neighborhood, risk taking (i.e., drug dealing) may represent a means for self determination or survival. Feelings that result from risk taking activities such as self-actualization are powerful reinforcers for continuing these activities (Lyng, 1993). Over time, individuals are thought to further develop and value the skillfulness of their behaviors (e.g., ability to avoid police detection, increase their territory for drug trade).

Although this sociological approach does not deny the volition of risk taking, it tempers its definition by focusing on the social structural conditions that constrain free action. In social systems where individuals are incapable of fully realizing their human potential, involvement in risk taking behaviors (i.e., delinquent criminal activities) represents one strategy to exert control over one's life.

The extent to which the concept of volition is integral to any definition of risk taking behaviors has implications for interventions. If risk taking behaviors are restricted only to those that an individual has control over, then truancy, delinquency, and criminal behaviors are not considered to be risk taking since it is plausible that they may represent reactions to social environments. On the other hand, if the concept of volition is not central to risk taking, then interventions might address a variety of socially defined deviant and non-deviant behaviors.

\subsection{Developmental Versus Stationary Eramework for Understanding Youthful Risk Taking}

Most theories of adolescent risk taking incorporate a developmental perspective. Where theories differ is the extent to which physical and/or psychosocial development serve as an explanation for youthful risk taking behaviors. In general, theories which emphasize the importance of 
individual characteristics for risk taking place a high value on developmental maturation (Tonkin, 1987; Arnett, 1992; Elkind, 1985; Irwin, 1993) while those which consider the influence of social environment are more likely to argue for a continuity between adolescent and young adult behaviors (Jessor, 1992; Lyng, 1993). Still other theories while emphasizing individual characteristics as prime factors in explaining variation in risk behaviors view these behaviors as products of relatively stable personality traits which may exert a strong influence during puberty but whose effects persist across the life span (Zuckerman, 1979).

Development is an important feature of theories that highlight the impact of puberty on behavior (Irwin, 1993; Tonkin, 1987). Hormonal changes are seen as triggering physical development, secondary sex changes, and sensations which affect perceptions of body image, self-esteem, peers, family, and friends. These perceptual changes are associated with risk taking behavior. In addition, a certain amount of risk taking is seen as necessary for mastery of normal developmental tasks (Baumrind, 1987). Experimentation with adult behaviors such as sexual intercourse, substance use, and driving are important in identity formation and self competence (Baumrind, 1987). Adolescents who avoid all risk taking will be compromised in their ability to assume adult roles.

Adolescent egocentric thought is another example of the interface between development and risk taking (Elkind, 1985). Presumably as formal operational thinking becomes more consolidated with age, risk taking behaviors decline. According to these theories, the high prevalence of risk taking behaviors during adolescence is not accidental but rather the consequence of normal developmental maturation.

Other researchers, like Jessor (1992), place less emphasis on development, noting that development alone can not explain variations in behaviors associated with racial and sociodemographic characteristics or with the fact that most behaviors observed among adolescents are seen widely in adults. While not discounting adolescence as an important developmental stage of life, Jessor and his colleagues advocate an interactionist perspective which takes into account the influence of the social context in explaining behavior at any developmental stage.

Finally, researchers like Zuckerman (1979) view risk taking as a manifestation of sensation seeking which has both developmental and stationary components. Viewed as a dimension of personality, sensation seeking would be expected to be a relatively stable trait over the life span. On the other hand, sensation seeking has been linked indirectly to levels of sex hormones (Harman, 1978), suggesting that increasing prevalence of risk taking behaviors during adolescence associated with sensation seeking can be attributed to changes in testosterone and estrogen hormones during puberty. Thus, the intensity of sensation seeking is magnified during adolescence, however the trait itself is thought to influence behavior at every developmental stage.

Since development is a cross-cutting theme for all models of risk taking, it is an important element in the design of interventions to reduce the negative consequences of risk taking behaviors among the young. Those who emphasize pubertal timing and biological factors as 
triggers for risk taking behaviors will want to concentrate their efforts during early adolescence. Those who focus on changes in cognitive development will want to assess the extent of formal operational thinking and design interventions which match the mental capabilities of young people at varying developmental stages. Researchers who subscribe to an interactionist perspective will want to focus attention on the social correlates of risk taking at different developmental stages. For example, the influence of peers on adolescent behavior which tends to peak during middle adolescence would be a target for intervention among 15-17 year olds but might not be as emphasized among 18-24 year olds. Lastly, those who see risk taking as the product of some underlying personality trait will want to screen for individuals who possess the trait and design interventions that will help channel needs for sensation seeking or impulsivity in more structured and controlled ways.

\subsection{Conclusions}

Theories of youthful risk taking vary along many dimensions, some of which have been discussed in this chapter. For practitioners, program planners, and policy makers, the question is often "which theory is best?" Unfortunately, there is no clear answer. There are, however, some elements that are common to most theories and should be taken into consideration when selecting a theoretical framework for an intervention program. Increasingly, contemporary theories of youthful risk taking consider both biological and psychosocial factors as important in predicting risk taking. Pubertal timing, hormonal fluctuations, and genetics are being studied in combination with self perceptions, peer relationships, parenting styles, and other psychosocial factors in assessments of risk taking behavior. Theories which only emphasize one aspect of human development fail to explain the complexity of risk taking behavior. Theories are placing greater emphasis on social context effects on behavior. Researchers have noted that lower and middle income youth do not differ in the ages in which they initiate risk taking, or in the extent of their experimentation (Elliott, 1993). Class differences are mainly seen in the persistence of the behaviors. Middle income youth tend to abandon many risk taking behaviors like substance use after a time of experimentation, while lower class young people are more likely to adopt the behaviors as part of an overall lifestyle (Elliott, 1993). It is important to consider risk taking within a particular social context. Finally, most theories of risk taking take a developmental perspective that incorporates the dynamic changes occurring to young people during the second decade of life. Fifteen year olds are not at the same developmental stage as are twenty year olds. Taking risks has different meaning for these two groups and the factors which predict risk taking behaviors are also likely to vary. Theories that treat young people as a homogenous group will be ill equipped to address the causal processes associated with youthful risk taking behaviors. 


\section{SUBSTANCE USE}

This section discusses the prevalence and predictors of substance use among youths. It begins with a discussion of trends of substance use identified by national surveys and is followed by a review of selected research on hypothesized predictors of substance use.

The first thing that is needed is a clear definition of the problem. Unfortunately, it proves elusive. There are no clear definitions of "substance use" or "substance misuse." After reviewing the literature, Bailey (1989) concluded that substance use should be considered as a continuum from nonuse to "compulsive use." Newcomb and Bentler (1989) viewed substance abuse by adolescents as the following:

Occasional use of beer, wine, or marijuana at a party is not. abuse. However, overindulgence of any substance to the point of being very high or stoned is at least acute or temporary abuse, and if it continues this is chronic abuse (Newcomb \& Bentler, 1989, p. 243).

Youths may use or abuse a variety of substances. The most prevalent substance they use is alcohol. Large numbers also use nicotine and marijuana. Other substances used by youth include: inhalants, hallucinogens, cocaine, crack, heroin, stimulants, tranquilizers, and barbiturates.

The etiology of substance abuse by youths eludes researchers. Therefore, it is difficult to predict which youths will progress from nonuse or casual use to chemical dependency. However, predictors of substance abuse are thought to be a combination of biological, psychological, and social factors (Bailey, 1989). Many variables have been found to be related to drug use. As a result, the risk factor concept has been borrowed from epidemiology. From a risk factor perspective, "a greater aggregate number of risk factors not only is a reliable correlate of drug use but increases drug use over time, implying a true etiological role for these variables over time" (Newcomb \& Bentler, 1989, p. 245).

\subsection{The Prevalence and Major Trends of Substance Use Among Youths}

Two major sources of information about the prevalence of drug use among youths are The National Household Survey on Drug Abuse (U. S. Department of Health and Human Services 1994) and national survey results on drug use from the Monitoring the Future study conducted by the Institute for Social Research at the University of Michigan (Johnston, O'Malley, \& Bachman, 1994). Recent trends identified by these studies and others are discussed in the following subsections. 


\subsubsection{National Household Survey on Drug Abuse}

Estimates from the 1993 National Household Survey on Drug Abuse (U.S. Department of Health and Human Services, 1994) showed that 16.8 million 18- to 25-year olds had consumed alcohol in the past month, representing 59.3 percent of that age group. Among persons ages 12 to 17, 3.8 million or 18.0 percent had consumed alcohol in the past month. Table 1 indicates lesser usage of nicotine and marijuana among these age groups during the same time period, though the percentages are still arguably high.

\section{Table 1. Percentages Reporting Substance Use During the Past Month Estimates for 1993 by Age}

\begin{tabular}{|l|c|c|c|c|}
\hline Age & $12-17$ & $18-25$ & $26-34$ & $35+$ \\
\hline Alcohol & $18.0 \%$ & $59.3 \%$ & $62.8 \%$ & $48.8 \%$ \\
\hline Cigarettes & $9.6 \%$ & $29.0 \%$ & $30.1 \%$ & $23.8 \%$ \\
\hline Smokeless Tobacco & $2.0 \%$ & $6.4 \%$ & $4.4 \%$ & $1.9 \%$ \\
\hline Marijuana/Hashish & $4.9 \%$ & $11.1 \%$ & $6.7 \%$ & $1.9 \%$ \\
\hline $\begin{array}{l}\text { Any Illicit Drug } \\
\text { Other than Marijuana* }\end{array}$ & $3.0 \%$ & $5.3 \%$ & $3.1 \%$ & $1.1 \%$ \\
\hline
\end{tabular}

- Cocaine, Inhalants, Hallucinogens, Heroin, or NonMedical Use of any Psychotherapeutic (Stimulants, Sedatives, Tranquilizers, Analgesics). Taken from The National Household Survey on Drug Abuse (U.S. Department of Health and Human Services, 1994).

The percentages of youth reporting substance use in the past month have dropped significantly since 1985 (see Table 2). However, the data suggest that the momentum may have stalled somewhat in recent years. No statistically significant differences emerge when comparing 1992 and 1993 percentages except for alcohol use among youth ages 12 to 17, with the percentage of users actually increasing in 1993. 
Table 2. Percentages Reporting Substance Use During the Past Month $1985-1993$

\begin{tabular}{|l|c|c|c|c|}
\hline Age 12-17 & 1985 & 1991 & 1992 & 1993 \\
\hline Alcohol & $31.0 \%$ & $20.3 \%$ & $15.7 \%$ & $18.0 \%$ \\
\hline Cigarettes & $15.3 \%$ & $10.8 \%$ & $9.6 \%$ & $9.6 \%$ \\
\hline Smokeless Tobacco & $\mathrm{N} / \mathrm{A}$ & $3.0 \%$ & $2.6 \%$ & $2.0 \%$ \\
\hline Marijuana/Hashish & $14.9 \%$ & $4.3 \%$ & $4.0 \%$ & $4.9 \%$ \\
\hline $\begin{array}{l}\text { Any IIIIcit Drug } \\
\text { Other than Marijuana* }\end{array}$ & $6.7 \%$ & $3.9 \%$ & $3.2 \%$ & $3.0 \%$ \\
\hline Age 18-25 & 1985 & 1991 & 1992 & 1993 \\
\hline Alcohol & $70.7 \%$ & $63.6 \%$ & $59.2 \%$ & $59.3 \%$ \\
\hline Cigarettes & $36.6 \%$ & $32.2 \%$ & $31.9 \%$ & $29.0 \%$ \\
\hline Smokeless Tobacco & $\mathrm{N} / \mathrm{A}$ & $5.8 \%$ & $6.0 \%$ & $6.4 \%$ \\
\hline Marijuana/Hashish & $21.9 \%$ & $13.0 \%$ & $11.0 \%$ & $11.1 \%$ \\
\hline $\begin{array}{l}\text { Any Illicit Drug } \\
\text { Other than Marijuana* }\end{array}$ & $12.3 \%$ & $6.1 \%$ & $5.2 \%$ & $5.3 \%$ \\
\hline Cocan, Inta & & & & \\
\hline
\end{tabular}

-Cocaine, Inhalants, Hallucinogens, Heroin, or NonMedical Use of any Psychotherapeutic (Stimulanis, Sedatives, Tranquilizers, Analgesics). Taken Irom The Mational Household Survey on Drug Abuse (U.S. Department of Health and Human Services, 1994). 
Nearly 14 million youth ages 18 to 25 "tended" during the past year to use alcohol on a monthly basis, and more than 6 million tended to use it on a weekly basis. Comparable figures for the 12 to 17 age group were 2.8 million and 0.9 million, respectively. Almost 3.9 million persons aged 12 to 25 tended towards monthly use of marijuana, with about 2.3 million being weekly users. Almost three-quarters of these monthly and weekly marijuana users were in the 18 to 25 age group. Table 3 shows the percentages over time of monthly and weekly substance users.

\subsubsection{Monitoring the Future}

The Monitoring the Future study (Johnston, O'Malley, \& Bachman, 1994) is a national survey which provides information about the prevalence of substance use by 8th, 10th, and 12th graders, college students, and young adults who were previously surveyed when they were in the 12th grade. Participants are surveyed yearly about the use of licit and illicit drugs. It is important to note at the outset that this survey does not include adolescents who are not in school, though these youths may be at the highest risk for substance use. Therefore, the results reported by Johnston et al. (1994) likely understate the prevalence of substance use among the total population of youth (Newcomb \& Bentler, 1989).

Several alarming trends in the use of illicit drugs were identified in the 1993 survey. First, for junior and senior high school students the use of illicit drugs increased from the previous year. Although the proportion of youths who use substances had previously declined for a number of years, the authors noted that this was the second consecutive year in which there was an increase in the use of illicit drugs. Second, this also was the second consecutive year in which negative attitudes and beliefs about substance use declined. Perceived harmfulness has been shown in the survey to be a strong predictor of substance use. For different substances, usage historically has fallen with increases in perceived harmfulness, and risen with decreases in perceived harmfulness.

Experience with alcohol was widespread among the respondents. For example, two-thirds of the 8th graders surveyed had tried alcohol (67 percent), while almost all of the older respondents had tried it $(10$ th graders $=87$ percent, 12 th graders $=91$ percent, and college students $=91$ percent). In addition, the proportion of binge drinkers (drinking five or more drinks in a row in the two-week period prior to the survey) ranged from 14 percent for the 8th graders to 40 percent for the college sample. The percent of young adults who reported binge drinking was 34 percent. There were no statistically significant changes in the proportion who reported drinking alcohol (over the past 30 days) from 1992 to 1993 . However, there was a statistically significant increase in binge drinking for tenth graders from 1992 to 1993.

Large numbers of adolescents were found to be smoking regularly. Since the 1981 survey, the daily rate of cigarette use for high school seniors has basically remained unchanged. Nineteen percent of the seniors reported smoking daily in 1993 (compared to 20 percent in 1981). Approximately 30 percent of the high school seniors reported that they do not believe there are risks associated with smoking. 
Table 3. Percentages Reporting Monthly and Weekly Substance Use $1985-1993$

\begin{tabular}{|c|c|c|c|c|}
\hline Monthly Use & 1985 & 1991 & 1992 & 1993 \\
\hline Ages 12-17 & & & & \\
\hline Alcohol & $21.6 \%$ & $14.1 \%$ & $11.2 \%$ & $13.3 \%$ \\
\hline Marijuana & $9.8 \%$ & $4.8 \%$ & $3.8 \%$ & $4.8 \%$ \\
\hline Ages 18-25 & & & & \\
\hline Alcohol & $62.6 \%$ & $53.0 \%$ & $50.0 \%$ & $49.2 \%$ \\
\hline Marijuana & $18.8 \%$ & $11.9 \%$ & $10.9 \%$ & $10.1 \%$ \\
\hline Weakly Use & 1985 & 1991 & 1992 & 1993 \\
\hline Ages 12-17 & & & & \\
\hline Alcohol & $8.7 \%$ & $5.3 \%$ & $4.1 \%$ & $4.0 \%$ \\
\hline Marijuana & $6.6 \%$ & $2.4 \%$ & $2.2 \%$ & $2.8 \%$ \\
\hline Ages 18-25 & & & & \\
\hline Alcohol & $32.6 \%$ & $24.8 \%$ & $24.1 \%$ & $21.5 \%$ \\
\hline Marijuana & $11.5 \%$ & $6.8 \%$ & $6.3 \%$ & $5.9 \%$ \\
\hline
\end{tabular}

Taken from The Nationai Household Survey on Drug Abuse (U.S. Department of Health and Human Services, 1994). 
Daily usage rates for cigarettes for 8th and 10th graders increased from 1992 to 1993 (8th graders: $1992=7$ percent, $1993=8.3$ percent; 10 th graders: $1992=12.3$ percent, $1993=14.2$ percent). Fifty-three percent of 8th graders and 61 percent of 10th graders believed that there are no health risks associated with smoking a pack of cigarettes daily.

Johnston, O'Malley, and Bachman (1994) also reported substance use findings by gender. Males who were seniors in high school or who were in the college and young adult sample were more likely to use illicit drugs than the same-aged females, especially at levels of heavy use. The one exception was stimulant use, which showed no gender differences. For the eighth and tenth graders, there were few gender differences for illicit drug use. Stimulant use was slightly higher for females in the eighth and tenth grades than for their male peers.

There is a considerable gender difference in "occasions of heavy drinking" among high school seniors (females $=21$ percent; males $=35$ percent). Among college students, 33 percent of college females reported drinking five or more drinks in a row over the past two weeks compared to 45 percent of college males (Johnston, Bachman, \& O'Malley, 1994).

Among high school seniors, there were no differences in cigarette smoking between males and females. Females who were college students had a slightly higher chance of being a daily smoker than their male counterparts.

Another source of information about drug use among youths was a study conducted by Barnes and Welte (1986). They surveyed approximately 27,000 students in New York state about their drinking. The findings of their study were consistent with the findings of many others. First, the younger the initiation of alcohol use the greater the likelihood of heavy drinking in later years. Second, the rate of drinking tends to increase as youngsters get older.

The authors also found that the age at which a participant first became drunk was a predictor of current alcohol consumption. Those who first got drunk at younger ages had higher levels of current alcohol consumption. For example, for those who first got drunk at age 11, their current average daily alcohol consumption was approximately four drinks a day. Participants who first got drunk at age 14 or older had an average daily alcohol consumption of approximately one drink a day.

\subsection{Knowledge}

Knowledge of the consequences associated with substance use has typically not been found to be an effective deterrent to drug use among adolescents. In fact, adolescents tend to display little concern over the impact of psychoactive substances despite warnings from parents, teachers, and health care professionals (Botvin \& Botvin 1992). Adolescents like to feel they are in control, and tend to overestimate their own ability to avoid or discontinue use of harmful substances. It is not, for example, until trying seriously to quit smoking do youths realize their own level of dependency (Botvin \& Botvin, 1992). 
In a study examining effective counter-advertisement campaigns for tobacco, adolescents were found to be quite knowledgeable about the health risks of smoking (McKenna \& Williams 1993). However, this knowledge was not effective in stopping adolescents from experimenting with tobacco.

An exception to the poor results from education was reported in a study of anabolic steroid use among adolescents. DuRant et al. (1993) found that youths who had previously received education regarding HIV and AIDS were less likely to use anabolic steroids than those who did not. This may be significant because approximately one-fourth of the adolescent anabolic steroid users reported sharing needles with other users. However, this behavior was not seen as dangerous, as adolescents did not perceive the people they shared needles with to be "true" drug users. Adolescents who were knowledgeable about AIDS were reported to share needles less often than those who had received no education on HIV. Durant et al. (1993) also found frequent users of anabolic steroids more likely to use other substances as well. In particular, frequent use of anabolic steroids was associated with cocaine, marijuana, and smokeless tobacco use.

\subsection{Personality Factors}

Previous research indicates that a complex interplay of cognitive, developmental, personality, social, and environmental factors are important in determining which youths are at risk for substance abuse. Although personality clearly plays an integral part in adolescent substance use, no one characteristic has been found to be uniquely predictive of substance use involvement.

In a review of research undertaken between 1984 and 1988, Moncher et al. (1991) examined the psychosocial correlates of adolescent substance use. Personality characteristics which were frequently cited as relating to adolescent substance use were unconventionality, external locus of control, stress, and environmentally-related interpersonal factors (e.g., friends' use of alcohol and marijuana). An earlier review by Bailey (1989) reported several additional personality factors related to substance use. Factors reported to be associated with (and at times to predate the onset of) drug use were low self-esteem, anxiety, depression, lack of self-control, rebelliousness, poor school performance, and delinquency.

As noted, adolescent substance use has been studied and related to a broad range of personality characteristics. However, studies often define personality dimensions differently. To avoid confusion and misrepresentation of information, the following is a review of several studies individually, rather than a synthesis of the literature.

Towberman et al. (1993) examined the underlying dimensions of attitudes toward substance use among adolescents. Six factors -- perceived attitude among peers towards alcohol and drug use, personal attitude towards alcohol use, personal attitude towards drug use, belief that alcohol will negatively impact school performance, belief that the use of substances will portray a negative image, and perceptions of parents' attitude towards the use of drugs -- were found to relate both to drug use and to experimentation with drugs among youths. Among these factors, both drug 
and alcohol avoidant attitudes related most strongly to drug use, indicating that adolescents holding negative attitudes towards drugs are less likely to become involved with drugs.

LaBouvie and McGee (1986) examined the relationship between personality characteristics and drug use among males and females. Personality characteristics differed between light and heavy substance users, suggesting personality attributes may be antecedents of substance use. Using a shortened version of Jackson's (1968) Personality Research Form, adolescents were measured on 17 personality traits. Adolescents characterized as heavy substance users were found to score high on "risky attributes" such as autonomy, exhibition, impulsivity, and play. These attributes were accompanied by low scores on the "safe attributes" of achievement, cognitive structure, and harm avoidance. A reversal of these characteristics was found among light users, along with lower affiliation scores. The relationship of personality to substance use was strongest for males between the ages of 12 and 21 , while it was strongest for females between 18 and 21 .

Donovan and Jessor (1978) examined the psychosocial correlates associated with youths at risk for problem drinking. Differences in personality between problem and non-problem drinkers were noted, with problem drinkers reported to be less conventional, and more tolerant of deviance. Additionally, lower value on conformity to established institutions, lower value on academic achievement, and lower expectations of achievement were found. Youths characterized as problem drinkers also placed a greater value on autonomy and valued independence more than achievement.

As a follow-up to the previous study, Donovan et al. (1983) examined adolescent problem drinking and its ability to predict problem drinking in young adults. The strongest psychosocial predictors of young adult problem drinking were those which had been among the strongest predictors of adolescent problem drinking. Those most prone to problem drinking as adolescents were also most at risk for problem drinking as young adults. Problem drinking in young adulthood was more likely for those who, as adolescents, were unconventional and tolerant of deviance.

Although deviant behavior and tolerance of deviance has been associated with adolescent substance use, all youths characterized as deviant may not be equally at risk for substance use. Chassin et al. (1989) examined the relationship between adolescent deviance and the risk of substance use and negative health-related behavior. Two types of deviant behavior, constructive deviance and destructive deviance, were examined. Constructive deviance was characterized by independence, autonomy, and a lack of blind conformity. Destructive deviance was characterized by "anticonformity" and rebelliousness, and was tied more strongly to group norms. In relation to smoking behavior, adolescents high in destructive deviance were more likely to smoke cigarettes, and were more strongly influenced by peer opinions. The smoking behavior of adolescents high in constructive deviance was less tied to peer opinion or anticonformity. The authors suggested that youths high in constructive deviance may be less at risk for problem behavior associated with rebelliousness, anticonformity, defiance, or problems with family and school. However, the pursuit of new and different experiences, as well as the 
independence and assertiveness characterized by adolescents high in constructive deviance, may make them vulnerable to risk taking behaviors for different reasons.

Shedler and Block (1990) reported results of a longitudinal study which measured the frequency of drug use by adolescents 18 years of age. Subjects were divided into three groups based on past drug use: abstainers, experimenters, and frequent users. Abstainers had never used any drug, experimenters had used marijuana on a few occasions and no more than one other drug, and frequent users had used marijuana frequently and tried at least one other drug. The experimenter group contained the most subjects, and was considered most representative of typical adolescent behavior. This group was therefore used as a comparison group for the abstainers and frequent users. Clear differences in personality among the three groups were observed, with abstainers reported to be more fastidious, conservative, tense, overcontrolled, moralistic, unattractive, "not charming," and socially ill at ease. In childhood, abstainers were described as timid, fearful, overcontrolled, cold, morose, and immobilized under stress. Frequent users were found to be alienated, withdrawn, unhappy, rebellious, non-conforming, hostile, deceitful, and to have feelings of inadequacy. Frequent users expressed their maladjustment through undercontrolled and overtly antisocial behavior. In childhood, frequent users were characterized as relatively maladjusted, unable to form good relationships, insecure, and showed signs of emotional distress. According to the authors, these results suggest that personality correlates, specifically the maladjustment of frequent drug users, actually precede drug use, suggesting that drug use may be a symptom of social maladjustment, not a cause. They concluded that in order to adequately understand drug use, the context of the individual in question should be examined.

In summary, certain personality characteristics have consistently been associated with adolescent substance use, such as rebelliousness, unconventionality, conformity to peer norms, and deviance. Research has found differences in personality between light and heavy substance users, and identified personality characteristics that appear as antecedents of initial substance use behavior (Shedler \& Block 1990).

\subsection{Population Density}

The proportion of youth using illicit drugs does not differ substantially by urbanicity (Johnston, Bachman, \& O'Malley, 1994). Furthermore, Johnston, Bachman, and O'Malley (1994) reported similarities in the proportion of youth who use alcohol by urbanicity, with only one exception. The proportion of binge drinkers was higher in non-metropolitan areas than in metropolitan areas. In addition, among high school seniors, college students and young adults, the proportions of those who engaged in cigarette smoking and smokeless tobacco use were higher in non-metropolitan areas compared to metropolitan areas. The National Household Survey on Drug Abuse (1994) also showed minimal differences in the proportion of those who used substances by urbanicity, with the exception of cigarette smoking. A higher proportion of youths (ages 18 to 25 ) smoked cigarettes in non-metropolitan areas. 


\subsection{Race and Ethnicity}

This section discusses findings from national surveys concerning differences in substance use across racial and ethnic groups.

\subsubsection{Whites}

Johnston, O'Malley, and Bachman (1994) reported that for the twelfth grade sample, in the Monitoring the Future study, white students were more likely than black or Hispanic students to have used inhalants, hallucinogens, LSD, barbiturates, amphetamines, tranquilizers, opiates other than heroin, alcohol (including binge drinking), and cigarettes. In contrast, higher proportions of Hispanics than whites used dangerous drugs in the eighth grade.

\subsubsection{Blacks}

The Monitoring the Future study found that across ages examined in the survey, lower proportions of black youths used licit and illicit substances compared to whites and Hispanics. These findings also held for cigarette smoking and binge drinking (Johnston, O'Malley, \& Bachman, 1994).

Barnes and Welte (1986) obtained similar results. They found smaller percentages of black students drinking than white, Native American, and Hispanic students. The percentages of heavy drinkers were also smaller for black students than for Native American and white students. Moreover, black students had lower "average daily consumption of ounces of absolute alcohol."

Zimmerman and Maton (1992) interviewed black male urban adolescents about their drug use. The average age of the subjects was 17 years, and 70 percent had left school before high school graduation. Based on their responses to questions about school attendance, employment, church attendance, and delinquency, subjects were placed in the following groups: (1) delinquent group, (2) church group, (3) uninvolved group (e.g., unemployed and not attending school or 'church), (4) in-school group, and (5) employed group. Results showed that the groups differed on the use of alcohol and other substances. The delinquent group reported more use of all substances. The uninvolved group used cigarettes and alcohol more than the school group. In addition, the uninvolved group and the employed group used marijuana more than the church or school group. The authors suggested that there may be life-style behaviors that have a "compensatory" effect on other damaging behaviors.

\subsubsection{Hispanic Americans}

Johnston et al. (1994), in The Monitoring the Future study, found that Hispanics in eighth grade and in their senior year of high school were more likely to use cocaine, crack, and heroin compared to whites and blacks. In eighth grade, they also were more likely to have engaged in binge drinking, as well as used marijuana, hallucinogens, and cigarettes. 
In a study of minority high school students in New York City, it was found that being older, male, and Hispanic was associated with increased alcohol use, while being white or Hispanic was associated with cigarette use (Walter, Vaughan, \& Cohall, 1993). Barnes and Welte (1986), in their study of high school students in New York state, found Hispanic students reporting less alcohol consumption than their white and Native American peers. They had higher rates of alcohol consumption than blacks, West Indians, and Asian students. Analysis of students who were classified as drinkers revealed that Hispanic drinkers' "average daily consumption of ounces of absolute alcohol" was slightly higher than that of white drinkers.

\subsubsection{Native Americans}

Substance abuse among Native American youths is a serious problem. Numerous studies have demonstrated that, when compared with adolescents of other ethnic or racial backgrounds, Native American youths tend to use both drugs and alcohol at earlier ages and with higher frequencies (Moncher et al., 1990). The consequences of this abuse materialize early on in the form of academic failure and delinquent behavior during school. Later in life, the impact of substance abuse among Native Americans can be seen in the incidence of unemployment and violent crime (Moncher et al., 1990).

Beauvais (1992), examined factors inherent in the social structure of many Native Americans which contribute to the increased incidence of substance abuse among adolescents. Poor economic conditions often existing in Native American communities place a strain on the family resulting in a loosening of family structure, as well as a loss of cultural identification. These economic hardships often result in difficulties meeting basic physical needs, as well as inadequate parenting, and impoverished social conditions. These troubles may lead adolescents to choose friends with similar backgrounds, who are also experiencing problems with social integration. These associations may lead to the formation of peer groups characterized by deviant behavior and drug use. However, Beauvais (1992) also noted that the extended family structure common in Native American culture may be helpful in reducing risks for adolescents.

Moncher et al. (1990) examined factors associated with risk proneness for substance use among Native American adolescents. The authors developed a global measure of risk taking based on 16 questionnaire items that tapped information about the use of smokeless tobacco and smoked tobacco, experimentation and intentions to use substances, smoking by family members and peers, quality of family relations, deviance, school adjustment, problems in school, and cultural identification. The global measure of risk was related to use during the past week of smokeless tobacco, smoked tobacco, and alcohol. There was also a relationship between the global measure of risk and the use of inhalants, marijuana, and cocaine/crack although this relationship was not as strong as that found with tobacco and alcohol. When overall risk scores were used to divide subjects into high and low risk groups, significant differences between the two groups began to emerge. The high risk group was found to use significantly greater amounts of substances across all substances than did the low risk group. The highest incidence of use was found in alcohol, smokeless tobacco, and marijuana. The authors concluded that the results of the study support the risk factor concept. 


\subsubsection{West Indians and Asians}

Barnes and Welte (1986) reported that Asian students had the smallest percentages of drinkers (45 percent) compared to the other ethnic groups studied (white $=76$ percent; Native American $=73$ percent; West Indian $=61$ percent; Hispanic $=63$ percent; black $=59$ percent). West Indian and Asian students had the smallest proportion of heavy drinkers. Yet among heavy drinkers, Asian students had a higher "average daily consumption of ounces of absolute alcohol" than white, Hispanic, and Native American drinkers.

\subsection{Peers}

The peer group serves as a secure environment in which adolescents practice developing skills. Initial experimentation with cigarettes and illegal substances usually occurs within the setting of the peer group. Peer influence increases and parental influence decreases as youths reach adolescence. The greatest amount of peer influence is in preferences for styles of clothing and music. However, parents have greater influence than peers in issues concerning education and career choice (Botvin \& Botvin, 1992).

Several theories have been utilized to explain peer influences. Dinges and Oetting (1993) summarized two of them, differential association theory and peer cluster theory. Differential association theory posits that an excess of attitudes and beliefs favorable to using substances (in relation to beliefs contrary to using them) promotes substance use. Parental and peer messages that are favorable to drug use contribute to the proportional balance between pro-drug and antidrug beliefs (Dinges \& Oetting, 1993).

Peer cluster theory posits that drug use does not occur in isolation. It occurs in the presence of peers. Peers encourage ongoing use by tolerating drug use, providing emotional support, and furnishing education about drugs. Other factors, such as psychosocial ones, contribute to drug use, but only indirectly. Psychosocial factors influence the choice of peers (Dinges \& Oetting, 1993).

Dinges and Oetting (1993), in examining peer association, found a relationship between the particular substances used by youths and their peers. They surveyed 113,289 mostly white junior and senior high school students. The focus of the survey was on current use of illicit drugs (e.g., marijuana, uppers, downers, cocaine, and PCP) by self and friends. Six subgroups were derived from questions relating to drug usage during the past month. The groups were: (1) nonusers, (2) marijuana, (3) marijuana and uppers, (5) marijuana, uppers, and cocaine, (4) marijuana, uppers, cocaine, and downers, and (6) marijuana, uppers, cocaine, downers, PCP, and one other drug. Results indicated that adolescents who tended to use a particular type of drug had friends who tended to use the same drug. For example, the authors explained that "41.6 percent of nonusers had friends who used marijuana as compared to 97.5 percent of marijuana users who had friends using marijuana. Only 43.0 percent of those adolescents using marijuana had friends who used uppers as compared to 91.8 percent of the marijuana and uppers users who had friends who use uppers" (Dinges and Oetting, 1993, p. 259). 


\subsection{Religiosity}

Research suggests that adolescents who attend religious services more frequently are less likely to have problems with substance use. In a study of rural adolescents, Gibbons et al. (1986) found that those who attended religious services with greater frequency were less likely to drink alcohol. Zimmerman and Maton (1992) found similar results among urban black youths, with adolescents who more often attended religious services less likely to report alcohol or substance abuse. Additionally, comparisons among adolescents who had dropped out of school early showed that youths who attended religious services were less likely to become involved with drugs and alcohol than youths who did not.

\subsection{Family Factors}

No definitive way exists to predict which adolescents are at risk for substance abuse. It is commonly reported that adolescent substance use is related to substance use by family members and the nature and effectiveness of parenting. However, the structure of the nuclear family in America is rapidly changing, placing new and different stressors on adolescents (Stern et al., 1984). The results of these stressors often evidence themselves in teen alcohol and drug use (Stern et al., 1984). In addition to psychosocial correlates, support for biological correlates of substance use has also been found. By examining the role of heredity in substance use, it may be possible to identify individuals at greatest risk for substance abuse.

In a Special Report on Alcohol and Health, the U.S. Department of Health and Human Services (1993) discussed research relating to the role of genetics and biology in alcoholism. Studies on twins suggest genetics may influence behavior relating to the frequency and quantity of alcohol use. Genetics may also be helpful in predicting vulnerability to alcohol. Adoptions studies suggest children with an alcoholic biological parent may have as much as 2.5 times the risk of alcoholism than children without alcoholic parents. It has been estimated that as many as 80 percent of people who receive inpatient treatment for alcoholism have close biological relatives with a history of alcohol-related problems. Additionally, individuals with close relatives suffering from alcoholism have a risk factor which is four to five times higher than those who do not. The risk of alcoholism among males is higher than that found among females. Evidence for different "types" of alcoholics has also been found. Type I alcoholism is most common and is found in both men and women, with the typical age of onset occurring during middle adulthood. Type II alcoholism is much more common to men and is influenced heavily by genetics. Type II is characterized by aggressive behavior, which is also found in the father. Onset generally occurs during adolescence.

Stern et al. (1984) examined the effect of father's absence from the home on adolescent drinking, marijuana use, and sexual activity. Subjects were categorized into low, moderate, and heavy use groups for each behavior. Father absence was found to increase the likelihood of maie adolescents being categorized as heavy alcohol and marijuana users. Females from father absent homes were most likely to be categorized in the moderate alcohol use group. There was not a strong effect of father absence from the home on female marijuana use. 
In a paper examining research and trends in adolescent substance use, Halebsky (1987) reports adolescents as having a tendency to imitate the drinking habits of their parents, with the children of frequent drinkers likely to be frequent drinkers themselves. However, at the extremes of behavior, when parents are either alcoholics or complete abstainers, parental behavior was generally not mimicked by adolescents. Parental use of marijuana was reported to be related to adolescents' marijuana and drug use as well. In a later review and study of correlates of adolescent substance use, Dielman et al. (1991) found parental alcohol use related to both the frequency and quantity of adolescent alcohol use. Higher levels of alcohol use by parents was related to higher frequency and quantity of use by adolescents. Maternal substance use was reported to relate more closely to adolescent substance use than was father's use.

Several studies have looked at characteristics of parenting and the home environment which relate to adolescent substance use. In Halebsky's (1987) review, youths from homes characterized as cold and uncommunicative were reported more likely to be substance abusers. Additionally, families noted to be dysfunctional, to have high amounts of disagreement between parents, and to have strict control and/or inconsistent limit setting were associated with youthful substance abuse. In their longitudinal study of adolescent drug use, Shedler and Block (1990) examined the parent-child interactions of frequent substance users. Mothers of frequent users were found to be hostile, cold, unprotective, unresponsive, and non-spontaneous. These mothers tended to create situations which were unenjoyable and grim, leading to unpleasant interactions with their children.

In his review, Halebsky (1987) reported research relating Kandel's stages of drug use to parental and peer influences. According to Kandel's theory (1982), substance use occurs in stages, with each stage serving as a "gateway" to the next stage. Adolescents generally progress through each stage as their experience and involvement with substances increases. The four stages are: beer and wine; cigarettes and hard liquor; marijuana; and other illicit drugs. Both parental and peer attitudes toward drinking behavior, as well as parental permissiveness towards drugs and alcohol, were reported to be influential in both stages one and two. In stage three, peers were found to be most important in determining marijuana use. In the final stage, both parents and peers, as well as parental usage of marijuana, impacted upon adolescent drug use.

Gross and McCaul (1991) examined the psychological and behavioral characteristics of youths with family histories of substance abuse (FHP) as compared to families without a history of substance use (FHN). Adolescents with FHP were found to have a higher incidence of nonnuclear families, and showed a trend toward more use and experimentation with drugs than FHN adolescents. FHP youths also started using drugs at an earlier age and were more likely to be delinquent. Adolescents from FHP households were more likely to fall in the clinical ranges on a somatic scale and on a total problem scale. These findings were more pronounced for females than for males, although both sexes were much more likely than FHN adolescents to be classified as having a psychological disorder. 


\subsection{School Factors}

Adolescent substance abuse has been linked indirectly to factors relating to academics and school involvement. In a study of rural adolescents, Gibbons et al. (1986) found students who were less conscientious and less involved in extracurricular activities to consume more alcohol. Similarly, Ellickson and Hayes (1992) found that adolescents who were low in academic orientation and who had weak links with their school were also at an increased risk for exposure to pro-drug influences. Additionally, these students felt they would be less able to resist offers of drugs and that drug use would provide positive outcomes for them. However, Bentler (1992) reported that teen drug use did not necessarily reduce educational aspirations, but did reduce college involvement. The use of hard drugs was also found to decrease the chances of adolescents graduating from high school and to limit opportunities later in life.

\subsection{The Relationship Among High Risk Behaviors}

There is strong evidence that substance use is related to other problem behaviors as evidenced by the work of Jessor and his colleagues (Jessor \& Jessor, 1977; Donovan \& Jessor, 1978; Jessor, 1987). In a longitudinal study of problem behavior, Jessor and Jessor (1977) found that problem drinkers were also using marijuana, engaging in deviant behavior, and engaging in sexual activity. In a later study of high school juniors and seniors, risky driving corresponded to alcohol and marijuana use, and unprotected sex by males (Jessor, 1987).

Jessor's work has recently been replicated by Farrell, Danish, \& Howard (1992), with urban black seventh and ninth graders. The authors found that using substances more often was related to smoking cigarettes as well as using marijuana and other drugs. Higher frequency of substance use was also related to higher frequency of sexual intercourse and delinquent behavior.

Barnes and Welte (1986) found that, as grades in school dropped, drinking increased. They also found problems in school (e.g., cutting class, being sent to the principal's office, etc.) were the strongest predictor of alcohol consumption for subjects classified as drinkers.

There is strong evidence in the literature that substance use is predictive of earlier and more risky sex. These studies are summarized in section 4.10. 


\section{VIOLENCE}

For the population as a whole, injuries resulting from firearms were the second leading cause of injury-related death in the United States in 1991, second only to deaths from motor vehicles (Fingerhut et al., 1994). However, trends for these two types of fatalities have diverged in recent years. While the motor vehicle death rate declined 14 percent in the period 1988 through 1991, the firearm death rate increased 9 percent during this same period (Fingerhut et al., 1994). This increase in the firearm death rate was greatest for persons aged 15-24 years, a 40 percent increase. In many inner cities, homicide is now the leading cause of death among youth.

Over the last 15 years the literature on violence has grown enormously, encompassing child abuse, family violence, and criminal and delinquent behavior. The majority of studies on antecedents of violence are cross-sectional rather than longitudinal in nature, i.e. data are collected simultaneously on the "antecedents" of violence and the occurrence of violence, rather than being collected over time. However, in these cross-sectional studies, the retrospective period for which the occurrence of behaviors were measured varied from "over the past month" to lifetime experiences, depending on the behavior. Most studies have used large samples of either high school or college students. In recent years, case-control studies have been carried out in which cases of violence were ascertained through either hospital or prison records. Such cases were then compared to controls of the same age and gender, with no history of violence, to determine the role of past experiences and behaviors.

The most frequently studied risk factors for violence fall into three areas: physical or sexual abuse and neglect; exposure to violence, including exposure to television violence; and substance use - particularly alcohol, but also illegal drugs such as marijuana, psychedelics, amphetamines, and cocaine.

\subsection{Age/Gender}

Victimization and criminal offender data show violence most heavily concentrated among younger age groups, and among males. Data on homicide victims indicate that homicide rates are highest between ages twenty and thirty-four (Runyan and Gerken, 1991; Baker et al., 1992), followed by the fifteen-to-nineteen age group. Homicide rates are five to ten-fold higher for males than for females (Baker et al., 1992). Firearms are used in 80 percent of teenage homicides (Fingerhut, 1993). However, this is in part a reflection of the lethality of firearms compared to other weapons.

Data on the age breakdown for individuals arrested for serious crimes in 1992 (U. S. Department of Justice, 1992) showed that those under age 25 represented much of the arrests. For instance, over 50 percent of those arrested for murder and nonnegligent manslaughter, robbery, burglary, larceny-theft, motor-vehicle theft, or arson were under age 25 . Over 40 percent of those arrested for forcible rape or aggravated assault were in this age group. 


\subsection{Race}

Young black males are victims of homicides at far higher rates than whites (Chatman et al., 1991). In 1991, the rate of homicides for adolescents between ages 15 and 19 was 11.8 per 100,000 for white males, and 123.6 for black males. Among comparably aged females, the rate of homicides was 2.2 for whites and 11.2 for blacks per 100,000 (U.S. Department of Justice, 1992). In 1992, 2,851 adolescents between ages 15 and 19 were victims of homicide. Of these 1,664 were black, and 1,114 were white (U.S. Department of Justice, 1992).

\subsection{Violence as a Learned Behavior}

A theme that pervades much of the literature on violence is that it is a learned behavior or response. The most extensive recent review of the literature is that by Widom (1989) who examined literature relating to the "violence breeds violence" hypothesis. She noted: "By and large, these studies indicate with some consistency that abused children manifest more aggressive and problematic behavior, even at early ages" (Widom, 1989, p. 19).

In her review of studies on delinquents, Widom noted that the more offenders were victimized by routine family violence, "being hit with a belt or stick or some other hard object," the more violent crimes they committed. She further noted that abused children have more aggressive behavior, even at early ages, and that aggressiveness is a fairly stable personality trait. As cited by Widom, Olweus (1980) wrote "a preadolescent or adolescent boy characterized by an aggressive reaction pattern is not very likely to outgrow his mode of reaction, and his behavior may fairly easily develop into more directly antisocial forms of behavior" (p.645). Olweus concluded that the stability of aggressive reaction patterns over time was not much lower than that typically found in studies of the stability of intelligence.

There is considerable literature identifying histories of sexual or physical abuse as risk factors for later violence, much of which is included in Widom's 1989 review. A recent study by Hernandez et al., (1993) contributes further to the field by examining how much of risk taking behavior of black males is explained by a history of child sexual or physical abuse. The authors and others have noted that such a history is two to three times more prevalent for black compared to white males. The authors found that when sexual and physical abuse were also considered, the effect of race decreased in six of seven risk-taking behaviors, including violent acts, in which blacks were significantly more likely to engage.

There are two learning components related to aggression, violence, or delinquency. There is learning the behavior itself, and also learning the "appropriateness" of such behavior. Moral development, discussed in the next section, may affect whether an individual believes a certain behavior to be appropriate or not. In addition, there may be subcultures where violent responses in general are considered appropriate. Some authors, Singer (1986) for example, have examined this "subcultural theory". This theory posits that there is a subculture of violence in which a violent response is encouraged to resolve intergroup conflicts. In such a subculture, victims of serious violence are frequently offenders. Indeed, this pattern may help maintain the norms of 
violence among the group (Singer, 1986). As yet there is no consensus on the most likely explanation for the correlation between experience as a violence victim and the experience of committing serious violence. However, learning the violent response and learning that response is appropriate within certain cultures is a possible explanation.

\subsubsection{The Relationship of Moral Development to Juvenile Delinquency}

A large and comprehensive body of work in the area of moral development has emerged over the past 25 years. Part of this work focuses on the relationship of moral development to engagement in illegal activities by youths. Kohlberg's theory of moral development stimulated theoretical and empirical work examining the underlying processes relating to sociomoral development.

In Kohlberg's schema there are three progressive stages of moral development which span childhood and early adolescence. These stages are the preconventional, conventional, and postconventional. Kohlberg believed that an individual's moral orientation unfolds as a result of cognitive development (Santrock, 1993). At each stage there is greater capacity for abstract reasoning about the "social contract between individual and society" (Morash, 1983). For example, the preconventional stage of moral reasoning is controlled by external rewards and punishments. In the conventional stage, individuals are guided by certain standards, but they most likely are the standards of others. In the postconventional stage, moral reasoning is controlled by internal standards and principles. The individual at this stage explores different moral courses, subsequently developing a personal moral code (Santrock, 1993).

Within this framework, age normative understanding of human social life is gained through roletaking opportunities. Role-taking is a means for youths to "restructure their own moral schemata and incorporate those of others" (Muss, 1988). Taking the perspective of others may play a role in stimulating an individual to construct more mature moral judgments (Mason \& Gibbs, 1993). A study by Keasey (1971) showed that higher levels of moral judgment were associated with more participation in social clubs. Mason and Gibbs (1993) found perspective-taking opportunities during early adolescence, such as participating in class discussions, discussing opinions with friends, and reading newspapers, were associated with advanced moral judgment in freshman and senior college students.

Kohlberg originally identified 10 to 13 years as the transition period from preconventional to conventional thinking. He theorized that conventional moral judgment served as a protective factor when personal or environmental forces provided opportunities to break the law (Morash, 1983). Thus, delinquency is attributed to a developmental arrest in sociomoral development. Kohlberg (1978) found that youths institutionalized for juvenile delinquency were more likely than a noninstitutionalized control group to be at the preconventional level of reasoning. Some studies of delinquent or conduct-disordered youths showed that conduct-disordered youths were at lower stages of moral development (Gibbs, 1991). Other studies showed mixed results, with some not finding a relationship between level of moral reasoning and delinquency (Morash, 1981; Emler, Winton, \& Heather, 1977). 
One hypothesis about the relationship of moral development to juvenile delinquency is that those who have no experience in role-taking are left with a typically self-centered world view. These youths may be susceptible to antisocial behavior as a result. Morash (1983) argued that at the age American youths develop from the preconventional to the conventional level of moral development they ". . . are increasingly segregated from adults. Minority and lower-class youths in particular are cut off from employment opportunities, and from meaningful educational and leisure-time activities (p. 392)." Peers suffering from a similar lack of opportunities for role-taking may be unable to stimulate more mature levels of moral development among one another.

Gibbs (1991) argued that antisocial youth often solidify their sociomoral development by employing cognitive distortions. Cognitive distortions are often self-serving and untrue. There are two types of cognitive distortions: primary distortions and secondary distortions. Primary distortions are self-centered cognitive distortions stemming from egocentric bias - "because I want it, that makes it mine." Subsequent distortions or secondary distortions are rationalizations. Externalization of blame and mislabelling are two types of secondary distortions. They serve to neutralize inhibitory stresses (e.g., empathy) and remove antisocial acts from negative self-evaluations. Gibbs (1991) relates discussions with juvenile felons which illustrate secondary cognitive distortions:

I first encountered the problem of externalizing distortions several years ago during a moral discussion with male juvenile felons of a problem situation concerning shoplifting. During the discussion I was prompted to ask -rhetorically, I thought-- "Who's to blame in this situation?" I thought it was obvious that the primary person to blame was the shoplifter. To my surprise, several of the boys in the group quite seriously answered that the person at fault was the store owner. Their reasoning was that if the store owner wasn't alert enough to spot and catch a shoplifter, he deserved to be robbed. "It's on him," as one group member put it (Gibbs, 1991, p.99).

He continued to explain how youths involved in a gang-rape of a Central Park jogger used cognitive distortions to rationalize their crime. Some of the gang members said they were just "having fun." Others suggested that the blame should be placed on the woman for being raped because she should not have been jogging in Central Park at night (Gibbs, 1991).

\subsubsection{Early Aggressive Behavior}

Maiuro and Eberle (1989) reviewed the highlights of a 1988 World Conference conducted by the International Society for Research on Aggression, with a particular focus on topics related to interpersonal violence. While higher aggression rates were found among males, investigators have begun to examine female aggression. Results indicated that boys employed more verbal and physical means of aggression, whereas girls used more indirect and passive-aggressive means. 
There is an indication that the relationship between child and parental behaviors is bidirectional and reciprocal, i.e., that the punishing behavior of parents sometimes increases aggressive behavior in the child and that the child's aggression sometimes increases the parent's punishing responses. Maiuro and Eberle (1989) suggested that there is a need for "early intervention targeted at both parent and child." They summarized the developmental studies as follows:

The measures of early aggressive behavior for the boys and girls were significantly related to later aggressive acts...Both the mother's and father's aggression were associated with the child's violent (largely male) and antisocial (both male and female) behaviors during adolescence...strong evidence is provided for the emergence and stability of aggressive traits during childhood development (Maiuro and Eberle, 1989, p. 7).

White et al. (1992) examined the separate effects of early aggression and alcohol use on subsequent alcohol-related aggression. They used data collected by the Rutgers Health and Human Development Project, a prospective longitudinal study of adolescent development employing interviews and psychological tests. The authors found that for males, early aggressive behavior was a better predictor than alcohol use of later alcohol-related aggression. For females, early alcohol use was a better predictor of later alcohol-related aggression than was aggressive behavior. The authors pointed out, however, that both alcohol use and aggression have shared antecedents, such as family pathology and childhood victimization experience.

\subsubsection{Television}

Since 1970 there has been considerable interest in the impact of violence portrayed on television on children's behavior. Many of the studies are correlation-based -- indicating that an increased amount of televised violence was correlated with an increased amount of aggression among children. A review by Singer (1985) discusses five processes by which watching violence on television may lead to an increase in children's violent behavior: observational learning, catharsis, physical arousal, attitude changes, and justification processes. Singer's (1985) review found strong support for observational learning. She pointed out there is "a solid body of research evidence suggesting that children who see someone rewarded for a particular kind of behavior are more likely to imitate this behavior." Empirical support for this process was very strong, with heavy television viewing, especially of programs with violent content, predicting aggressive behavior a year or two later, even when other family behaviors or factors, such as discipline style or family stress, were taken into account.

This review also indicated that children's attitudes toward aggressive behavior are affected by the kinds of television programs they watch. In particular, brief exposure to violent films can increase a child's willingness to accept aggressive behavior in other children, suggesting that their view of the world is affected by the exposure. Singer stated that there is little empirical research to support the justification theory--that people who are already aggressive watch programs that are violent because they can then justify their own behavior. 
A case-control study by Heath and her colleagues (1986) assessed the relationship between selfreported television viewing at 8,10 , and 12 years of age and subsequent commission of a violent criminal act. Subjects were 48 males between 18 and 25 years old incarcerated for violent crimes, and 45 nonincarcerated nonviolent males matched on age, race, and neighborhood of residence during adolescence. The authors found that it was the interaction of heavy doses of television viewing and exposure to either maternal or paternal abuse that related to violent crime.

High exposure to television during childhood years was related to the commission of a violent crime during adulthood if violence was also present in the home. Exposure to television without violence in the home was not associated with violent crime. (Heath, Kruttschnitt, \& Ward, 1986, p.186).

These results are helpful in understanding why television has a negative effect on only some viewers. As pointed out by Heath and colleagues (1986), mass media effects do not operate in a vacuum. Congruence between the media message and the life experiences of the observer are necessary for an association with subsequent violent behavior.

One problem with research in this area is that violent and nonviolent television viewing are highly correlated, preventing researchers from separating the effects of each.

\subsubsection{Victim-offender Patterns}

The relationship that has been observed between victim-offender patterns in violence (i.e., that experience as a victim of serious criminal behavior is associated with a greater likelihood of having committed serious criminal violence) has led to the proposition that there is a subculture of violence, described earlier, in which violence is learned. Singer (1986) concluded that subcultural violence is more likely to arise in environments where the likelihood of violent victimization and rationalization of violence is high. "If there is an absence of legitimate forms of social control, (and thus, moral development) to sanction the perpetrator of a violent offense, then the victim experience may be seen as justification for criminal conduct (p.68)."

\subsection{Alcohol and Violence}

Review of studies on alcohol and violence indicates that binge drinking is the feature of alcohol consumption primarily related to increased risk of violence:

- Drinking binges were significantly associated with fighting. For example, Valois and his colleagues (1993) found that those who engaged in binge drinking were three times more likely to be involved in violence than those who did not. These same authors found that the likelihood of carrying a weapon during the past month was greater if the students had also consumed alcohol during the past thirty days. 
- While the acute effects of alcohol have been found to be significantly associated with incarceration for a violent offense (Collins and Schlenger, 1988), chronic alcohol effects were not significantly associated with incarceration for a violent offense. This is consistent with findings that binge drinking is a particularly strong risk factor, suggesting that alcohol affects violence directly, possibly by lessening inhibitions, rather then indirectly through underlying personality factors or through other mediating factors.

One hypothesis is binge drinking may turn an argument into a fight. It may also turn the possession of a weapon into using it; i.e., alcohol may lessen inhibitions that restrain violent behavior.

\subsection{Illegal Drug Use and Violence}

Studies have examined the co-occurrence of violence and substance abuse. For example, Kingery and colleagues (1992) examined violence and drug use among adolescents using a representative sample of U.S. 8th and 10th graders. Taking risks such as going to a dangerous place, walking in unsafe neighborhoods, and hitchhiking was associated with drug use. Drug users were found to fight more than nonusers. Users were also more likely to be assaulted, both at school or on the bus, and outside school supervision.

Huizinga, Loeber, and Thornberry (1993), in a sample of urban youth, found a relationship between delinquency (e.g., robbery, burglary, major theft, and gang fights) and substance use. Most drug users were involved in delinquency. However, many of the delinquents were not substance users.

Earls and Powell (1988) examined the correlates of substance use in an inner-city sample of adolescents using primary health clinics. The results revealed a strong relationship between level of substance use and interaction with the criminal justice system. Those who were regular substance users or abusers were more likely than "abstainers/low users" to experience legal problems such as police arrests, jailings, fines, and court appearances. Those who regularly used alcohol or drugs in the 12 months preceding the study were more likely to have conduct disorder symptoms (e.g., fighting, stealing, truancy, and property destruction) than those who were classified as "abstainers/low users." 


\section{SEXUAL BEHAVIOR}

Studies in this area typically involve administering questionnaires to large groups of high school or college students in metropolitan areas. Several studies rely upon the National Survey of Family Growth conducted in 1984 and 1988 and the National Survey of Males conducted in 1989 which randomly sampled households. A considerable amount of the research also looks at the behavior of adolescents, usually young females, who visit health clinics. More recently, studies have examined the differences between subgroups of adolescents; for example, Hispanics, blacks and whites, or rural and urban adolescents. Little work has been done on the dropout population, which may be disproportionately more likely to engage in risk taking behavior than those adolescents who stay in school.

Dryfoos (1990) reported that responses to surveys about adolescent sexuality are not always accurate. Males tend to exaggerate their rates of sexual activity, while females tend to report less sexual activity than they actually experience. In addition, the number of reported abortions is most likely lower than those actually experienced. Nevertheless, reliable estimates for the number of births do exist (e.g., birth certificates).

Among the sexual risk taking behaviors examined in the literature were early initiation of intercourse, ineffective or no contraceptive use, sex with a high number of partners (more than four), high coital frequency, intercourse with risky partners (those one does not know well, those who have multiple partners, or those who use IV drugs), and the incidence of pregnancy and fathering a child.

\subsection{Trends}

In Sex and America's Teenagers, the Alan Guttmacher Institute (1994) presented some disturbing trends and statistics regarding adolescent sexuality. Since the mid 1950 s, there has been a rise in the incidence of adolescent sexual activity. During the mid-50s, only one-quarter of females reported being sexually active by the age of 18 . In contrast, more than one-half of females and three-quarters of males now report being sexually active by age 18. Additionally, females who reported having sex at early ages were less likely to report having voluntary sex. In fact, 74 percent of females having sex before age 14 and 60 percent of females having sex before age 15 , reported having involuntary sex.

Differences in levels of sexual activity were noted across races, with blacks reporting a higher frequency of sexual activity than whites. By age 15, one-half of black males reported being sexually active. However, it is not until age 17 that the same rate of sexual activity was found among white and Hispanic males. Among black females, half reported being sexually active by age 16.5, while it is not until age 17.5 that white and Hispanic females reported similar levels of sexual activity.

Income was also reported to relate to rates of adolescent sexual activity, with those from poor or low income backgrounds having a greater incidence of sexual activity. Approximately half 
of young males from families with incomes less than $\$ 20,000$ per year reported having sex by age 16. Among females, half of those from poor or low income families reported having sex by age 17 .

Approximately one million teenagers become pregnant each year. Eighty-five percent of adolescent pregnancies are unplanned, which accounts for 25 percent of all unplanned pregnancies across the entire population. There are racial and economic differences among those who become pregnant and those who do not, with older teens and adolescents who are poor or black having the highest proportion of pregnancies. Approximately, 19 percent of black females between the ages of 15 and 19 become pregnant. Thirteen percent of Hispanic females ages 15 to 19 become pregnant, while 8 percent of white females in this age group become pregnant.

The way an adolescent pregnancy is resolved depends in part on SES, with poor and disadvantaged youth more likely to give birth than have an abortion. Those from higher income homes are more likely to have an abortion.

\subsection{Demographics}

\subsubsection{Younger Versus Older Adolescents}

Younger adolescents typically are less likely to engage in sex than are older adolescents, although sexual activity is initiated very early in some contexts. When sexual behavior begins early in an adolescent's life, there is little evidence that the type of risky sex or the motivations for having risky sex change as he or she becomes older (in the absence of interventions against risky sex). However, there is evidence that late initiation of sex leads to less risk taking (see next section).

DuRant and Sanders (1989) found that higher "sexual age" (years of sexual activity) was related to greater coital frequency. This association was noted to be stronger among white adolescents than blacks.

\subsubsection{Timing of Initial Sexual Intercourse}

The literature suggests that adolescents who begin having sex later in life may take fewer risks, sexual and otherwise. Studies have investigated which factors are associated with early initiation of intercourse. Becoming sexually active early in life seems related to certain environmental and familial characteristics. Handler (1990) found the three most important correlates of early initiation of sexual intercourse among young urban black females were lower levels of maternal education, being the daughter of a teen-aged mother, and type of public school attended by the adolescent. Unfortunately, information about the schools in Handler's study was not collected (e.g., characteristics of the students, educational philosophy, information about peer norms, etc.). So it was impossible to draw conclusions about "type" of school. 
Zabin et al. (1986) found that on average, inner-city black males' first experience of sexual intercourse occurred 2.5 years earlier than inner-city whites' first experience. However, the difference between black and white females was only half as large. It was also found that malefemale differences in coital onset were twice as great among blacks as among whites. Furthermore, Zabin et. al. (1986) found that younger age of first sexual intercourse was associated with greater substance abuse for all groups except black males. This finding seems to fit with the findings of Stanton et al. (1993), who pointed out that early initiation of sex among black adolescents is not associated with other risk or problem behaviors. They found that blacks consistently depicted sex as forming a different domain from other problem behaviors. However, Stanton et al.'s (1993) finding may be less applicable to black females, given the association that Zabin et al. (1986) found between black females' coital onset and substance abuse. Hogan and Kitagawa (1985) reported that for black females aged 13-19, timing of initial intercourse and the likelihood of pregnancy was affected by factors such as neighborhood, family structure, number of siblings, whether a sister had a pregnancy without being married, and the laxness of parents' control of their daughters' dating habits.

Faulkenberry et al. (1987) found that contraception use during the initial coitus experience was higher among college students who first had intercourse between the ages of 17 to 20 years than among those who first had intercourse at 16 years or younger. In addition, the students who had delayed initial intercourse until at least 17 years had more committed relationships with their first partner, spent more time discussing and planning contraception use, and used more reliable and authoritative sources of information about contraception. Similarly, Galavotti and Lovick (1989) found that among black adolescents, older age at first intercourse predicted more frequent contraceptive use.

Despite this apparent need for early intervention, sex education courses in schools seem to have little effect on timing of intercourse. In fact, Marsiglio and Mott (1986) reported that previous sex education had only a weak effect on timing of first coitus among adolescents aged 15 and 16. The age at which teens first had intercourse was more strongly associated with frequency of church attendance, parental education, race, and SES.

\subsubsection{Male/Female Differences}

Adolescent girls face greater risks when engaging in sexual activity than do adolescent boys, both because of potential pregnancy, as well as increased likelihood of contracting a sexually transmitted disease. Most studies find girls somewhat more likely to display cautious sexual behaviors (Baldwin and Baldwin, 1988). Goodman and Cohall (1989), however, found girls actually less likely than boys to insist on condom use at last intercourse (only 27 percent versus 51 percent). Similarly Kegeles et al. (1988) found that while males were quite positive about condom use, females were mildly negative. Fortunately, girls tend to be easier to reach with interventions, because they are more likely to seek help and information at school and community health clinics. 
Although girls are more likely than boys to cite the desire for a child to be a reason for avoiding contraception, boys may also report the desire to be a father as a reason for not using protection. For example, Strunin and Hingson (1992) found that 23 percent of their sample of 1,152 Massachusetts adolescents claimed they would be "happy if they or their partner became pregnant" (Strunin \& Hingson, 1992, p. 142), with over twice the proportion of males as females saying they would be happy.

Newcomer and Udry (1987) found that both boys and girls who changed from living in a two parent to a "mother only" household were more likely to initiate coitus in the two year period they were studied. However, initiation of coitus among boys was attributed to the disruption of the household, while for girls it was attributed to the state of being in a single parent household.

Ensminger (1990) compared family origin, school behavior previously reported in first grade, current school behavior, and parental supervision in three groups of adolescents classified according to number of risk taking behaviors: no-problem group, sexually active group, and a multiproblem group. Males who were in the sexually active group did not differ from the noproblem males on any of the measures. Multiproblem males were more likely than males in the no-problem and sexual activity groups to have had behavior problems in first grade, to be truant, and to have fewer curfew rules. Multiproblem males were also more likely to have been born to a teenaged mother than the no-problem males.

The results for females showed a different pattern, with the sexually active females having a greater likelihood than no-problem girls of being born to a teenaged mother, to have mothers who did not complete secondary school, and to have lenient weeknight curfews. The two groups did not differ on early or present school behavior. Multiproblem females reported weaker ties with school and more truancy than no-problem females. Females in the sexually active group had stronger school ties than the multiproblem girls (Ensminger, 1990).

\subsection{Knowledge, Attitudes, Beliefs and Patterns of Sexual Behavior}

\subsubsection{Relationship of the Mechanics of Safe Sex to Changes in Behavior}

In general, research indicates that although adolescents may know and understand the risks associated with unprotected sex, they do not necessarily take precautions themselves. Hypotheses aimed at examining the apparent conflict between the knowledge and practice of safe sex theorize that adolescents may feel a lack of vulnerability toward sexually transmitted disease (Kegeles et al., 1988). Further, the information regarding disease may not be particularly salient to all youths. There is also some evidence indicating that those adolescents practicing unsafe sex may possess the least amount of knowledge regarding sexually transmitted diseases (Brown et al., 1992).

DiClemente et al. (1993) found that although a sample of rural adolescents knew more about AIDS than their urban counterparts, and knew how to protect themselves against the disease, 
they still engaged in riskier sexual behavior. The researchers hypothesized that although rural adolescents had received better preventive education, the low incidence of AIDS in their communities led them to believe the information was not personally salient to them.

Likewise, Kegeles et al. (1988) found that although the adolescents in their study understood that condoms prevent sexually transmitted diseases (STDs) and they assigned a high value to avoiding STDs, there was no increased intention to use condoms or actual increased use of condoms. They hypothesized that adolescents do not feel vulnerable to contracting diseases from their partners. In another study, Arnett (1990a) found that most girls who had sex without using contraception had also had sex with contraception, indicating that even where the information about safe sex has been appreciated, safer sex practices may be erratic.

MacDonald et al. (1990) examined two risk taking behaviors -- number of partners and low condom use -- and assessed the extent to which factors such as knowledge and worry about sexually transmitted diseases and pregnancy were associated with these behaviors. They found little or no association. They also found no relationship between condom use and history of sexually transmitted disease. However, they did find that insufficient knowledge about HIV in particular (in contrast with STDs in general) was related to irregular or no condom use.

However, the results of other studies make unclear the relationship between knowledge specific to AIDS and safer sex practices. For example, Pleck et al. (1990) found an association between worry about AIDS and intentions to use condoms. Pendergrast (1992) in contrast, did not find a similar relationship. Goodman and Cohall (1989) found that higher levels of knowledge, concern, and perceived risk of AIDS were related to changes in high-risk sexual behavior (i.e., using condoms and abstinence). Yet none of the AIDS-related knowledge variables tested by Keller et al. (1991) were associated with the level of sexual risk taking among their subjects. Rickert et al. (1989) reported that although increased knowledge about AIDS corresponded with increased contraceptive use among female adolescents as well as with increased comfort in discussing contraception with a partner, only 17 percent of the females reported actually purchasing or using a condom to prevent AIDS transmission.

Education about pregnancy and sexually transmitted diseases has been found to have little effect on adolescent sexual behavior. Hanson et al. (1987) found that sex education did not significantly affect the chances that a black or white teenager would have a child in the two-year period under study. As reported above, Marsiglio and Mott (1986) found that the effect of prior sex education on first intercourse at ages 15 to 16 is very small. Dawson (1986) did find that among ever-users of contraception, those who had pregnancy or contraception education before first coitus were more likely to use contraception at first coitus.

Other studies indicated that adolescent perceptions of the risk of pregnancy were quite different from their actual risk. The subjects in a study by Galavotti and Lovick (1989) vastly overestimated their fertility when asked to guess the percentage chance of getting pregnant if they had sex just once without using birth control (the average estimate was 65 percent). In a study of young females in New York City, Namerow et al. (1987) found that the perceived 
probability of pregnancy among females who were at risk for pregnancy and those who were not at risk was about the same. The perception of risk was based on the perceived likelihood of pregnancy at last intercourse and whether or not they had used contraceptives. Galavotti and Lovick (1989) found no association between perceived risk of pregnancy and contraceptive use.

\subsubsection{Beliefs and Attitudes about Contraception, and Patterns of Contraceptive Use}

A number of studies (MacDonald et al., 1990; Pendergrast et al., 1992) show the best predictors of risky sexual activity by adolescents are beliefs and attitudes about the immediate short-term costs of engaging in safe sex, such as embarrassment, or the perceived benefits of engaging in risky sex (e.g., it is more spontaneous). For example, MacDonald et al. (1990) found that the factors most associated with irregular or no condom use included embarrassment about buying condoms and the belief that condoms interfere with sexual pleasure. Pleck et al. (1990) found that sexually experienced males reported lower perceived embarrassment costs for condom use than did inexperienced males. However, they perceived condoms as being more costly in terms of reduction of pleasure. Kegeles et al. (1989) found that among female adolescents, increased intentions to use condoms correlated most highly with the belief that using condoms is popular with one's peers, that condoms enable one to have sex on the spur of the moment, that they are clean and easy to use, and that they require one's partner to have self-control. Among male adolescents, increased intentions to use condoms were most highly correlated with the belief that condoms are easy to use, and the belief that condoms are not painful or uncomfortable. Increased motivation to use condoms was not associated with an increased belief in the preventive effects of condoms.

In a study by Norris and Ford (1994), black and Hispanic youth between the ages of 15 and 24 living in low-income, urban areas in the midwest rated 16 statements about beliefs related to condom use. Males were either neutral or positive about condom use, whereas females had stronger positive feelings about condoms than males. Blacks had a more positive view of condom use than did Hispanics. There were significant differences within the Hispanic subsample on twelve beliefs. Those who were more acculturated had a more positive view of condom use.

Pendergrast and colleagues (1992) found that among adolescent males, neither the perceived likelihood of acquiring an STD nor the degree of concern about HIV was significantly associated with past or intended condom use. Rather, past use of condoms was related to greater selfconfidence and to perceptions that their girlfriends have positive attitudes toward condom use. Lower rates of past condom use were related to perceived hassles of use. This study also found greater condom use corresponded with younger age, greater reported degree of exposure to STD education, greater perceived condom safety, and increased perceived risk of STD if not wearing a condom.

Pendergrast et al. (1992) reported that the strongest predictor of intended future condom use was the frequency of past condom use. Pleck et al. (1990) also found that condom use at last intercourse was a good predictor of intended condom use among experienced adolescent males. 
Condom nonuse was a good predictor of engagement in other risky sexual behavior. Biglan et al. (1990) found that not using a condom was associated with having sex with a partner who was not well known to the subject.

Some studies showed that adolescents may be unaware of their peers' real attitudes toward contraception use. Kegeles et al. (1988) found that their male subjects believed their partners wanted them to use condoms, whereas females were uncertain about males' desires regarding condom use.

Unfortunately, some studies suggested there may be no more of a relationship between generally positive attitudes toward contraception and actual contraception use than there is between knowledge about contraception and contraception use. Reis and Herz (1989) noted that although over 80 percent of the females in their study reported that they would use birth control if sexually active, based on prior rates of pregnancy in the school, the authors predicted that 13 percent of them would become pregnant by the end of the 10th grade.

\subsubsection{Coital Frequency}

Higher coital frequency among youths has been found to be related to physical development, longer heterosexual relationships, and for females, having more partners. DuRant et al. (1990) examined the relationship between coital frequency and sexual behavior and risk taking. Greater coital frequency was associated with both physical and sexual development. As expected, higher levels of coital frequency were found to correspond to longer heterosexual relationships. However, greater coital frequency was also found to correspond to the number of boyfriends females had during the past three months, with females who had more boyfriends reporting higher coital frequency. Both high coital frequency and longer relationships were related to an increased likelihood of engaging in unprotected coitus.

Coital frequency has also been found to be predictive of contraceptive risk taking behavior (DuRant \& Sanders, 1989). Effectiveness of previous contraceptive methods, as well as a good understanding of contraception, were related to increased coital frequency (DuRant et al., 1990).

Coital frequency was also reported to relate to females' perceived risk of pregnancy (DuRant et al., 1990). Female adolescents who reported greater coital frequency also reported higher levels of worry over the perceived risk, and greater frequency of previous pregnancy scares. Previous pregnancy scares were associated with worry over becoming pregnant (DuRant et al., 1990). Additionally, adolescents who perceived their parents as feeling negatively toward them becoming pregnant reported decreased coital frequency, although perceptions of parental approval or disapproval of sexual activity were not related to lower levels of coital frequency.

\subsubsection{Number of Sexual Partners}

MacDonald et al. (1990) found no relationship between number of sexual partners and grade point average, mental health score, self-esteem, quality of relationship with parents, fear of 
AIDS, worry about STD or pregnancy, church attendance, and STD knowledge. They did find greater numbers of sexual partners were associated with substance abuse, a casual attitude towards sex, oral contraceptive use, and having a good relationship with peers.

Baldwin and Baldwin (1988) found that measures of sexual conservativeness such as a lower average number of partners per year predicted more cautious sexual behaviors such as avoiding casual sex and using condoms more regularly. They did not find a significant relationship between having four or more partners per year and condom use.

\subsubsection{Length of Sexual Relationship}

The length of time couples are in a relationship has been associated with unprotected sex. DuRant et al. (1990) found that greater unprotected coitus corresponds to greater length of time females had been dating their present boyfriend. Long term relationships, or "going steady" have also been associated with an increased likelihood of childbirth (Hanson et al., 1987).

\subsection{Psychological and Personality Factors}

Some studies have found significant correlations between psychological factors and sexual risk taking, while others have not.

\subsubsection{Sensation Seeking and Egocentrism}

In a study of 124 white female adolescents, Arnett (1990a) reported that unprotected sex was more prevalent among subjects scoring higher on sensation seeking (as measured by Zuckerman's Sensation Seeking Scale), especially in the Disinhibition and Boredom Susceptibility subscales. The findings indicated that sensation seeking and adolescent egocentrism contributed to reckless behavior among adolescents, particularly to the tendency of some adolescent girls to have sex without contraception.

\subsubsection{Self-directed Decision-making and Autonomy}

Langer et al. (1993) reported that self-directed subjects (i.e. those with a self-directed orientation in decision making) displayed the least risky sexual attitudes and behaviors, while peer-directed subjects displayed the most risk, and parent-directed subjects fell in-between. More girls were self-directed than boys.

A few studies reported a relationship between autonomy and (less) sexual risk taking. Hart and Hilton (1988), for example, found that contraceptively protected adolescents had higher levels of autonomy and ego development. Turner et al. (1993) found that young adolescents who perceived parents as encouraging independence and skill development were less likely to begin sexual intercourse than those who did not. 


\subsubsection{Self-esteem}

Most studies do not find a relationship between level of self-esteem and sexual behavior. For instance, Burger and Inderbitzen (1985), in a sample of sexually active college students, found no association between self-esteem and contraceptive behavior. Galavotti and Lovick (1989) found that being sexually active was not related to level of self-esteem. MacDonald et al. (1990) found no relationship between number of partners and self-esteem, and DuRant et al. (1990 found that coital frequency was not associated with self-esteem or locus of control. In an exception to these findings, Pleck et al. (1990) reported that higher levels of self-esteem corresponded with greater intended condom use among inexperienced males.

\subsubsection{Self-efficacy}

Basen-Engquist and Parcel (1992) examined the impact of norms, attitudes, and self-efficacy on aspects of sexual behavior. Both norms and attitudes were found to be related to, and predictive of, the intent to limit the number of sexual partners. Self-efficacy was found to be only indirectly related to the intent to limit the number of sexual partners. Self-efficacy was, however, found to be predictive, and directly related to, the intent to use condoms. Attitudes and norms were only indirectly related to intended condom use.

\subsubsection{Communication Skills}

Higher confidence in one's ability to communicate with partners about contraception, and better reported ability to communicate with partners, is associated with safer sex practices (Rickert et al., 1989). MacDonald et al. (1990) found no relationship between condom use and plans to discuss sexual experience with one's partner, nor trust in the partner's information about previous sexual experiences, but did find that irregular or no condom use corresponded with reported difficulty in discussing condom use with one's partner. Burger and Inderbitzen (1985) found that subjects who had good communication skills exhibited greater frequency and effectiveness of condom use. This is consistent with reasoning that effective contraception requires planning before sexual intercourse. Catania et al. (1990) found a decreased number of sexual partners was associated with increased health protective sexual communication skills and better general communication skills. Increased condom use was associated with increased health protective sexual communication skills.

\subsubsection{The Belief that Pregnancy is a Mark of Maturity}

There is evidence that some adolescents risk pregnancy because they believe that becoming a parent is a sign of adulthood. Reis and Herz (1989) found, among males who attributed contraceptive responsibility to themselves, an increased acceptance of intercourse among those who had stronger beliefs that parenthood leads to adulthood. They also found, among female adolescents who accepted responsibility for contraception, less knowledge of human sexuality among those who believed that parenthood leads to adulthood. 


\subsection{Peer Influence}

Hayes (1987), in summarizing the literature on peer influence, explained that early studies evaluating peer influence on sexual behavior tended to rely on adolescents' perceptions of the sexual behavior of their peers. Another problem with research on peer influence is that because data is collected at one point in time, delayed effects of peer pressure are not measured.

Billy and Udry (1985), using self-reports of sexual behavior by respondents as well as best friends, showed that peer influence varies by gender and race, with white females being more susceptible to peer influence than white males or blacks. Smith et al. (1985) found that females who were pubertally mature and were sexually active had same-sex friends who were also sexually active.

\subsection{Ethnicity and Race}

Studies report racial and ethnic differences in early initiation of sexual activity. For example, Dryfoos (1990) reported that the percentage of black males having had sexual intercourse before age 15 was 15 percent, while for black females it was 10 percent. Among whites, 12 percent of males and 5 percent of females reported having had sexual intercourse before the age of 15 . Among Hispanics, 19 percent of males and 4 percent of females reported having had sexual intercourse before the age of 15 .

Contraceptive use has also been related to race, with black adolescents more likely (71.4 percent) than white adolescents (59.6 percent) to use oral contraceptives. In contrast, white females have been found to be more likely to use condoms ( 24.7 percent) than were black females (13 percent) (Boyer \& Kegeles, 1991). DuRant and Sanders (1989) found that a higher rate of religious attendance was associated with increased contraceptive risk taking among white adolescents and decreased contraceptive risk taking among black adolescents.

The literature on condom use among Hispanic adolescents is contradictory. In their study of urban college students, Baldwin and Baldwin (1988) found greater condom use among Hispanics, as compared with Asians and blacks. Pleck et al. (1990) however, found that among sexually experienced males of high school age, being Hispanic was related to decreased intended condom use.

Zabin et al. (1986) found the incidence of pregnancy among sexually active girls between the ages of 11 and 19 in inner city schools was 23.1 percent for black females and 18.9 percent among white females. Among males of corresponding ages, approximately 16 percent of black males reported fathering a child compared to 9.8 percent of white males. Racial differences have also been found for pregnancy outcomes, with black families reported to be less likely than white families to choose alternatives to childrearing such as abortion or putting the infant up for adoption (Casper, 1990). 


\subsection{Religiosity}

In a study of 851 college students, Baldwin and Baldwin (1988) found no significant effects of religiosity on sexual risk behaviors. Similarly, MacDonald et al. (1990) found no relationship between number of partners and church attendance in a survey of Canadian college students.

In contrast to college students, religiosity does seem to have an effect on sexual behavior of high school students. For example, DuRant and Sanders (1989) found greater coital frequency related to lower attendance at religious services. Marsiglio and Mott (1986) found that one of the strongest determinants of first coitus at ages 15 and 16 was infrequent church attendance.

However, among sexually active teens, risky sexual behavior may be more likely among religious than nonreligious adolescents. In a study by Studer and Thornton (1987) contraception use was associated with lower church attendance, suggesting sexually active adolescents who attended church frequently were less likely to use a form of contraception.

As noted earlier, Durant and Sanders (1989) found greater church attendance associated with increased contraceptive risk taking among white adolescents, but with lower contraceptive risk taking behavior among blacks. The researchers concluded that the values bestowed upon black adolescents during religious services stress avoidance of pregnancy and out-of-wedlock births, rather than the avoidance of sexual activity.

Pleck et al. (1990) found that the belief that religion was important in one's life was related to greater intended condom use among sexually experienced males. Among sexually inexperienced males, religious belief was related to lesser intent to use condoms.

\subsection{School Factors}

Educational aspirations have an impact on adolescent sexuality. For instance, Hanson et al. (1987) found that white females (high school sophomores) were less likely to experience childbirth if they held high educational expectations for themselves. Black teens with high educational expectations were 32 percent less likely than their peers to experience out-of-wedlock childbirth. Hogan and Kitagawa (1985) found that career aspirations showed only marginal significance as a predictor of contraceptive use at first intercourse. Pleck et al. (1990) found that among inexperienced males, intentions to use a condom occurred more often with higher educational aspirations.

\subsection{Family Factors}

\subsubsection{Communication Between Parents and Children}

Communication between parents and teens seems to have little influence on risky sexual behavior, probably because the level of communication between parents and teens on sexual matters is typically very low (Casper, 1990). Newcomer and Udry (1985), for example, found 
that parent-child discussions of sex and contraception did not affect later sexual and contraceptive behavior. In fact, both teens and parents frequently contradicted each other when describing their sex-related conversations.

Galavotti and Lovick (1989) did find that increased discussions of sexuality with family members were related to being more sexually active among blacks, but not among Mexican Americans. They found no relationship between contraceptive use and discussion of sex at home. Likewise Zabin et al. (1986) found that generalized communication with parents did not appear to influence sexual behavior. A related measure, quality of relationship with parents, also showed no association with such risk taking behaviors as greater number of partners and low condom use in a study by MacDonald et al. (1990).

\subsubsection{Marital Status of Parents}

Marital status of parents appears to have differential effects on whether adolescents are sexually active, on contraceptive use and the incidence of pregnancy, and on the initiation of sex among adolescents.

In a study of black adolescents, Galavotti and Lovick (1989) found greater sexual activity among teens from one-parent families. Hogan and Kitagawa (1985) found that black adolescent females whose parents were no longer together by the time they had reached age 11 were 36 percent more likely to become pregnant than were teens whose parents were still together at age 11 . Additionally, the rate of initial intercourse among adolescents with single-parent families was one-third higher than among youths with families with two parents present.

Newcomer and Udry (1987) found that the effect of marital breakup on initiation of coitus seemed to be different between boys and girls. For boys, it was the disruption of the two-parent family that triggered the initiation of coitus (boys in stable single parent households were no more likely to initiate intercourse than those in stable two-parent families). For girls it was the state of being in a single parent family that predicted initiation of coitus. Newcomer and Udry hypothesized that this difference was due to the difference in the support girls received during marital breakup. Because this study found a greater likelihood of all adolescent risk behaviors in disrupted and single-parent families, Newcomer and Udry hypothesized that the effect of marital status on adolescent sexual risk taking is probably mediated by a general loss of parental control over the children.

\subsubsection{Parental Supervision and Control}

Biglan et al. (1990) found that high risk sexual activity was significantly more likely among adolescents with limited family availability, low levels of parental monitoring, and low levels of parental support. Similarly, Hanson et al. (1987) found that white females were less likely to experience childbirth if they had parents who were concerned about their children (i.e. monitored homework; talked with child often) and who had high educational expectations for their children. They found that these two parental values reduced the likelihood of early 
childbirth in white females by 36 percent and 42 percent respectively. Having concerned parents reduced the chances that a black teenager will experience an out-of-wedlock childbirth by 30 percent.

Hogan and Kitagawa (1985), found parental supervision of dates to be an important factor in the rate of adolescent pregnancy. Black adolescent teens who reported lax parental supervision of early dating experiences had higher rates of sexual activity than adolescent females whose parents carefully supervised their dates. Additionally, the incidence of pregnancy among black female adolescents was 64 percent higher among girls whose parents provided little supervision during early dating experiences than among girls whose dates were under close parental supervision.

\subsubsection{Parental Attitudes and Norms}

Studies on the relationship between parental attitudes and norms, and adolescent sexual behavior, show interesting and unusual patterns. DuRant et al. (1990) found negative parental attitudes toward adolescent pregnancy to be associated with lower coital frequency. Newcomer and Udry (1985), on the other hand, found no relationship between parental attitudes toward premarital sex and adolescent sexual and contraceptive behavior.

Jorgensen and Sonstegard (1984) found that parental norms, compared with peer or partner norms, played a relatively small role in the adolescent's decisions either to initiate marijuana use or to become sexually active. However, parental norms were strongly related to regularity of any contraceptive use and to regularity of effective contraceptive use. The authors further noted that the majority of teens informed their parents that they intended to seek contraceptives, and in some cases, parents actually brought their sexually active daughters to family planning clinics.

\subsubsection{Parental Education}

Baldwin and Baldwin (1988) found condom use among college students related to higher paternal education. Casper (1990) found higher maternal education to be associated with decreased likelihood of initiating sexual activity before age 19, and with increased probability of using contraceptives. Marsiglio and Mott (1986) found that one of the strongest predictors of first coitus at ages 15 and 16 was lower parental education (fewer than 12 years). On the other hand, DuRant and Sanders (1989) found that among adolescent females aged 15 to 20, coital frequency was not associated with either parent's level of education.

\subsubsection{Parental Income}

Casper (1990) reported higher parental SES corresponded to a lower likelihood of adolescents initiating sexual activity. Baldwin and Baldwin (1988) found that among college students, increased condom use was related to higher parental income. 


\subsubsection{Family Structure and the Behavior of Siblings}

Hogan and Kitagawa (1985) found family size to be related to the rate of pregnancies among black female adolescents. Girls from families with five or more siblings were found to have pregnancy rates 55 percent higher than those in small families. Adolescent girls with at least one sister who was a teenage mother had a 38 percent higher incidence of pregnancy than girls from families with no teenage mothers present (Hogan and Kitagawa, 1985).

\subsection{Relationship to Other Risk Taking Behaviors}

The literature provides strong evidence that alcohol and drug use among adolescents is related to earlier and more risky sex. Zabin et al. (1986) found that at each age from 12 to 18 , sexually active teenagers had a significantly higher score on an index of substance abuse than virgins. Teenagers found to be high on the index of substance abuse were noted to be behind in grade level for their age and to view teenage childbearing positively. Additionally, sexually active females were reported to have delayed attendance to a clinic by a year or more after coitus. MacDonald et al. (1990) found that substance abuse corresponded with having had more sexual partners.

Shafer and Boyer (1991) found that alcohol and drug use were the best predictors of sexual risk behaviors in a sample of urban ninth graders. In a study by Keller et al. (1991), alcohol and drug use each predicted high risk sexual behavior in both a clinic and school sample. The fact that relatively small amounts of substances were involved led the researchers to believe that the contribution of alcohol and marijuana is not limited to their disinhibiting effects, but may also identify behavioral characteristics related to high risk sexual behaviors.

Strunin and Hingson (1992) found that 49 percent of adolescents in a telephone survey were more likely to have sex if they and their partner had been drinking, although 61 percent of sexually active adolescents believed sex is less pleasurable after drinking. Seventeen percent said that they used condoms less often after drinking (regardless of concerns about AIDS, other STDs, and pregnancy). Among the adolescents in the survey, 32 percent said that they would be more likely to have sex if they and their partner had used drugs, with 10 percent less likely to use condoms after drug use (again, regardless of concerns about AIDS, and so on). The authors concluded that, since condom use among adolescents already is low, while alcohol and drug use increases sexual activity, the greatest risk factor for STDs and unwanted pregnancy is the use of alcohol and drugs rather than the reduced rate of condom use.

Biglan et al. (1990) found that adolescents reporting high levels of involvement in risky sexual behavior were more likely to report antisocial behavior (aggressive behavior and delinquent acts such as stealing and vandalism), smoking, alcohol use, and other drug use. 
PART II: RISK TAKING AND DRIVING AMONG YOUTH 


\section{INTRODUCTION TO DRIVING}

Most reviews of research carried out in youthful risk taking and driving begin by discussing the difficulties of summarizing research in this area from a methodological perspective. Jonah eloquently describes them in his comprehensive review published in 1986. First, there is wide variation in the operational definition of the young driver. The age range of this project is 15 to 25 years. However, most studies characterize youthful drivers in much narrower terms. For example, most studies focus either on high school or college students, but rarely both. Second, many studies do not control for years of driving experience or exposure. This complicates the task of disentangling the multiple influences on risky driving. Finally, numerous methodological approaches are utilized across studies. They include self-reports, observations of on-the-road behaviors, and testing procedures utilizing audio-visual stimuli and/or simulators.

Ranney (1994) cogently presents an overview of the evolution of models of driving. He argues that there has been little progress in developing a comprehensive model of driving:

A number of reasons have been proposed for this stalemate. These include a preoccupation in the highway safety field with accidents and accident-causing behaviors. As a result, it has never been clear whether theories should explain everyday driving, or accident-causing behaviors, or both. Secondly, motivational models, which emerged in the 1960s and 1970s as alternatives to skill-based models of driving (e.g., Naatanen and Summala, 1976), have failed to generate testable hypotheses necessary for developing a body of empirical findings. Finally, as noted by Michon (1985), the cognitive revolution has failed to influence driving theory (Ranney, 1994, p. 1).

Traffic safety researchers have provided detailed discussions of the problems inherent in crash data. For example, Elander and his colleagues (1993) summarized some of the major biases in recording crash data. Self-reports of crash data may include biases caused by forgetfulness or a willingness to underreport crash involvement. Public records, although better at reflecting reality, are also subject to biases. For example, crash reports may not include the level of specificity necessary for behavioral research. Additionally, many nonfatal crashes are not reported (Elander, West, \& French, 1993).

\subsection{Demographics}

Injuries sustained in motor vehicle crashes are the leading cause of death for people between the ages of one and thirty-four (Baker, O'Neill, Ginsburg \& $\mathrm{Li}$, 1992). Data show that teenagers and youths in their early twenties, especially young males, have the highest crash involvement rate of any age group. This occurs regardless of whether the rate is based on population size, number of licensed drivers, or number of vehicle miles traveled. 


\subsubsection{Crash Statistics}

In 1993, 9,803 youths between age 16 and 24 were killed in motor vehicle crashes. Another 883,000 youths were injured in crashes that year.

Table 4 shows the continued overrepresentation of youth among crash fatalities and injuries, the rate here based on population size. The figures indicate a measure of improvement in recent years. However, the fatality and injury rates for youth remain markedly above other age groups.

\subsubsection{Gender}

Males have higher crash fatality rates than females for every age group per 100,000 population (see Table 5 for 1993 data). Among the 16 to 20 and 21 to 24 age groups, their populationbased fatality rates are more than twice as high as those for females. Less proportional disparity occurs between the sexes with injury rates, with females ages 16 to 20 actually showing a slightly higher injury rate than their male counterparts in 1993.

\subsubsection{Race/Ethnicity}

There is little published information about the relationship of crash/fatality rate to ethnicity or race. Only two relevant sources were found during the conduct of this literature review. Baker and her colleagues (1992) reported that Native Americans as a group (all ages combined) have the highest crash fatality rate compared to other ethnic and racial groups. They also found agerelated differences between groups in the pattern of fatality rates. Fatality rates peak between the ages of 15 and 24 for whites, while they peak between the ages of 20 and 24 for Native Americans and blacks. The high fatality rate for Native Americans has often been attributed to alcohol. Additional factors may play a role. Native Americans often live on reservations which may only be accessible by rural roads. These may tend to be more dangerous than other types of roads (Baker, O'Neil, Ginsburg, \& Li, 1992). Popkin and Council's study (1991) which examined the race/ethnicity issue from a slightly different perspective, found that alcohol-related crash rates were lower for whites than for a group of nonwhites that was predominantly black in all age groups studied with the exception of younger drivers (16 to 24).

\subsection{Types of Crashes}

Young drivers tend to be involved in different types of crashes than older drivers. Results from a recent study carried out with drivers injured in single-vehicle crashes in Sweden showed 18and 19-year-olds having six times greater than average risk for a single vehicle crash (Brorsson, Rydgren, \& Ifver, 1993). Compared to 25- to 54-year-olds, 18- and 19-year-olds had a ten times greater risk of running off the road. They had a 49 times greater than average risk for single-vehicle crashes on weekend nights. 
Table 4. Occupant' Fatality and Injury Rates per Population by Age Group $1975-1993$

\begin{tabular}{|c|c|c|c|c|c|c|c|c|c|c|c|c|}
\hline \multirow[b]{2}{*}{ Year } & \multicolumn{11}{|c|}{ Age Group (Years) } & \multirow[b]{2}{*}{ Total } \\
\hline & $<5$ & $5-9$ & $10-15$ & $16-20$ & $21-24$ & $25-34$ & $35-44$ & $45-54$ & $55-64$ & $65-74$ & $>74$ & \\
\hline \multicolumn{13}{|c|}{ Fatality Rate per 100,000 Population } \\
\hline $\begin{array}{l}1975 \\
1976 \\
1977 \\
1978 \\
1979 \\
1980 \\
1981 \\
1982 \\
1983 \\
1984 \\
1985 \\
1986 \\
1987 \\
1988 \\
1989 \\
1990 \\
1991 \\
1992 \\
1993\end{array}$ & $\begin{array}{l}4.50 \\
4.50 \\
4.68 \\
4.61 \\
4.35 \\
4.24 \\
3.74 \\
3.66 \\
3.53 \\
3.11 \\
3.15 \\
3.39 \\
3.74 \\
3.77 \\
3.88 \\
3.31 \\
3.13 \\
2.98 \\
3.13\end{array}$ & $\begin{array}{l}2.71 \\
2.56 \\
2.83 \\
2.66 \\
2.84 \\
2.67 \\
2.43 \\
2.22 \\
2.32 \\
2.31 \\
2.34 \\
2.27 \\
2.56 \\
2.60 \\
2.87 \\
2.50 \\
2.39 \\
2.40 \\
2.34\end{array}$ & $\begin{array}{l}5.71 \\
6.14 \\
6.44 \\
6.60 \\
6.13 \\
6.00 \\
5.24 \\
4.85 \\
4.59 \\
5.19 \\
5.50 \\
6.04 \\
5.96 \\
5.70 \\
5.43 \\
5.26 \\
4.87 \\
4.75 \\
4.64\end{array}$ & $\begin{array}{l}38.77 \\
40.95 \\
42.86 \\
44.45 \\
44.36 \\
42.96 \\
38.67 \\
34.70 \\
33.46 \\
35.35 \\
34.22 \\
38.82 \\
37.39 \\
38.85 \\
35.67 \\
34.17 \\
31.85 \\
28.51 \\
29.17\end{array}$ & $\begin{array}{l}34.90 \\
35.01 \\
38.73 \\
40.75 \\
40.06 \\
39.87 \\
37.47 \\
32.87 \\
31.14 \\
33.14 \\
33.09 \\
34.19 \\
33.40 \\
34.35 \\
31.66 \\
30.63 \\
28.80 \\
25.93 \\
26.65\end{array}$ & $\begin{array}{l}21.57 \\
21.27 \\
22.27 \\
24.26 \\
24.96 \\
24.80 \\
24.16 \\
20.38 \\
19.76 \\
20.13 \\
19.34 \\
20.84 \\
20.83 \\
20.25 \\
19.82 \\
19.81 \\
17.78 \\
16.51 \\
16.41\end{array}$ & $\begin{array}{l}15.67 \\
15.27 \\
15.61 \\
16.72 \\
17.11 \\
16.85 \\
16.63 \\
14.29 \\
13.85 \\
13.89 \\
13.83 \\
13.80 \\
14.11 \\
14.17 \\
13.86 \\
13.34 \\
12.29 \\
11.71 \\
11.84\end{array}$ & $\begin{array}{l}13.42 \\
13.71 \\
13.90 \\
14.07 \\
14.03 \\
14.51 \\
13.80 \\
11.81 \\
11.75 \\
11.81 \\
11.82 \\
11.42 \\
12.01 \\
12.22 \\
12.33 \\
12.20 \\
11.12 \\
10.62 \\
10.53\end{array}$ & $\begin{array}{l}13.29 \\
13.58 \\
13.55 \\
13.44 \\
13.24 \\
12.83 \\
12.66 \\
11.20 \\
10.86 \\
11.08 \\
11.22 \\
11.26 \\
11.78 \\
11.97 \\
11.98 \\
11.91 \\
10.75 \\
10.53 \\
10.87\end{array}$ & $\begin{array}{l}14.72 \\
14.92 \\
14.03 \\
14.79 \\
13.59 \\
12.96 \\
13.14 \\
11.82 \\
11.86 \\
12.89 \\
12.52 \\
13.30 \\
13.39 \\
13.89 \\
13.99 \\
13.36 \\
13.21 \\
13.26 \\
12.71\end{array}$ & $\begin{array}{l}16.98 \\
17.27 \\
16.13 \\
16.36 \\
15.51 \\
15.28 \\
14.95 \\
14.91 \\
15.51 \\
16.21 \\
16.77 \\
17.75 \\
18.27 \\
19.30 \\
19.43 \\
18.49 \\
19.18 \\
18.86 \\
20.76\end{array}$ & $\begin{array}{l}16.67 \\
17.05 \\
17.81 \\
18.70 \\
18.67 \\
18.45 \\
17.60 \\
15.36 \\
14.87 \\
15.34 \\
15.10 \\
15.86 \\
15.84 \\
15.94 \\
15.34 \\
14.89 \\
13.78 \\
12.89 \\
13.01 \\
\end{array}$ \\
\hline \multicolumn{13}{|c|}{ Injury Rate per 100,000 Population } \\
\hline $\begin{array}{l}1988 \\
1989 \\
1990 \\
1991 \\
1992 \\
1993\end{array}$ & $\begin{array}{l}412 \\
365 \\
338 \\
383 \\
323 \\
369\end{array}$ & $\begin{array}{l}437 \\
461 \\
429 \\
469 \\
436 \\
469\end{array}$ & $\begin{array}{l}728 \\
721 \\
736 \\
710 \\
686 \\
652\end{array}$ & $\begin{array}{l}3,361 \\
3,298 \\
2,864 \\
2,922 \\
3,005 \\
2,901\end{array}$ & $\begin{array}{l}2,724 \\
2,531 \\
2,507 \\
2,314 \\
2,248 \\
2,305\end{array}$ & $\begin{array}{l}1,778 \\
1,649 \\
1,671 \\
1,574 \\
1,573 \\
1,598\end{array}$ & $\begin{array}{l}1,305 \\
1,277 \\
1,233 \\
1,144 \\
1,102 \\
1,173\end{array}$ & $\begin{array}{r}1,021 \\
975 \\
988 \\
978 \\
971 \\
949\end{array}$ & $\begin{array}{l}863 \\
787 \\
842 \\
801 \\
783 \\
819\end{array}$ & $\begin{array}{l}699 \\
701 \\
749 \\
727 \\
721 \\
691\end{array}$ & $\begin{array}{l}657 \\
618 \\
515 \\
522 \\
588 \\
570\end{array}$ & $\begin{array}{l}1,312 \\
1,244 \\
1,224 \\
1,162 \\
1,141 \\
1,147\end{array}$ \\
\hline
\end{tabular}

Taken from Trafilc Satehy Facts 1993 (Nalional Highway Traffic Salety Administration, 1994b).

'An occupant is any person who is in or upon a motor vehicle in transport.

Includes the driver, passengers, and persons riding on the exterior of a mator vehicle. 
Table 5. Persons ${ }^{2}$ Killed or Injured and Fatality and Injury Rates per 100,000 Population by Age and Sex

\begin{tabular}{|c|c|c|c|c|c|c|c|c|c|}
\hline \multirow[b]{2}{*}{$\begin{array}{c}\text { Age } \\
\text { (Years) }\end{array}$} & \multicolumn{3}{|c|}{ Male } & \multicolumn{3}{|c|}{ Female } & \multicolumn{3}{|c|}{ Total } \\
\hline & Killed & $\begin{array}{l}\text { Population } \\
\text { (Thousands) }\end{array}$ & Rate & Killed & $\begin{array}{l}\text { Population } \\
\text { (Thousands) }\end{array}$ & Rate & Killed & $\begin{array}{l}\text { Population } \\
\text { (Thousands) }\end{array}$ & Rate \\
\hline $\begin{array}{c}<5 \\
5-9 \\
10-15 \\
16-20 \\
21-24 \\
25-34 \\
35-44 \\
45-54 \\
55-64 \\
65-74 \\
>74 \\
\text { Unknown } \\
\text { Total** }\end{array}$ & $\begin{array}{r}462 \\
494 \\
923 \\
3,847 \\
3,368 \\
5,897 \\
4,173 \\
2,528 \\
1,813 \\
1,618 \\
2,045 \\
125 \\
27,293\end{array}$ & $\begin{array}{r}10,078 \\
9,483 \\
11,283 \\
8,895 \\
7,727 \\
20,958 \\
20,240 \\
14,010 \\
9,932 \\
8,236 \\
5,057 \\
\star \\
125,898\end{array}$ & $\begin{array}{r}4.58 \\
5.21 \\
8.18 \\
43.25 \\
43.59 \\
28.14 \\
20.62 \\
18.04 \\
18.25 \\
19.65 \\
40.44 \\
\\
21.68\end{array}$ & $\begin{array}{r}414 \\
345 \\
587 \\
1,566 \\
1,019 \\
2,076 \\
1,685 \\
1,132 \\
991 \\
1,298 \\
1,661 \\
29 \\
12,803\end{array}$ & $\begin{array}{r}9,625 \\
9,037 \\
10,737 \\
8,451 \\
7,473 \\
20,948 \\
20,590 \\
14,655 \\
10,995 \\
10,417 \\
9,082 \\
\star \\
132,010\end{array}$ & $\begin{array}{r}4.30 \\
3.82 \\
5.47 \\
18.53 \\
13.64 \\
9.91 \\
8.18 \\
7.72 \\
9.01 \\
12.46 \\
18.29 \\
\text { * } \\
9.70\end{array}$ & $\begin{array}{r}878 \\
840 \\
1,511 \\
5,414 \\
4,389 \\
7,974 \\
5,860 \\
3,661 \\
2,805 \\
2,916 \\
3,708 \\
159 \\
40,115\end{array}$ & $\begin{array}{r}19,703 \\
18,520 \\
22,020 \\
17,346 \\
15,200 \\
41,906 \\
40,830 \\
28,665 \\
20,927 \\
18,653 \\
14,139 \\
\star \\
257,908\end{array}$ & $\begin{array}{r}4.46 \\
4.54 \\
6.86 \\
31.21 \\
28.88 \\
19.03 \\
14.35 \\
12.77 \\
13.40 \\
15.63 \\
26.23 \\
\star \\
15.55\end{array}$ \\
\hline \multirow[b]{2}{*}{$\begin{array}{c}\text { Age } \\
\text { (Years) }\end{array}$} & \multicolumn{3}{|c|}{ Male } & \multicolumn{3}{|c|}{ Female } & \multicolumn{3}{|c|}{ Total } \\
\hline & Injured & $\begin{array}{l}\text { Population } \\
\text { (Thousands) }\end{array}$ & Rate & Injured & $\begin{array}{l}\text { Population } \\
\text { (Thousands) }\end{array}$ & Rate & Injured & $\begin{array}{l}\text { Population } \\
\text { (Thousands) }\end{array}$ & Rate \\
\hline $\begin{array}{c}<5 \\
5-9 \\
10-15 \\
16-20 \\
21-24 \\
25-34 \\
35-44 \\
45-54 \\
55-64 \\
65-74 \\
>74 \\
\text { Total }\end{array}$ & $\begin{array}{r}39,000 \\
54,000 \\
91,000 \\
264,000 \\
192,000 \\
357,000 \\
243,000 \\
127,000 \\
78,000 \\
59,000 \\
38,000 \\
1,542,000\end{array}$ & $\begin{array}{r}10,078 \\
9,483 \\
11,283 \\
8,895 \\
7,727 \\
20,958 \\
20,240 \\
14,010 \\
9,932 \\
8,236 \\
5,057 \\
125,898\end{array}$ & $\begin{array}{r}386 \\
572 \\
810 \\
2,972 \\
2,491 \\
1,705 \\
1,200 \\
906 \\
780 \\
713 \\
747 \\
1,225\end{array}$ & $\begin{array}{r}39,000 \\
54,000 \\
89,000 \\
254,000 \\
172,000 \\
339,000 \\
256,000 \\
157,000 \\
99,000 \\
75,000 \\
48,000 \\
1,583,000\end{array}$ & $\begin{array}{r}9,625 \\
9,037 \\
10,737 \\
8,451 \\
7,473 \\
20,948 \\
20,590 \\
14,655 \\
10,995 \\
10,417 \\
9,082 \\
132,010\end{array}$ & $\begin{array}{r}405 \\
594 \\
826 \\
3,009 \\
2,297 \\
1,620 \\
1,242 \\
1,075 \\
902 \\
723 \\
530 \\
1,199\end{array}$ & $\begin{array}{r}78,000 \\
108,000 \\
180,000 \\
519,000 \\
364,000 \\
697,000 \\
499,000 \\
284,000 \\
177,000 \\
134,000 \\
86,000 \\
3,125,000\end{array}$ & $\begin{array}{r}19,703 \\
18,520 \\
22,020 \\
17,346 \\
15,200 \\
41,906 \\
40,830 \\
28,665 \\
20,927 \\
18,653 \\
14,139 \\
257,908\end{array}$ & $\begin{array}{r}395 \\
583 \\
818 \\
2,990 \\
2,395 \\
1,663 \\
1,221 \\
992 \\
844 \\
718 \\
608 \\
1,212\end{array}$ \\
\hline
\end{tabular}

- Mot applicable.

** Includes 19 fatalities of unknown sex.

Source: Population-Bureau of the Census.

Taken from Iraftic. Salety Facts 1993 (National Highway Traftic Saiety Administration, 1994b).

\footnotetext{
${ }^{2}$ Occupants plus non motorists (e.g. pedestrians; pedalcyclists).
} 
Sixteen-year-old drivers have a larger proportion of rollover crashes than individuals of any other age (Evans, 1991). The likelihood of involvement in a rollover crash decreases with age, while the likelihood of a side impact crash increases with age. There is some difference of opinion about whether young drivers are overinvolved in rear-end crashes. Lalonde (1979) suggests that young male drivers are more involved in rear-end collisions than drivers in other age groups. However, data presented by Evans (1991) suggests that the number of rear end collisions remains fairly stable across ages.

Analyses conducted by the National Highway Traffic Safety Administration (1993a) of police crash reports contained in NHTSA's 5-state Crash Avoidance Research Data File (CARDFILE) describe additional characteristics of younger driver crash patterns. NHTSA reported that the hour-by-hour pattern of crashes for younger drivers (15 to 24) is similar to that of drivers between ages 25 and 64. The majority of crashes occur between 7:00 a.m. and 8:00 p.m.. During morning rush hours, there is a slight peak in the numbers. During evening rush hours, the number of crashes peaks much more dramatically. After 8:00 p.m. the crash numbers slowly decrease to a minimum around 4:00 a.m. (ages 25 to 64) or 5:00 a.m. (ages 15 to 24). Crash involvement for drivers 65 and older has a different pattern. Crashes increase in number between 7:00 a.m. and 11:00 a.m. and remain flat until 4:00 p.m. before declining.

Understandably, the relationship between crashes and light conditions is similar to the pattern of crashes by time of day. While the majority of all crashes occur during daylight hours, the number of crashes occurring in daylight versus darkness differs by age. The percentage of crashes that occur after dark decreases as age increases. For example, drivers in the young (ages 15 to 24) and middle (ages 25 to 64) groups had 33 percent and 25 percent of their crashes after dark. In contrast, drivers 65 to 74 have only 12 percent of their crashes at night while drivers older than 75 have only 8 percent (NHTSA, 1993a).

The distribution of crash severity is similar across age groups. Approximately 60 percent of all crashes involve property damage only. Twenty-two percent involve possible injury; 12 percent non-incapacitating injury; 5 percent incapacitating injury, and fewer than 1 percent of crashes involve a fatality (NHTSA, 1993a).

Most crashes involve two vehicles. Two-vehicle crashes represent 68 percent of crashes for younger drivers (15 to 24). They represent 71 percent of crashes for 25- to-64 year-old drivers and 80 percent for those 65 and older (NHTSA, 1993a). Younger drivers have the highest proportion of single-vehicle crashes ( 21 percent). This is important to note because "the most common type of crash leading to a car-occupant fatality is a single-car crash" (Evans, 1991).

Approximately 50 percent of crash involvement for the younger (ages 15 to 24) and middle groups (25 to 64) occurs at intersections. For older drivers, approximately 60 percent of their crashes occur at intersections (NHTSA, 1993a). Additionally, more than 50 percent of all crashes regardless of age group involve the vehicle going straight just before the crash. This was the case for 59 percent of the crashes in the 15- to 24-year-old group, 57 percent in the 25to 64-year-old group, and 53 percent among those 65 and older. 


\subsection{Experience}

Age-related and experience-related factors have long been implicated in the elevated crash rates for youthful drivers. Yet, our understanding of the joint contribution of age and experience is limited because of the difficulty of separating the effects of both (Brown \& Groeger, 1988; Traffic Injury Research Foundation of Canada, 1991). In 1975, the Organization for Economic Cooperation and Development stated that the relative contribution of age-related and experiencerelated factors to crashes was rather obscure. More than ten years later, Jonah (1986) perceived no change in this situation based on his review of the literature. He pointed out that important variables such as amount of travel per year, patterns of travel, and location of travel received almost no attention. Additionally, other factors complicate the relationship between age and experience. For example, driving experience and exposure are often confounded (Jonah, 1986). It is nearly impossible to become a proficient driver without spending time driving. However, the only way for a new driver to gain experience is to get on-the-road experience, thus putting her/himself at risk. Warren and Simpson (1976) coined this phenomenon the "young driver paradox."

Attempts to separate the effects of age-related factors from experience-related factors in traffic crashes have only recently shed some light on this area. In New to the Road (Traffic Injury Research Foundation of Canada, 1991), the authors reported the following findings:

- Crash rates for males of various ages with four years of driving experience showed that the risk of a crash decreased with age.

Twenty-year-olds had approximately 110 crashes per 10,000 licensed drivers, while 24- to 28-year-olds had approximately 91 crashes per 10,000 licensed drivers.

- Crash rates for newly-licensed females of various ages showed that the risk of a crash decreased with age.

Sixteen-year-olds had approximately 81 crashes per 10,000 licensed drivers, while 28 - to 34 -year-olds had approximately 50 crashes per 10,000 licensed drivers.

Crash rates decreased with increases in driving experience among drivers of the same age.

Thirty-year-old males with less than one year of experience had approximately 130 crashes per 10,000 licensed drivers, while 30-year-old males with two to three years of experience had approximately 80 crashes per 10,000 licensed drivers. 
- Increases in experience had a greater impact on 30-year-old drivers than 20-yearold drivers.

The crash risk of 30-year-olds with experience was approximately 38 percent less than that for 30 -year-old novice drivers. In contrast, the difference was only about 8 percent for the 20 -year-olds.

These data suggest that experience in driving is important at any age, but age-related factors contribute greatly to driving behavior (Traffic Injury Research Foundation of Canada, 1991). Earlier studies attempting to separate experience and exposure found that 18- and 19-year-old drivers had the highest violation and crash rate in comparison to older drivers while controlling for exposure and experience (Pelz \& Schuman, 1971).

Evans (1991) speculated on the specific implications of the role of experience-related factors in youthful crash rates. He argued that although skills cannot be the solitary contributing factor in youthful crashes, the lack of skill may still make a contribution. For example, 16-year-olds are involved in a higher proportion of rollover crashes than any other age group. He postulated that a rollover crash may result from an inability to steer.

\subsection{Driver Performance and Driver Behavior}

Driver performance pertains to skills involved in the driving task, while driver behavior refers to the manner in which individuals actually drive. Elander and his colleagues (1993) referred to this as the driving skill-driving style dichotomy. Factors related to driver performance and driver behavior are presented in the following paragraphs.

\subsubsection{Driving Skills}

Summala (1987) defined the driving task "as a skilled activity with several distinct levels, hierarchically organized. It is usual to differentiate, from top to bottom, the control (operational), maneuvering (guidance), and planning (navigational) levels" (Summala, 1987, p. 79). At the beginning, steering, braking, and tracking are under conscious control. With more practice, these skills become increasingly automated. Novice drivers quickly attain a minimum proficiency in these skills with the exception of tracking, which is related to lane placement. Evans (1991) reported that eye fixations change as a result of driving experience. Specifically, studies show that novice drivers initially scan over wide areas, including points well above the horizon. Also, novice drivers frequently glance at the curb to estimate the vehicle's lane position (Evans, 1991). After a month's experience, visual fixations are more confined to the plane above the roadway. After three months' experience, fixations are more concentrated in the vehicle's projected path. As drivers gain experience, they concentrate their eye fixations in a smaller area. Peripheral vision is used more to locate the vehicle in the lane, with visual fixations focused further down the road. 
There is little evidence linking simple reaction times with crashes (Elander, West, \& French, 1993). Simple reaction times are fastest at approximately 20 years of age (Welford, 1980). Laboratory tests by Quimby and Watts (1981) showed that simple reaction times (a single predefined event to which the subject must respond, with a single predefined response) and choice reaction times (more than one stimulus and more than one response) start to increase at approximately 25 years of age. It is interesting to note that when subjects were asked to react to filmed traffic hazards, response time decreased with age (until 45 years of age).

\subsubsection{Speed}

Driving is, to a certain extent, a self-paced task. Drivers can make the task more or less difficult depending on the margin of error or safety they leave for themselves. One aspect of difficulty is the speed of driving. It is well established that young drivers tend to drive faster than older drivers (Jonah, 1986; Elander, West, \& French, 1993), particularly in light traffic where there is a greater opportunity to drive fast. For youth, speeding is a primary collision factor in fatal automobile crashes (McKnight \& Resnick, 1993). Young drivers are more likely than older drivers to die in roll-over crashes, a type of crash that is likely to involve high speed (Evans, 1991).

That younger drivers accept higher speeds was supported in a study by Wasielewski (1984). Researchers photographed vehicles traveling on a rural two-lane road near Detroit. Vehicle speeds along with a photograph of the vehicle were recorded. Information regarding the vehicle such as car mass, make, and model year, and owner information such as age, sex, and driving record were obtained from owner records using the vehicle's license plate number. When owner age and sex were compatible with the photographed driver, the owner was assumed to be the driver. Of the total sample of 6,638 observations, owner information was obtained for 2,632 vehicles, which excluded instances in which the owner information was incompatible with the photographed driver. From this observational data, it was found that drivers age 20 years and under had the highest observed speeds. Driver sex did not have a significant effect on vehicle speed.

Young drivers' attitudes regarding speeding also differ from the attitudes of older drivers. In a survey by Parker, Manstead, Stradling, and Reason (1992) carried out in England, results showed that younger drivers endorsed positive aspects of speeding and dangerous overtaking more strongly than did older drivers. For example, younger drivers believed that speeding or overtaking in a risky situation would get them to their destination more quickly, while older drivers were more likely to believe that by speeding they would annoy other drivers on the road. Further, younger drivers reported more social pressure to commit speeding violations, and perceived more approval from their peers for speeding, close following, and risky overtaking. Finn and his colleagues (1985) found that younger drivers perceived speeding to be less dangerous than experienced drivers. 


\subsubsection{Tailgating}

Young drivers are more likely than older drivers to follow too closely (Evans \& Wasielewski, 1983; Jonah, 1986; Bergeron, 1991). For example, shorter gap acceptance by youth was observed in a photographic study of vehicle headway and driver characteristics at freeway sites in Michigan and Ontario (Evans \& Wasielewski, 1983) with methodology similar to that reported in the previously mentioned study by Wasielewski (1984). Elsewhere, Staplin and Lyles (1991) analyzed police-report fatal crash records for 1977 to 1986 and nonfatal multiple-vehicle crash records from 1984 to 1986 in the Pennsylvania Department of Transportation database. The data revealed that younger drivers tended to be over-represented in crashes involving improper car following (tailgating), careless lane changes, and careless passing.

\subsubsection{Safety Belt Usage}

While failure to wear a safety belt may not directly cause crashes, non-compliance places the driver and any passengers at higher risk of incurring an injury if involved in a crash. There is evidence that drivers who do not wear safety belts have more crashes and violations than drivers who do wear belts (Jonah, 1986). Overall, safety belt usage tends to increase with age, although a study by Jonah (1990) found that the usage rate for 20- to 24-year-olds was even lower than that for the 16- to 19-year old age group. Surprisingly, in a study by Wasielewski (1984), drivers in the 20 and under category had higher usage rates than drivers in the 50 to 55 age group and drivers over 70 years of age. Caution should be exercised, however, in considering older belt use findings such as those by Wasielewski (1984) because belt use laws were not as widespread at the time, plus there are different types of occupant restraint systems now available.

From 1983 to 1991 NHTSA sponsored a yearly observational study of restraint use in 19 cities across the nation. The results consistently showed that teens were less likely to wear safety belts than adults. In 1991, observations of those sitting in the front seat revealed that 45.9 percent of teens and 52.2 percent of adults were wearing safety belts (Datta \& Guzek, 1992). Observations also showed 10.9 percent of teenagers and 7.0 percent of adults in the back seat wearing belts. It bears noting that teens were more likely to be seen riding in the back than the front, whereas adults were more likely to ride in the front than the back. As a result, overall belt usage rates were much lower for teens than adults because of the minimal usage occurring in the back seat (22.9 percent for teens and 40.5 percent for adults across all seats).

A number of factors have been proposed that may influence safety belt use. To test some of these factors, Donohue (1988) surveyed 709 high school students across Michigan aged 18 and under. Five factors emerged as predictors of belt usage: comfort, free choice, risk of crashing, social norms, and perceived effectiveness of belts. The results suggested that young adults want their belts to be comfortable, and they do not want to be told they must wear their belts. In addition, whether or not their friends wear belts, as well as the perceived effectiveness of the belts, is important in determining usage and compliance among young drivers. 


\subsubsection{Type of Car}

It has been proposed that since youths usually have limited income, they may not only drive or own older cars, but may also have inadequate resources for proper vehicle upkeep and maintenance. In a review of the literature, McKnight and Resnick (1993) reported that students who own cars tend to drive smaller and older vehicles than those driven by students who don't own vehicles. They also reported that older cars had greater crash involvement for all ages. Whether this can be attributed to component failure in older cars, or the possibility that drivers of older cars worry less about the consequences of their actions, was not clear.

\subsubsection{Passengers}

Other passengers in the vehicle may distract the driver from the driving task. McKnight and Resnick (1993) reported three separate studies which found that internal distraction and driving with peers were related to the crash involvement of youth. The absence of passengers, or only one passenger, was associated with a lower risk of crashes. Farrow (1987b) interviewed 192 youths (whose average age was 17) about dangerous driving situations they experienced during the past six months. In 85 percent of the situations, there were one or more peers in the car while in 12 percent of the situations there were no passengers in the car. 


\section{THEORIES OF RISK AND DRIVING}

This chapter provides a descriptive overview of various theories of risk and driving. The theories have been categorized according to how the concept of risk is defined. Thus, timebased theories measure risk per unit of time, spatial theories measure risk per unit of space, motivational theories consider risk from an individual driver's personal motives, decision making theories view the individual's perception of risk as an information-processing task, and social context theories look at driving as a group rather than individual process.

Some of the theories have not been empirically tested. Others have been applied to controlled laboratory and field study settings. Only a few empirical studies are cited in this chapter for illustrative purposes.

\subsection{Time-Based Theories}

\subsubsection{Risk Homeostasis}

Thesis and Relationship to Driving Behavior. The theory of risk homeostasis as proposed by Wilde $(1982,1986 a)$ maintains that people in any given activity have a target level of acceptable risk which is usually greater than zero. Individuals do not attempt to minimize risk, but instead seek an equilibrium by adjusting their actions to maintain this target level. If a certain risk is reduced or eliminated the individual will seek other compensating activities or behaviors, so that the net safety gain is zero. The actual overall level of risk incurred by the individual and collective group in any activity is maintained over time through this compensating or control process. Therefore, the only way that the actual level of risk can be reduced is by motivational measures that are effective in creating in people a stronger desire to live a safe way of life, rather than just simply eliminating risk. Some researchers (Lerner et al., 1988) have classified risk homeostasis as an extreme version of a broader, system-wide class of theories known collectively as "danger compensation."

Risk homeostasis theory (RHT) contends that crash risk is independent of factors such as the physical features of the vehicle, the road environment, and operator skills. Any safety modification made to the traffic system will be offset by risky behavior manifested elsewhere. Risk level ultimately depends upon the level of crash risk accepted by the overall driver population over a prolonged period of time (Wilde, 1985). A jurisdiction's total loss due to road crashes per time unit of aggregate driver exposure is the output of a closed-loop control process in which the target level of risk (i.e., the inverse of the level of safety desired) operates as the unique reference ("set-point") variable (Wilde, 1984, 1985, 1986b). The target risk is set at a point where there is optimal exchange for other benefits derived from the system, the greatest benefit being mobility. Economic, cultural, and person-related variables may also factor into expected costs and benefits. 
Whenever a discrepancy between target risk and experienced risk is perceived, the individual will make some behavioral adjustment to restore the balance. Some safety measures may not be directly observable by the driver. For example, more crashworthy vehicles or more forgiving roadside hardware (e.g., light poles, guardrails, sign supports, etc.) may reduce risk in ways that are not immediately perceivable. The theory suggests such measures may have only transient benefits because it assumes that ultimately the driving public may acquire a revised sense of the risk of injury. Another possible outcome is that an invisible improvement may have a generalized effect but compensation may occur elsewhere within the driving population; the difficulty is knowing where to look for an effect (Hoyes \& Glendon, 1993). Long-term changes in the per capita crash rate are seen to occur primarily through changes in the target level of risk within the driving population, which is related to safety motivations. As long as the target level of risk remains unchanged, the crash toll of the population and caution on the part of individuals are viewed as relating to one another in a compensatory function.

Methodological Concerns. Risk homeostasis theory has been widely criticized. Absence of a well-defined and succinct statement of the theory makes it difficult to assess its validity. Perhaps the most commonly cited criticism of RHT is that it cannot be subjected to the rigors of empirical testing. Moreover, many claim there has been no convincing evidence supporting it, and much evidence refuting it (Evans, 1986; Adams, 1988).

Many (e.g., Evans, 1991) have presented crash statistics that appear to refute RHT. In defense, RHT advocates claim that compensation may occur in behavioral domains besides driving (Hoyes \& Glendon, 1993) including other transportation modalities such as air and rail transport, bicycles, or pedestrian activity (Wilde, 1986b). They believe that compensation can occur in other life activities, but exactly what other life activities are rarely specified. Given this logic, it seems the theory is predicting everything and nothing simultaneously.

RHT claims that homeostasis occurs at the population level, not the individual level. Aggregated over the population are billions of decisions resulting in many overall compensating activities. Risk is held at a constant level over the aggregate, rather than the individual level. RHT does not define who the population is, what situations are to be included, and what time period should be measured. Given a sufficiently large enough sample with a lengthy time period, the collective level of risk may indeed hold steady over a period of time. But is this information practical, informative, or even useful?

\subsection{Spatial Theories}

\subsubsection{Accident Migration}

Thesis and Relationship to Driving Behavior. Accident migration occurs when an engineering improvement at a roadway problem site, usually referred to as a blackspot, is accompanied by a degradation in safety at another location. These findings have been documented in research studies as well as anecdotal reports. Typically a blackspot is selected for rehabilitation because of its high crash rate. Following renovation of the blackspot, there tends to be an increase in 
crash rates elsewhere in the road system network (Boyle \& Wright, 1984; Persaud, 1987; Maher, 1987), usually at a site nearby the original blackspot. Previous research (Smith \& Lovegrove, 1983) has referred to this phenomenon as danger compensation. Since the measures are defined in terms of units of space, typically a roadway network, accident migration is classified as a spatial theory of driver risk perception.

From an individual motivational perspective, Smith and Lovegrove (1983) have proposed that accident migration occurs when a traffic control measure at one site forces motorists to drive below their preferred levels of subjective risk. If risky driving practices such as speeding are curtailed at one location, a driver might compensate by traveling less cautiously at other sites in the roadway network. Alternatively, where a blackspot is treated, drivers will be subjected to fewer dangers at that site and consequently may be less aware of the need for caution. This reduced awareness may persist for some distance downstream (Boyle \& Wright, 1984). Whether drivers adjust their behavior elsewhere in the traffic system to compensate for the safety improvement, or alter their perception of the risks or dangers at the original blackspot as well as other adjacent sites, is unknown.

Most studies have attempted to quantify the effects of accident migration at actual traffic sites. Boyle \& Wright (1984) recorded crashes at 133 blackspots (before and after treatment) and at surrounding areas at comparable time intervals. Results showed that over a three-year period after treatment, there was a 22 percent decrease in crashes at the blackspots, while crashes at surrounding areas rose about 10 percent.

Other researchers have reported modest support for accident migration. For example, Persaud (1987) examined crash rates at 61 intersections in Philadelphia for one year. Intersections studied were converted from two-way stop to four-way stop. Converted intersections showed a decrease in crashes, while nearby unconverted intersections showed an increase in crashes.

Methodological Concerns. Critics of accident migration argue that it is highly unlikely that improvements made to decrease the risk of a crash will result in higher crash rates at other locations. A likely alternative explanation for accident migration is statistical in nature, specifically, regression to the mean (Persaud, 1987). Since it is normal practice to choose as remedial treatment sites those which record unusually high numbers of crashes, the untreated neighboring sites tend to record relatively few crashes during that same period. Further, the treated sites are not a random sample from the population of all sites, but have been selected because of their poor crash record. This bias in selection may lead to bias in the effectiveness of the treatment (Maher, 1990). Even if the treatment is completely useless at the blackspot, laws of chance may cause the treated sites to record a decrease in crashes while the converse may happen at the untreated sites.

Another methodological problem with accident migration studies is the absence of proper control groups. The ideal procedure for establishing a control would be to select a number of blackspots, measure crash rates prior to treatment, randomly select and treat half of the blackspots, and then compare the changes in crash numbers at the blackspots and in their 
surrounding areas after a sufficient period of time. For previous studies that have attempted to use controls, typically the control group or period is defined retroactively, with crash rates for that time period obtained from existing databases. Given the debate of accident database reliability, these kinds of control groups may be of dubious value.

The network of roadways in which accident migration is studied is usually defined by the physical area that it encompasses. However, the exact dimensions of roadway networks are hardly ever specified. Thus, comparing results from one study to another is tenuous, since crash rates may vary greatly depending on geographic size and location. When comparing a treated blackspot to a second test site, usually a site adjacent to the original blackspot is chosen (Smith \& Lovegrove, 1983). However, the best test sites for migration effects may not always be neighboring sites, but rather sites located elsewhere in the network (Maher, 1987).

An additional methodological concern is that crash rates may not be the only form of migration. Migration by type of crash or severity of injury may also occur (Boyle \& Wright, 1984).

\subsection{Motivational Theories}

\subsubsection{Zero Risk Theory}

Thesis and Relationship to Driving Behavior. The zero risk theory (Naatanen \& Summala, 1976; Summala, 1988) posits that driving behavior is motivational in nature, with the primary motive for using the traffic system being the mobility provided by the vehicle. An illustration of this theory can be found in Figure 3 (Naatanen \& Summala, 1976). The theory is based on avoidance learning because the driver tends toward escaping and avoiding "frightening" subjective risk. Although many novice drivers initially feel a sense of uncertainty or fear in many traffic situations, reduction of perceived risk occurs with increased experience as drivers successfully negotiate situations or traffic procedures. Adaptation to risk is therefore largely a function of increasing self-confidence to the ultimate point of experiencing zero risk or no risk at all. The two most important concepts in the zero risk theory are (1) the motivational basis of driver behavior and (2) adaptations to perceived risks on the road.

According to the zero risk theory, the perceived risk in traffic is the product of the perceived probability of a hazardous event and the importance attached by the individual to the consequences of the event (Ranney, 1994). In most cases, perceived risk is equal to zero due to a reduction process; drivers generally feel as if there is no real risk at all. If a subjective threshold is exceeded, hypothetical mechanisms are activated in an attempt to lower the risk level. One such compensation mechanism is a margin of safety, defined either spatially or temporally. It is proposed that safety margins are the critical measures which control perceived risk (Summala, 1988). Since driving is a self-paced activity wherein the driver can choose the degree of difficulty associated with the task via certain factors such as vehicle speed, the driver is able to self-regulate the desired safety margin acceptable for the situation. 


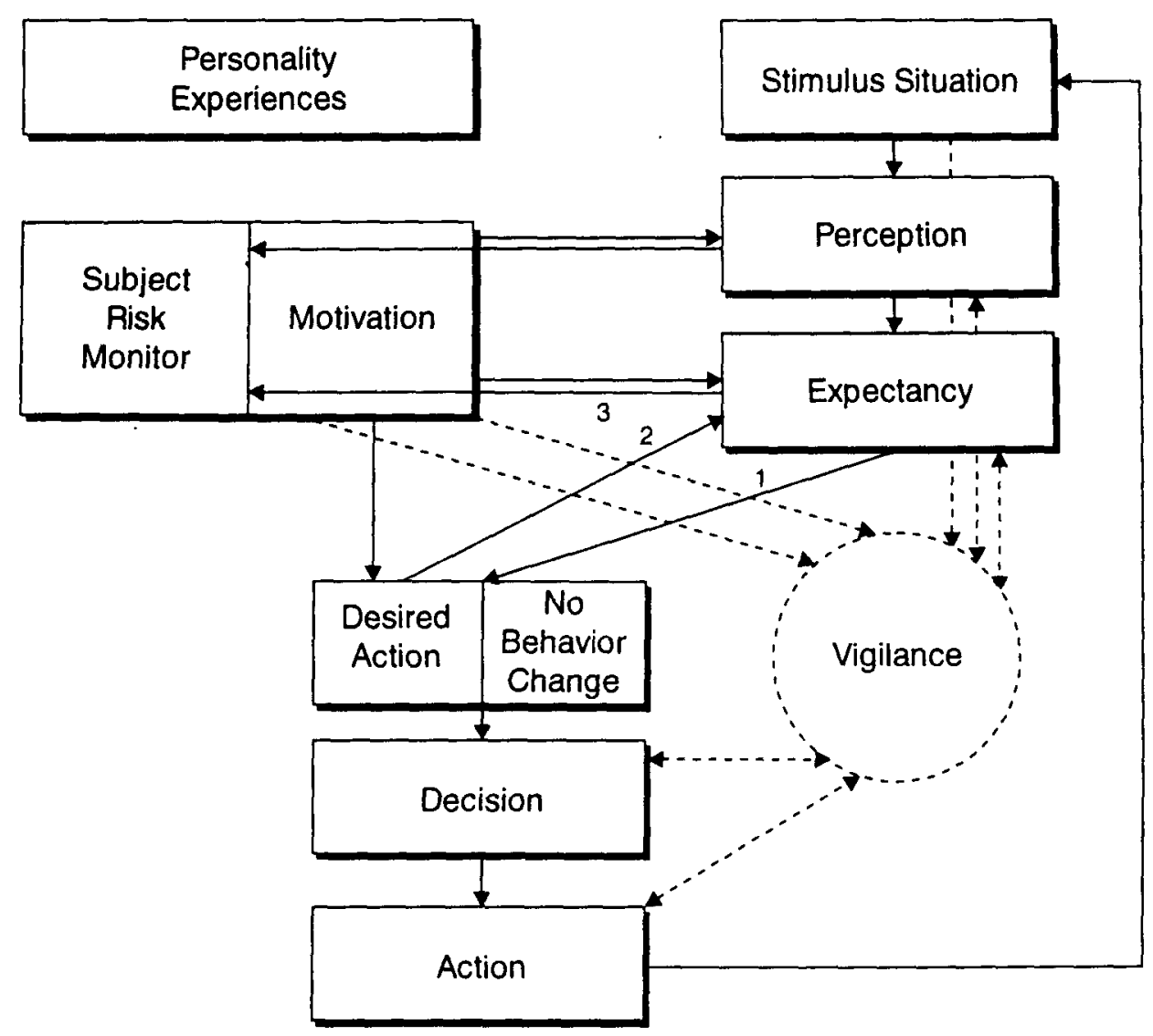

Figure 3: Zero Risk Theory (from Naatanen and Summala, 1976). 
The driver balances excitatory and inhibitory motives during the driving task while satisfying needs. The perceived risk of a crash is seen as the most important motive. Perceived crash risk exerts an inhibitory influence on the driver's decision making and behavior which counteracts the mainly excitatory influences generated by other motives. It is the driver who determines the degree of difficulty of the perceptual-motor tasks belonging to driving; the individual to a crucial degree determines whether or not he/she gets into those exceptionally demanding circumstances and situations.

Driving is a habitual activity based largely on automatized control of safety margins in partial tasks. Driver behavior may be viewed as the satisfying of various motives for using the traffic system, the most utilitarian being that of transport or getting from one place to another. To a degree, higher speed means shorter travel time, which is quite motivating. Speed choice is also a major way to control the driving workload due to the self-paced nature of the driving task. In addition, high speed provides outlets for a number of different driver motives (Summala, 1988), such as thrill seeking, an expression of social competence, status, or an outlet for anger or aggression. The different utilities associated with speed and other motives all tend to push drivers towards faster driving and higher objective risks, assuming that high speed is a risk. If the traffic system provides environmental opportunities to satisfy motives, drivers are inclined to do so with the most obvious resultant behavior being higher speeds.

\subsubsection{Threat Avoidance Model}

Thesis and Relationship to Driving Behavior. The threat avoidance model (Fuller, 1984) proposes that driving is motivational in nature, similar to the proposition of the zero risk theory. However, rather than reducing risk to zero, drivers instead learn to anticipate hazardous events and avoid them by making appropriate adjustments so that negative consequences do not occur. Thus, the driver rarely experiences any perceived risk of a crash at all. Since driving is a selfpaced task, it generally is the driver's own actions which determine whether or not the interaction with the road environment will be punishing or negative. When confronted with a cue for a potentially aversive event, the actions a driver takes not only depend on the strength of the learning of the relationship between the cue and risk, but also depend in part on the rewards and punishments for alternative responses. This intrinsic reward structure also includes the driver's motivation which may be as important, if not more so, than limitations of perceptual-motor capabilities (Fuller, 1984). The threat avoidance model is illustrated in Figure 4.

Learning the relationship between cues for potentially aversive events and aversive consequences is no simple matter, since the associations between the cues and resulting events are complex and may vary from situation to situation (Fuller, 1988). Inexperienced drivers are more likely than experienced drivers to make delayed rather than anticipatory avoidance responses. It requires experience of the road environment to learn the precursors of hazards and to develop the association between discriminative and potentially aversive stimuli. This experience does not always have to occur first-hand. As other theories such as learning theories (Naatanen \& Summala, 1976; Fuller, 1984) or sociological theories (Kasperson et al., 1988; Rothe, 1992) 


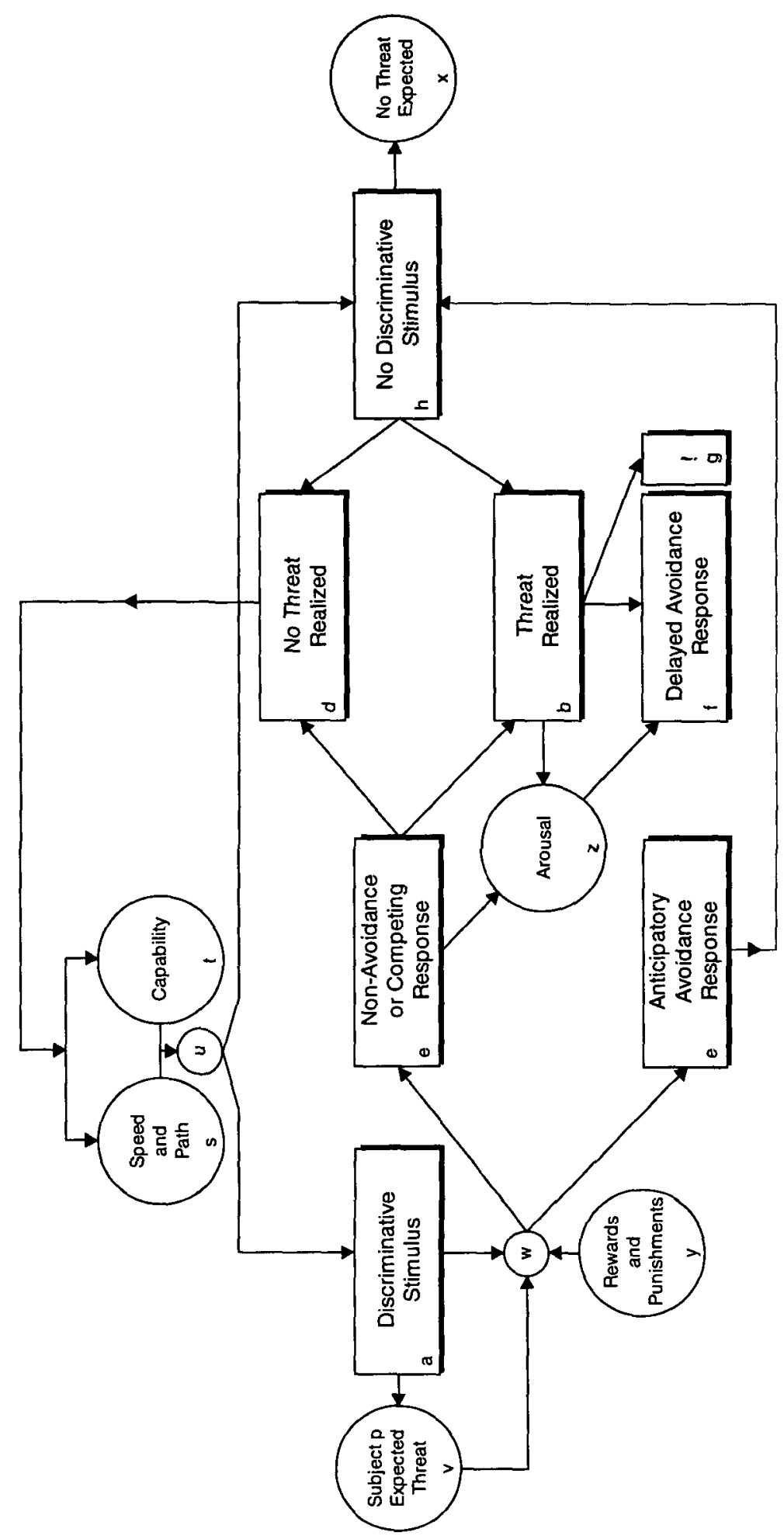

Figure 4: Threat Avoidance Model (from Fuller, 1984). 
contend, media display or observation of others' behavior can also serve as powerful examples, which are not necessarily always positive. Delayed avoidance responses when brought forward in time become anticipatory responses; most of what is involved in learning to drive safely is characterized by this shift (Fuller, 1984). The learning of the consequences of one's actions in particular stimulus situations is fundamental to the learning of safe driving.

Methodological Concerns. The zero risk model proposes that drivers opt for no risk; the risk homeostasis model proposes that drivers seek to maintain a target level of risk greater than zero. The threat-avoidance model presupposes that drivers opt for zero risk of a crash, but they may make anticipatory avoidance, competing, or delayed avoidance responses depending on a variety of factors, including rewards and punishments associated with each kind of response. The threat avoidance model is based on a conceptualization of the driving task as involving learned avoidance responses to potentially aversive stimuli and an application of well-established principles of behavior to the driving situation. How this learning is established, and how other transient factors such as fatigue, alcohol, inclement weather, or unusual traffic patterns influence avoidance responses, is not clearly addressed by the theory.

\subsubsection{Behavior Feedback}

Thesis and Relationship to Driver Behavior. The purpose of behavior feedback is to provide a systematic organizational scheme to account for observed driver responses after a change in a traffic system has occurred. Behavior feedback, unlike other theories of risk perception and driving behavior, does not attempt to explain any underlying mechanisms that might affect drivers' perceptions or cause behavioral changes. Although it may not be a theory in the same sense as for example learning theory, behavior feedback is a widely cited formal explanation of driving behavior within the traffic safety literature. It would be negligent not to include it within this discussion of models of driver behavior.

Engineering improvements aim at upgrading standards in order to create safe, comfortable, and uniform driving conditions throughout the road network (Mahalel \& Szternfeld, 1986). But improvements to the roadway or environment do not always have the intended effect. It is difficult to predict precisely how the driver will interact with a new component of the system. According to behavior feedback, actual safety changes in traffic systems are related to the intended or expected change through the introduction of a human behavior feedback parameter. When a system is changed, drivers are not seen as passive elements of the system who ignore changes. Rather, they dynamically respond by some type of behavior change based upon the feedback or interactions among all the elements or instructions within the system. Change ranges along a continuum where the outcome of a safety program can vary all the way from producing larger benefits than expected to producing effects opposite in direction to those originally intended.

Behavior feedback attempts to relate safety benefits ( $\mathbf{S}(\mathrm{act})$ ) to engineering changes ( $\mathbf{S}(\mathrm{eng})$ ) by the formula: 


$$
S(\text { act })=(1+f) S(e n g) \text {, }
$$

where $\mathrm{f}$ is a parameter that characterizes the degree to which there is feedback or interactions in the system. When $\mathrm{f}<-1$, the outcome is perverse or completely opposite relative to the intention. When $\mathrm{f}=-1$, the safety measure has no effect. When $-1<\mathrm{f}<0$, the outcome has positive but discounted safety benefits. When $f=0$, the benefit is as calculated; and finally, when $f>0$, the benefits are greater than expected. Some examples suggested by Evans (1991) and illustrated in Figure 5 are: 1) the $55 \mathrm{mph}$ speed limit having a greater than expected safety benefit; 2) in the United Kingdom the implementation of a mandatory safety belt use law producing the expected increases in safety; 3 ) Rumar's study showing studded tires having a less than expected safety benefit; 4) traditional driver education having no effect on safety; and 5) pedestrian cross-walk markings, or "flashing green" traffic signals in Israel having a perverse effect where the measure actually reduced safety.

Methodological Concerns. In the past, three approaches have been used to understand and estimate the effects of safety countermeasures on traffic crashes. An engineering approach states that safety benefits from roadway improvements are given by a straightforward calculation, assuming that the individual user is a passive player in the system. An economic approach (also known as utility maximization or risk compensation) assumes that the driver treats safety as one of a number of economic goods; what really occurs involves trade-offs or a cost-benefit analysis. Finally, risk homeostasis contends that users maintain a constant perceived level of risk, independent of physical or engineering changes in the system (Evans, 1985). Behavior feedback takes a systems approach by acknowledging that users are an active component of the traffic system, and that the effectiveness of many safety measures are a function of dynamic user interactions within the system.

Although behavior feedback does fit safety outcomes rather well, this is not surprising since it retroactively accounts for the variance identified in past performance. What is needed is a theory or model of driver behavior that can predict the outcome of intended safety measures prior to implementation; then traffic officials might have an idea of how best to implement safety measures to insure the intended outcome. A second concern of this approach is that it maintains that safety outcomes can be better, poorer, or what was intended. This in essence is saying that anything can happen within the system, which indeed it can. However, this lack of specificity and sense of noncommitment is not useful for predicting or testing hypotheses. 


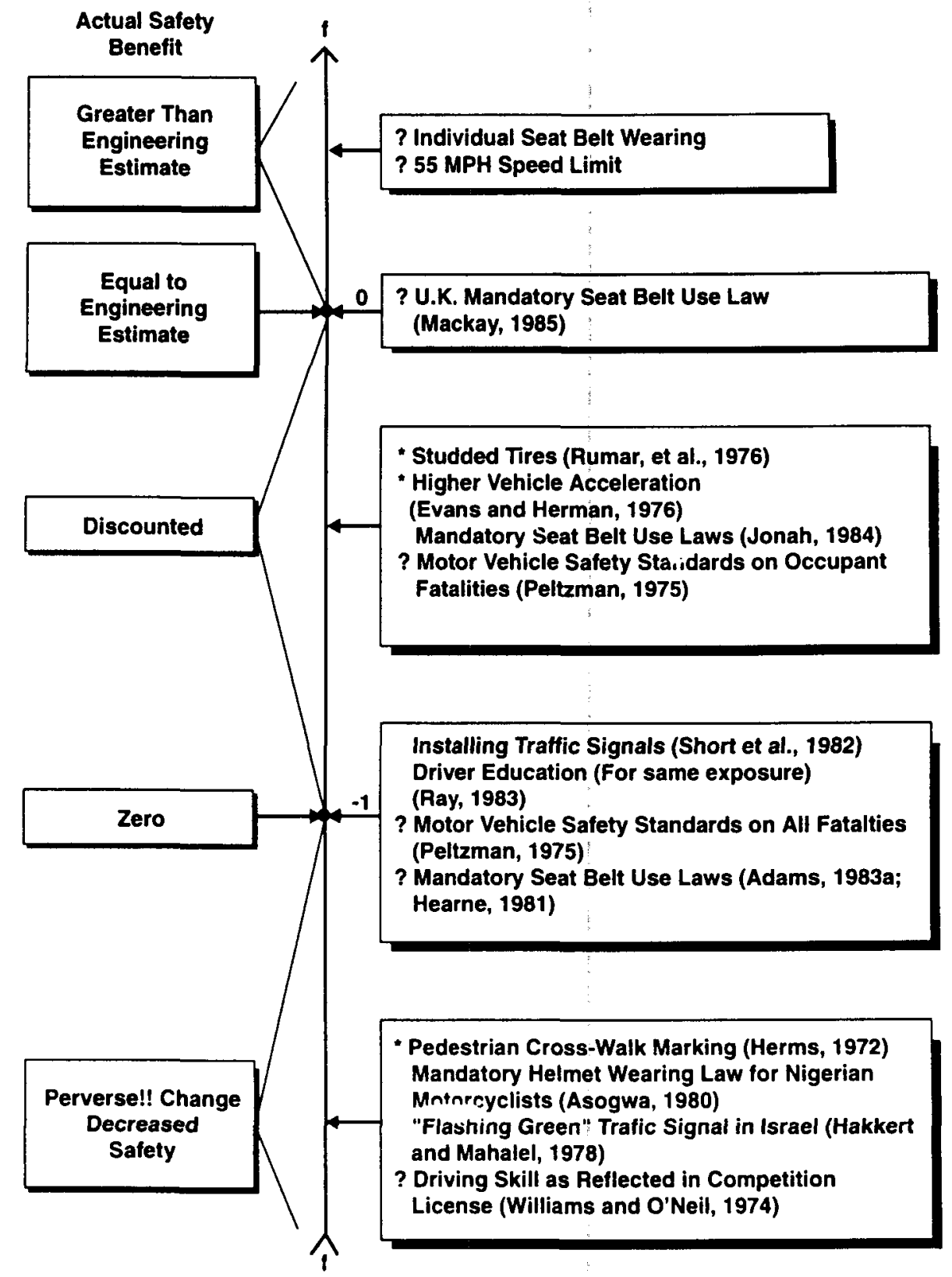

Figure 5: Behavior Feedback (from Evans, 1991). 


\subsubsection{Utility Maximization Model}

Thesis and Relationship to Driving Behavior. This group of models (Blomquist, 1986; Janssen, 1990; Haight, 1986; O'Neill, 1977) is economic in that they propose that individuals perform a mental "cost-benefit" analysis of the risks and benefits of certain behaviors associated with driving. Sometimes these models are referred to as risk (Blomquist, 1986) or danger compensation (O'Neill, 1977). A utility model maintains that individuals possess multiple goals, including safety and non-safety, which enhance utility or well being. Because individuals face a scarcity of time, energy, and money, and because there are several ways to achieve goals, individuals must make choices and substitute among the methods to achieve those goals. Ultimately the individual will seek a utility-maximizing set of methods within the limits of situational constraints.

Drivers have goals which can be expressed as mathematical utility functions, in which desired outcomes are seen as positive, and unwanted outcomes are negative forces. Drivers attempt to maximize this function according to their needs at the present time. The driver's choice of driving behavior reflects a balance of positive and negative. If safety is viewed as a positive outcome while other outcomes, such as loss of time or probability of being involved in a crash, are viewed as negative, then as long as the expected gain in safety is less costly than the expected cost of the negative factors, drivers will engage in more safety effort (Haight, 1986).

A cost-benefit analysis may be applied to a specific situation, or to an overall trip. In the latter case, the economy of safety would be embedded within the larger economy of the trip (Janssen, 1990). In order to make safety as enticing as possible, some have proposed incentive schemes providing rewards for crash-free driving. This is similar to conditional or group insurance rates, where safe or crash-free drivers are rewarded by lower premium costs. The effect of an incentive scheme on overall traffic safety will at least depend on (1) whether it is an all-ornothing or a proportional scheme; (2) whether it is extended on the basis of a groupwise or an individual contingency; (3) what the magnitude of the contingency is; and (4) how large the incentive is relative to the cost of time.

Methodological Concerns. It is questionable whether people have the cognitive abilities to go through the mental arithmetic the economic models propose (Howarth, 1988). Risk taking may not be a formal calculated effort, but an underlying spur-of-the-moment behavior. Furthermore, risk compensation is a contrast effect, contrasting "safe" versus "unsafe" situations (Streff \& Geller, 1988). Thus, behavior change may occur only if the design changes significantly alter perceptions of safety. In regards to incentive schemes for rewarding crash-free driving behavior, questions such as who will be included in the driver population, how will the temporal period for good performance be determined, what will be the reward, how will it be distributed, should it be an all-or-nothing scheme, or should it be graduated, need to be addressed. 


\subsubsection{Problem Behavior Theory}

Thesis and Relationship to Driving Behavior. Problem Behavior Theory (PBT) is a psychosocial theory proposed by Jessor (Jessor \& Jessor, 1977; Jessor, 1987). From Jessor's perspective, the influences on adolescent risk taking behavior are no longer thought of as single causative factors, such as low self-esteem, genetic disposition, etc. (Jessor, 1993). Rather, the causes of adolescent risk behavior are "multiple interacting domains that now range from biology to the social environment" (Jessor, 1993, p. 119). Another major tenet of PBT is that problem behaviors are interrelated. In other words, adolescents who tend to engage in one problem behavior will engage in others as well.

Problem behavior is defined as behavior that departs from the norms, both legal and social, of the larger society. The basic premise is that adolescent problem behavior derives from the psychological, social, and behavioral characteristics of the adolescent, the relevant dimensions of the larger social environment, and the attributes of the situation in which the behavior takes place (Jessor, 1987). The primary focus is on three major systems which influence problem behavior: 1) the personality system, 2) the perceived environment system and, 3) the behavior system. Within each of these systems are numerous explanatory variables which can either instigate problem behavior or control against it. These systems are interrelated and generate a resulting dynamic state called problem behavior proneness, which is synonymous with the concept of risk.

Like other motivational models of driving, PBT is based on the notion that adolescents sometimes engage in risky behavior to fulfill a variety of purposes. For example, risky driving may serve to impress peers, to affirm independence from adults, to cope with feelings of inadequacy or failure, or just to have fun and enjoyment. Further, how a person chooses to drive may be closely related to more general lifestyle characteristics. Risky driving like other problem behaviors may be part of a larger syndrome. Thus, it may be useful to deal with it as part of an overall lifestyle rather than as separate or discrete behaviors.

Early work on PBT assessed (and supported) its applicability to a wide variety of behaviors of concern to the public health and/or juvenile justice communities; such as drinking, delinquency, drug use, smoking, and early sexual activity. Jessor (1987) subsequently analyzed data to determine whether the theory could be expanded to include risky driving. The data came from a questionnaire administered to junior and senior high school students during the 1985-86 school year. Sizeable proportions of both males and females admitted that during the past six months they had "taken some risks when driving in traffic because it makes driving more fun." Jessor (1987) correlated responses to this item with a "total" score for six other risky behavior items, none of which involved driving. He found a strong relationship between the two measures suggesting that risky driving is part of a larger pattern of risk taking for fun or thrills. Other analyses showed the risky driving item to be related to individual problem behaviors such as marijuana use, problem drinking, and impaired driving.

Jessor (1987) then constructed a Risky Driving Scale comprised of four items which both directly and indirectly implicate risk in driving: (1) taking deliberate risks when driving, (2) 
safety belt use, (3) drinking while driving, and (4) smoking marijuana while driving. When correlated with other measures from the general theoretical framework of problem behavior theory, risky driving was significantly related not only to other problem behaviors (e.g., smoking, marijuana use, drunkenness) but also to psychosocial characteristics such as greater tolerance of deviance, higher value on independence relative to achievement, and lower religiosity. According to Jessor, "risky driving behavior emerges from these analyses as an aspect of a larger adolescent lifestyle and as embedded in the same set of personality, perceived environment and behavior variables as other adolescent problem behaviors such as delinquency, problem drinking, and illicit drug use."

Added support for the applicability of PBT to driving comes from Beirness and Simpson (1987), who found that crash-involved youth could be distinguished from youth not involved in crashes on a number of psychosocial and behavioral characteristics drawn from PBT. This was true not just for driver involvement, but also when youth were involved in crashes as passengers. The researchers concluded that "lifestyle factors are associated with all types of traffic accident involvement, whether the individual is actually in control of the vehicle or not."

Beirness and Simpson (1988) expanded on the above work in a study that identified psychosocial and behavioral differences between four groups of students: (1) crash-involved drivers; (2) crash-involved passengers riding with young drivers; (3) other crash-involved students; and (4) students with no crash involvement. Crash-involved students were more likely than those with no crash involvement to express a willingness to engage in exciting, high risk, and novel activities. They also were more tolerant of deviance, reported more liberal attitudes toward alcohol use, exhibited less mature attitudes pertaining to responsible use of alcohol, and were less concerned with traditional values (e.g., academic achievement, compatibility with parental values, religiosity). Among the four groups, crash-involved drivers reported the greatest willingness to engage in exciting/risky activities, the most tolerance of deviance, and the least concern for traditional values. Students involved in crashes as nondrivers showed the greatest willingness to engage in novel experiences. Moreover, those involved in crashes as passengers with young drivers displayed the most liberal attitudes toward alcohol use of all four groups. Significant differences were not found among the groups on self confidence (i.e., ability to deal with everyday situations and difficulties) and peer influence. Besides being associated with various psychosocial variables from PBT, crash involvement was related to a number of problem and health compromising behaviors. Crash involved students (particularly drivers and passengers with young drivers) were more likely to smoke, to refrain from using seat belts, to report a lack of sleep, to report fatigue, to use drugs, to indicate problem drinking, and to ride with drunk drivers.

Wilson and Jonah (1988) explored whether the applicability of PBT to risky driving differs according to age. They correlated behavioral and psychosocial measures from PBT to a risk index computed as the sum of responsible crashes, traffic violation convictions, and license suspensions within the past three years. Analyses showed PBT having far greater power to predict risky driving by persons below the age of 36 than by older adults. The researchers 
suggested this was attributable to a lack of variability in measures caused by the decrease in frequency of problem behavior with age.

Methodological Concerns. While revealing relationships between variables, Problem Behavior Theory cannot be used to draw cause and effect conclusions since most studies testing the theory used correlational analyses (Beirness \& Simpson, 1988). In addition, the reliability and validity of self-report survey and interview data may at times be suspect depending upon the circumstances under which the information was collected. For example, interviewees may give socially acceptable answers instead of truthful ones.

The utilities for risk taking in general among youth may include an outlet for stress, aggression, expression of independence, a means of increasing arousal, impressing others, or a means to another end. The relative importance of these utilities has yet to be demonstrated empirically (Jonah, 1986). Some young drivers may be overrepresented in traffic crashes as a result of their propensity to drive too fast, drive too close to vehicles, accept gaps that are too narrow, and drive while impaired by alcohol. However, not all young drivers take risks. Perhaps the frequency of driver risk taking is distributed such that most drivers take relatively few risks, while a decreasing minority take repeated risks. This implies that a minority of young drivers account for the majority of driver risk taking and hence the majority of traffic crashes among the younger driver population.

\subsection{Decision Making Theories}

\subsubsection{General Decision Making and Information Processing}

Thesis and Relationship to Driving Behavior. Decision making and information processing models assume that the individual is an active rather than passive processor of incoming information. However, the amount of information which can be processed per unit of time is limited by individual characteristics such as short-term and long-term memory storage capacity, the person's general knowledge about the task, and other situational demands or workload imposed upon the driver. These models typically are represented as a sequence of stages, which include perception, decision making and response selection, and response execution. Each stage is assumed to perform some processing of data and to take some time for its completion. Much experimentation has been directed at determining which types of processing occur simultaneously and which occur sequentially (Ranney, 1994).

The concept of automaticity has been proposed as a means by which the amount of information that can be processed at one time is increased. Automaticity is characterized as fast, effortless processing which evolves following extended consistent practice (Ranney, 1994). Naatanen and Summala's zero risk theory (Naatanen \& Summala, 1976; Summala, 1988) and van der Molen and Botticher's hierarchical risk theory (1988) both incorporate an automatic processing stage as well. Automatic processing of basic skills such as steering or braking can improve overall task performance by leaving other cognitive resources available to process the inconsistent, unexpected, or novel situations which can arise during driving. 
Michon (1985) has proposed that the driving task be viewed as adaptive control of thought as opposed to automatic processing of behavior. He proposes that rule-based or production systems be used as a model to represent driving behavior. These systems are based on the work of Newell and Simon (1972) who proposed a format termed production systems. These systems take the form of a set of IF-THEN, or condition-action statements which, when executed, will perform a certain task. In the initial stages of learning, these production systems are very simplistic; for example, in learning to shift transmission gears, the driver must execute a series of actions by the following formalization: IF the goal is to shift gear, THEN release the gas pedal and apply the clutch pedal and move the gear stick to the proper position. In later stages of learning, and with practice, automaticity sets in so that these behaviors become habitual and occur with little attention devoted to them.

\subsubsection{Hierarchical Risk Model}

Thesis and Relationship to Driving Behavior. The hierarchical risk model (van der Molen \& Botticher, 1988), illustrated in Figure 6, provides a structural framework to describe the perceptual, judgmental, and decision processes of traffic participants at all levels of traffic tasks. Other models emphasize the motivational aspect of the risk concept, i.e. drivers are motivated to keep risk levels below or at specified levels. The hierarchical model breaks down the driving task into a three-layer hierarchy, with each successive layer becoming more and more specific in regards to the tasks carried out within that layer. Tasks at each layer have their own subjective probabilities and utilities associated with behavioral outcomes. In the hierarchical risk model, driving is broken down into a strategical, a tactical, and an operational level (van der Molen \& Botticher, 1988; Michon, 1985; Oppe, 1988). These three levels have also been referred to as navigation, guidance, and control (Ogden, 1990). At the highest strategical level, general route planning takes place. This stage of planning quite likely occurs prior to the actual trip itself, although planning can also occur at the next two levels. At the tactical level, concrete maneuvers are planned, such as whether or not to overtake another vehicle enroute. Maneuvering plans are implemented at the operational level by means of steering movements, accelerator movements, and other basic skills.

Driving performance is continuously monitored by the driver because of changes in the physical environment. Perception of the physical environment at any moment and any task level is influenced by the driver's internal representation of similar situations, also known as driver expectations or prior knowledge. Driver perceptions also are influenced by knowledge of one's own skills, limitations, and interactions with the environment and possible consequences of these factors. The driver's motivations determine the subjective meaning attached to each of the possible alternatives at any level of the hierarchy. 


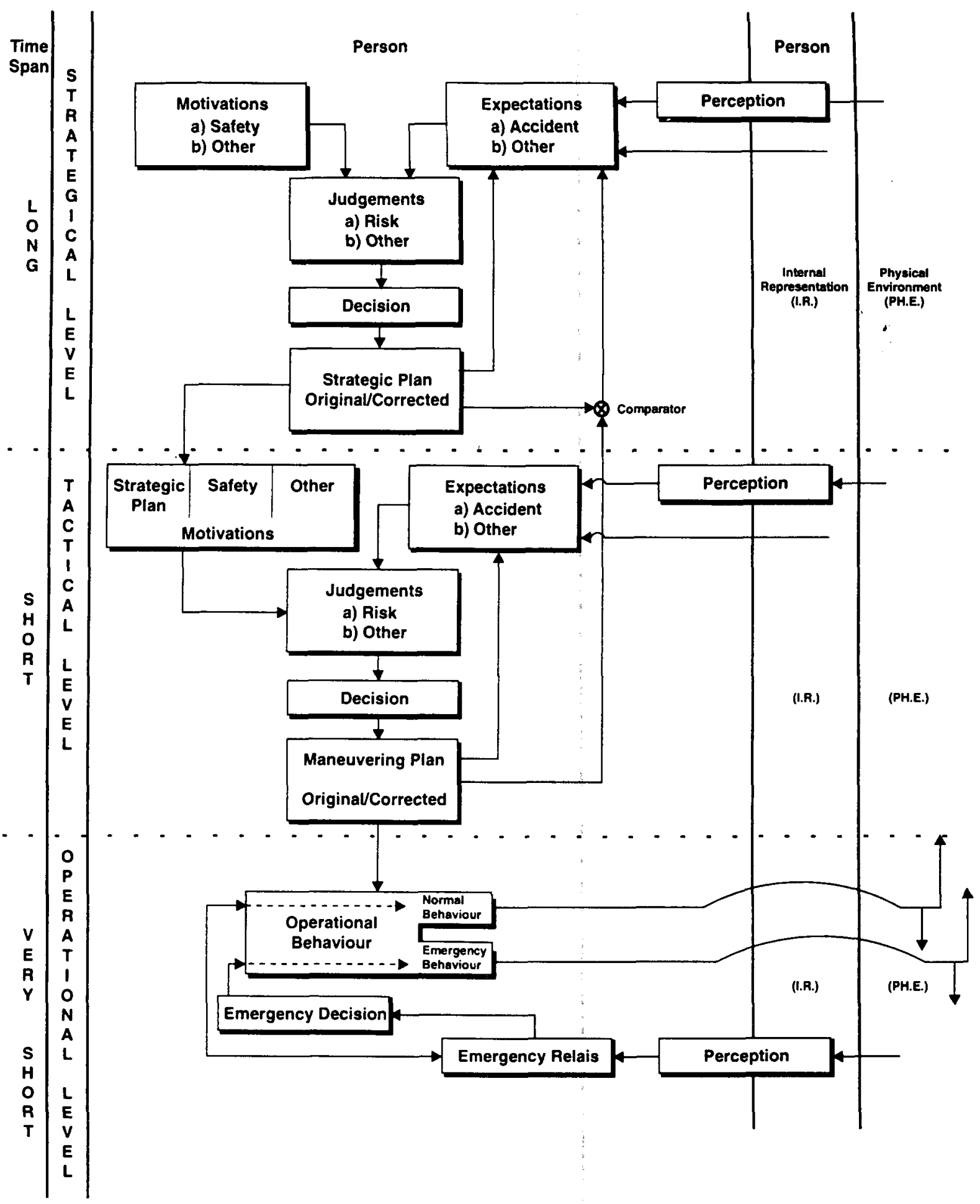

Figure 6: Hierarchical Risk Model (Van Der Molen and Botticher, 1988). 
Motivations and expectations at the strategical level of the hierarchy are integrated into judgments. Integration takes many forms and some people may give more weight or importance to expectations, others to motivations. In addition, the differential importance of expectations and motivations may vary at different levels within the hierarchy. The probability of risk calculated at the strategical level regarding the overall planned trip may be much greater than any one individual maneuver carried out at the lowest, or operational level. At the strategical and tactical levels, a decision is made to carry out a particular behavior by applying a decision rule to the judgment and comparing these decisions to some criteria value. At the operational level, the strategical and tactical plans are carried out via on-going behavior. These decisions and plans can be interrupted, however, whenever the driver suddenly perceives a situation with a high expected crash probability. During such emergency situations, decision making requires the individual to choose rapidly from a limited number of emergency behavior stereotypes, such as braking or turning the steering wheel. Past driving experience or individual motivation may greatly affect driving behavior in emergency situations.

Methodological Concerns. The ultimate behavioral response is a calculated decision, very similar to decision tree analysis. However, whether drivers consciously think in terms of statistical probabilities of infrequent events is highly unlikely. More likely, the three hierarchical levels are processed at an unconscious level. Laboratory studies testing this theory are needed. Also, this model has been criticized for failing to distinguish between aggregate and individual levels of analysis (Ranney, 1994).

\subsubsection{Bounded Rationality}

Thesis and Relationship to Driving Behavior. The driver has limits on the availability of cognitive resources to devote to the driving task (van der Colk, 1988). Human contributions to errors and road crashes derive from breakdown in the supervisory and control functions of the driver's task.

Risk taking in traffic can be defined as the result of discrepancy between the driver's selfimposed demands of speed and accuracy and the actual availability of human aptitudes and psychological resources to meet those demands (van der Colk, 1988). The ideal or "normative" decision maker has an extensive set of relevant information available. This exhaustive data base is optimally accessed, processed, and incorporated into the appropriate decision rules in order to achieve the best possible outcome. However, there also is an upper limit to the amount of information that the individual can process given certain task parameters. Hence, performance is less than perfect, and the driver must make decisions regarding expected losses and gains for various driving maneuvers.

Methodological Concerns of Decision Making Theories. While motivational models are often criticized for failing to account for cognitive functioning, decision making and information processing models sometimes fail to account for driver motivation and emotions (Michon, 1985). In addition, cognitive processing is difficult to measure. At best, only indirect measures are 
available. Whether these measures are generalizable and valid of the driving task are not totally known.

\subsection{Social Context Theories}

Driving occurs in a social context. A driver's perceptions and concerns are influenced by the presence of passengers, by other drivers, by social conventions or cultural differences, by local practices, and other social context factors. When in the presence of others, drivers manage information about themselves, their feelings, their relationships, their character, and their social status, in order to convey the particular impressions they wish to make. Drivers outwardly present themselves to create an image of competence and confidence regardless of internal doubt they may feel.

From the driver's perspective, social identity or social competence and tact perhaps are more important than safe driving. Operating a vehicle includes not only perceptual and motor skills, but also the need for a smooth social performance (Rothe, 1992). However, there is a general lack of knowledge as to how these social factors may influence a driver's perception of risk. Although a few sociological theories may be relevant to driver perception of risk, what is needed is an overall theory to further our understanding of risk perception within this social milieu, and its practical application to highway design and operations.

\subsubsection{Social Amplification of Risk.}

Thesis and Relationship to Driving Behavior. Although the theory of social amplification of risk (Kasperson et al., 1988) has not been directly applied to driving situations, it may be informative in helping to understand how individuals perceive risky situations. In a narrow technical sense, risk focuses on the probability of events and the magnitude of specific consequences; risk is defined by multiplication of probability and magnitude. However, this formula cannot account for the wide discrepancy in risk assessment between technical experts and the general lay population. For example, although technical experts may perceive nuclear power and its consequences quite benign, the general public's perception of this form of energy is less than enthusiastic (Slovic, 1987).

Other aspects of risk such as personal ability to influence the risk, familiarity with the hazard, and the catastrophic potential also shape public response. Public perceptions are composed of intuitive biases, economic interests, and reflect general cultural values. Yet no comprehensive theory exists to explain why risks assessed as minor by technical experts, such as nuclear power or genetic engineering, sometimes are "amplified" within the public. A comprehensive theory is needed which is capable of integrating the technical analysis of risk with cultural, social, and individual response structures.

Much like the driving task, social amplification of risk is dynamic, taking into account the learning and social interactions accrued from experience with risky events. Risk can be experienced either directly via personal experience or indirectly via secondary information 
received about the risk. Direct experience with risky activities can be either reassuring or alarming. Generally, experience with dramatic crashes or risk events increases the memorability and imagery of the hazard, thereby heightening or "amplifying" the perception of risk. But direct experience can also provide knowledge on the nature, extent, and manageability of the hazard, affording better perspective and enhanced capability for avoiding risks. Thus, whereas direct personal experience can serve as a risk amplifier, it can also act to attenuate risk. Learning behavior models such as Fuller's threat avoidance hold similar views.

Learning the consequences of risky activities does not have to occur first-hand. Since one's friends, family, or other outside sources such as the media or activist social organizations may provide reference points for validating perceptions and are also likely to share a more general cultural view or bias, the potential exists for these sources to either amplify or attenuate risk. Within social group interaction, interpretations of risks will tend to be integrated into larger frames of values and analysis in a sort of ripple effect, and to become resistant to new, conflicting information.

\subsubsection{Other General Traffic Sociology Theories.}

Thesis and Relationship to Driving Behavior. Traffic is structured by social dynamics. Everything that relates to driving, for example the highway code, police, insurance companies, etc. are the products of society and a result of social action (Barjonet, 1989). Rothe (1992) proposes that traffic is a game where the basic rules of play are the traffic laws that serve as normative procedures or specified schemes of conduct. Within the basic rules are preference rules where drivers act according to the more vaguely defined principles of social mores and folkways. When drivers and passengers decide to take risks, they probably do so with little objective or empirically measurable deliberation. Preference rules and cultural attitudes support the daily decisions drivers make concerning risks. Thus, driving on public streets is an orderly affair structured subjectively by an understanding of the social mores, a trusting that others will act in a similar and predictable manner, and objectively by laws and regulations.

To illustrate the theory of traffic sociology, Rothe (1992) assessed the influences of social factors on driver perceptions via three major British Columbia studies. Information was obtained through open-ended interviews with young drivers, drivers age 65 and older who were victims of injury producing crashes, and drivers who considered themselves to be regular seat belt wearers. Overall findings revealed four major "preference" rules: (1) consideration for others overrides personal safety; (2) presentation of self as competent driver overrides personal doubt; (3) good drivers know how to take risks; and, (4) risks are OK for good reasons. For many interviewees good driving was synonymous with ability, technical skills, and a personal history of crash-free driving.

Safety belt wearing is a widely accepted safety procedure, and many people make it a habit to always wear a seat belt. Yet one surprising finding from Rothe's (1992) interviews was that regular seat belt wearing is sometimes negotiated according to social situations. For example, motorists often will permit more passengers than there are seat belts, especially when the 
passengers are children. Passengers also often provided drivers with the support that the driver is competent and reliable by not wearing seat belts. Anecdotal evidence supports this attitude among youthful drivers, especially males.

As expected, there were differences between younger and older age groups in regards to attitudes pertaining to risks (Rothe, 1992). Youths are very concerned about social interactions with their peers and the car is a popular setting for such interactions. Nonetheless, especially among inexperienced drivers, driving demands attention to the driving task. Youths however tend to reverse the order of first being attentive to driving and second engaging in social discourse. Rather than avoid conversation with passengers and be labelled social boors, young drivers willingly engage in animated interaction because of the social expectation that in-car social gatherings demand conversation. This may lead to inadequate attention left for driving so that hazards and dangers are either erroneously recognized, or not recognized at all. In addition, pressure from peers may downplay the driver's perceived severity of risks associated with driving, as well as exacerbate risk taking behavior.

Methodological Concerns of Sociological Theories. Although direct applications of sociological research are scarce, studies from a social context point of view are highly promising in clarifying driver risk perception. However, methodologies must be carefully selected so as to provide data that are reliable, valid, and can be easily applied to everyday traffic situations.

The structured interview, a popular research tool, has certain advantages since all respondents are asked the same set of questions. However, especially with face-to-face interviews, the researcher must be aware of the possibility of bias on both the part of the interviewer and the interviewee. In addition, the researcher needs to be aware of sample size and representativeness issues so that proper conclusions can be drawn from the study. It may be worthwhile to look to other fields of study for methodologies (e.g., focus groups) that are more appropriate for answering questions about social context. Finally, it is important to realize that social context issues are multidimensional, and interactions between factors may turn out to be complex. 


\section{RISK PERCEPTION AND DRIVING}

Youth differ from older drivers in how they perceive hazards and in how they perceive the likelihood of a crash or injury. Although younger drivers engage more frequently in various risky behaviors, such as speeding, this could be due either to differences in how the risk is perceived, or to differences in how the risk is accepted. Because simply observing driver behavior can not discriminate these factors, studies of risk perception are generally based on self-report and ratings of perceived risk. Various studies have obtained these judgments for videotaped or photographed situations, verbally-described scenarios, or actual on-the-road situations. Some studies have addressed perceived driving risk very generally (e.g., the likelihood that you may be involved in a collision), while others have dealt with very specific scenarios. Perceived risk is jointly determined by the perceived likelihood of an outcome, and the perceived severity of that outcome, and both appear related to youthful driving. However, young driver studies have not attempted to discriminate the relative contribution of these two factors as determinants of age differences in overall perceived risk.

Although there are some differences in findings among particular experiments, various reviewers of the driver risk perception literature (e.g., DeJoy, 1992; Dekker, Kotwal, and Lerner, 1994; Jonah, 1986; Lerner, Williams, and Sedney, 1988) have agreed on major conclusions. Younger drivers do tend to perceive hazards somewhat differently than older drivers. For most situations, they report less perceived risk, although for a few situations (e.g., driving in snow) they may perceive more. Younger drivers tend to overestimate their skill and ability to control or avoid a collision, and perceive their ability as superior to same-age peers. Thus it appears that younger drivers' misperceptions of risk occur at several points: they are less likely to recognize and appreciate a potential hazard; they are likely to overestimate their own ability to control the situation; and they see less personal vulnerability should a crash occur.

The finding that young drivers see themselves as more skillful and less vulnerable to a crash than others has been observed across a number of studies. However, this bias is more consistent and pronounced for young male drivers than for young female drivers (Matthews and Moran, 1986; Finn and Bragg, 1986; Trankle, Gelau, and Metker, 1990; Groeger and Brown, 1989; Sivak, Soler, Trankle, and Spagnhol 1989; DeJoy, 1989, 1992). The tendency to rate oneself as more skillful, or less vulnerable, than one's same-age peers is not unique to younger drivers; however, the tendency is more pronounced for younger drivers (Matthews, 1986). Given the objective data on the greatly increased crash risk of young drivers, there is an obvious misperception for this group. Some of the studies that involved comparisons of one's self with others required the subjects to make these comparisons along several dimensions. For example, Matthews (1986) obtained ratings for overall driving ability, vehicle handling skills, driving judgment, and driving reflexes. Younger drivers rated themselves superior to same-age peers on all of these dimensions. In terms of crash likelihood and general driving ability, they rated themselves comparable to more mature drivers. For vehicle handling and reflexes, they rated themselves superior to more experienced drivers. Similarly, DeJoy (1989) found stronger optimism biases 
for self-ratings of driving skill and driving safety than for general crash likelihood. The general findings from these studies are: moreso than other age groups, young drivers underestimate personal risk and overestimate driving ability; this effect is more robust for males than for females; and the effect appears more pronounced for judged ability than for crash likelihood.

Various studies have investigated the risk perceptions of young drivers as related to specific sorts of hazards or scenarios. Since it is already established that younger drivers tend to perceive less driving risk in general, the interest here is with those situations where age differences may be most pronounced. Many of the studies that collected data for a range of situations have not fully reported the situation-specific results. Studies have tended to use different scenarios or to categorize situations in quite different ways. A number of the studies also have been conducted in countries other than the U.S. These factors make direct comparison difficult, but across the range of studies, certain situation-specific aspects of young driver hazard perception do emerge.

Several of these studies obtained judgments of risk during actual on-the-road trips. Bragg and Finn (1985) had subjects make risk ratings at 15 sites as they travelled an urban route, both as passengers and drivers, with and without seat belts on. They compared the ratings of a group of 18-24 year olds with a group of 38-50 year olds. The complexity of the research design, the presence of uncontrolled sequence effects, and the finding of several statistically-significant higher-order interaction effects makes the study difficult to interpret in a straight-forward way. Age was not a statistically significant main effect, but it did interact with the features of the trip. Young and older subjects did not differ in their ratings when they were passengers; but if they were drivers, and were not wearing seat belts, younger drivers rated the situations as less risky. Bragg and Finn did not find any significant interaction of age with the particular driving scenario. They did find that younger driver ratings of the most objectively hazardous situations were most affected by the difference between being a driver and a passenger. The Bragg and Finn study suggests that the presence of age differences in on-road ratings of particular risk scenarios may be sensitive to whether the subject is making the comparisons as a driver or as an observer. However, based on on-road results, no particular situation emerged as one for which younger drivers, or observers, were particularly different from older subjects.

Lerner, Williams, and Sedney (1988) had subjects ride as passengers over an extended route of rural and suburban highways and freeways. The subjects continuously adjusted a hand-held dial to reflect the momentary level of perceived risk. The computerized in-vehicle data recording system permitted these ratings to be tied to precise roadway locations, so that a "perceived risk profile" could be obtained for any stretch of roadway and related to particular roadway features. The Lerner et al. study compared a group of young drivers (18-25) to a group of older drivers ( 55 and older). Although young and older driver groups had similar risk profiles, the younger drivers rated less risk in general, and tended to show less anticipation (more abrupt changes in perceived risk). Younger drivers appeared to be less influenced by the formal communication devices of warning signs and markings. Although formal statistical comparisons could not be made, the general impression was that the younger drivers' sense of risk did not show the anticipation and susceptibility to safety warnings that older drivers did. Differences between age groups were more pronounced for rural highways than for freeways. Younger drivers also rated 
substantially less risk at stop-controlled intersections. In the post-experiment debriefing, Lerner et al. had subjects indicate what factors were most important to them in making their risk judgments. While the importance of various factors was generally similar, young subjects reported less significance of speed than did older subjects.

Soliday (1974) used a verbal report technique in which subjects drove a route and were asked to verbally report and describe "everything considered to be dangerous." The report does not provide much detail on sites, methods, or findings, but the primary result is of interest. Age and driving experience (confounded) were significantly correlated with the relative frequency of comments about traffic, as opposed to comments about the roadway. Younger, less experienced drivers gave more reports about roadway features (e.g., sharp curve), and fewer reports about moving traffic (e.g., erratic driver or nearby pedestrian). Thus younger drivers appeared relatively less sensitive to the risks associated with other roadway users compared to risks associated with roadway geometry.

Most studies comparing various driving situations have been in laboratory situations, using photographed, videotaped, or verbally described scenarios. Finn and Bragg (1986) found younger drivers perceiving less risk for themselves compared to same-age peers for situations involving alcohol or driving on wet roads; and less risk for themselves compared to older drivers for situations involving speed, tailgating, alcohol, and night driving. In an Australian study, Cairney (1982) compared inexperienced drivers (mean age 19.6 years, mean years driving 1.3) with more experienced drivers for 38 different situations, and found lower perceived risk by the younger group to be especially pronounced for passing situations, approaching signalized intersections, encountering construction zones, or driving in heavy holiday traffic. Sivak, Solar, Trankle, and Spagnhol (1989) compared different age groups using subjects from four countries (U.S., Germany, Spain, and Brazil), but while they found younger drivers providing a lower rating of risk overall, no scenario emerged as more extreme. For scenes involving high speed, younger drivers (18-21) saw less risk than older (65-75) drivers, but they did not differ from middle-aged (35-45) drivers. Trankle, Gelau, and Metker (1990) found that younger German male drivers reported significantly less risk than did older drivers for scenarios involving horizontal curves, hills, darkness, and rural settings. Armsby, Boyle, and Wright (1989), in a British study, reported that drivers under age 25 were less concerned with "predictability" than older drivers, giving relatively more weight to the highly attention-getting hazards. Matthews and Moran (1986) reported that younger drivers reported less risk for themselves in those scenarios where quick reflexes or good vehicle handling skills were important; this was not seen for scenarios where good driving judgment was central. Brown (1982) described findings from Laidlaw, which compared the risk ratings of younger male drivers (median age of 23) with those of experienced male police officers. Younger drivers rated substantially less risk for distant hazards, but not for near hazards. They also rated less risk for situations with hazard signs or warning markings, and for locations of traffic conflict. DeJoy (1989) had college students (mean age of 21) compare their risk of being involved in a crash relative to that of other students at the university. Subjects rated their risk as substantially less than that of others for situations involving driving while intoxicated, failure to yield right of way, loss of control at high speed, and scraping the side of the vehicle at a drive-in. 
Summarizing these studies, several factors emerge as particular problems. Beyond the general tendency to report less risk across situations in general, younger drivers appear to: associate less risk with high speed; be less influenced by warnings and markings; associate less risk with tailgating; see less degradation in their performance due to alcohol use; be less sensitive to, or anticipating of, distant or emerging hazards; and see less risk on rural roads. In general, young drivers appear to see less risk for situations where reflexes or vehicle handling skills are important (e.g., speed, tailgating, curves, passing). 


\section{PERSONALITY FACTORS AND RISKY DRIVING}

The role of personality factors in risk taking by adults has been widely investigated. This large and complex technical literature has focused almost entirely on behavioral measures of risk taking, and especially crash-involvement. There apparently has been minimal attention given to the role of risk perception. The belief that factors other than lack of skill may contribute in some way to the overinvolvement of youths in motor-vehicle-related crashes has stimulated interest in this area.

As in some of the areas previously reviewed in this report, particular disciplines approach the role of personality in risky driving from different perspectives (e.g., child and adolescent psychiatry, developmental psychology, etc.), and consequently view the underlying psychological processes related to risky driving in somewhat different ways. This section includes a discussion of the major hypotheses concerning the underlying personality factors that may cause risky driving, and the findings of recent studies testing them.

A brief summary of results from studies conducted with adults facilitates discussion of the work carried out with younger drivers. Findings from various studies of adult psychiatric patients reviewed by Barkely and his colleagues (1993) showed that psychiatric patients had as much as six times the risk of crash involvement as did control subjects. In general, these studies found that males with conduct and antisocial symptoms, and those with substance abuse disorders, are at highest risk of being involved in a vehicular crash.

Tsuang, Boor, and Fleming (1985) concluded from an extensive review of the literature that those who were involved in crashes were "generally described as displaying less control of hostility and anger, less tolerance of tension, less maturity, and less conformity; more difficulty with authority figures, more hyperactivity, and more belligerence; and a tendency toward risk taking" (Tsuang, Boor, \& Fleming, 1985, p. 544). The authors also noted that these relationships were stronger for males and many of these factors are highly correlated with age, which they speculated may partly explain the high crash rate of youths (Tsuang, Boor, \& Fleming, 1985).

There are many hypotheses addressing the relationship of personality factors to risky driving by youth. Among these are: (1) risk taking is an unconscious manifestation of suicidal intent; (2) individuals who tend to be impulsive and prone to deviant social behavior tend to be heavy users of intoxicating substances, which puts them at increased risk of risk taking and crashes; (3) risk taking is a personality factor such as sensation seeking, (4) adolescents engage in risk taking behavior to attain status with their peers; and (5) risk taking as a failure to protect one's health or safety may be related to developmental arrest (Clark, Sommerfeldt, Schwartz, Hedeker, \& Watel, 1990). Although these and other hypotheses are clearly articulated in the literature, recent studies tend to focus on only a handful of them. 
One hypothesis that has received increasing interest is the relationship between sensation seeking and the propensity towards risky driving. Zuckerman defines sensation seeking as "the need for varied, novel, and complex sensations and experiences and the willingness to take physical and social risks for the sake of such experiences" (Zuckerman, 1979, p. 10). Using a sample of readers of Psychology Today, Zuckerman and Neeb (1980) reported that faster drivers obtained higher scores on sensation seeking. This relationship held for both sexes. There was no change in the results when age was used as a covariate in the analyses.

Clark and his colleagues (1990) tested the hypothesis that "recklessness" including risky driving is a character trait akin to Eysenck's venturesome personality type or Zuckerman's sensationseeking type. High school students and psychiatric inpatients between the ages of 15 and 18 completed a ninety-nine item questionnaire that included demographic variables, personality measures (venturesomeness, thrill seeking, and impulsivity), severity of depression, and suicidal ideation. Factor analysis of the items yielded three factors of risky behaviors: (1) foolhardiness; (2) dangerous driving and substance abuse; and (3) smoking, using drugs, and choosing bad company. The items that loaded on the second factor included driving after drinking, speeding, drunk driving, driving in hazardous weather, driving in poor environmental conditions, riding with an impaired driver, driving while impaired, and receiving more than two moving violations. Higher scores on venturesomeness and impulsivity were related to higher levels of dangerous driving and substance abuse. Interestingly, normal and psychiatric patients had similar mean scores and score distributions on measures of dangerous driving.

Several other studies examined the relationship between level of sensation seeking and risky driving. Beirness and Simpson (1988) found that high school students who had been involved in a motor vehicle crash as a driver scored higher on the Thrill and Adventure Seeking subscale of Zuckerman's Sensation Seeking Scale than subjects who were involved in a crash as a passenger or those who were not involved in a crash at all. Arnett (1990), in a study of 17- to 19-year-old males, found that having driven a car while drunk in the past year was related to the total score on the Sensation Seeking Scale (Zuckerman, Eysenck, and Eysenck, 1978) and to several subscales (i.e., Thrill and Adventure Seeking, Disinhibition, and Boredom Susceptibility). Those who reported driving impaired during the past year received higher mean scores than those who reported not driving impaired. Impaired driving was not related to the Experience Seeking Subscale (Zuckerman, 1979). In contrast, Clement and Jonah (1984), in a study of 285 undergraduates, did not find a relationship between crash involvement and sensation seeking. However, males who were classified as sensation seekers tended to drive faster than males who were not categorized as such.

The relationship of sensation seeking to risky driving is also examined in the alcohol literature. McMillen, Smith, and Wells-Parker (1989) employed a pretest-posttest design in which psychology students' driving was evaluated while playing a video driving game. Six weeks prior to playing the video game, subjects completed the Sensation Seeking Scale (Zuckerman, 1979). During the pretest, subjects completed three trials operating the driving simulator. After the pretest condition, subjects were randomly assigned to "expectancy groups." Some were told they would be drinking an alcoholic beverage, while others were told they would not. Subjects 
in the alcohol expectancy group were either given two glasses of orange juice in which alcohol had been dabbed on the rim of the glass or two glasses of orange juice and vodka. Those in the no alcohol expectancy group were given two glasses of orange juice. After consuming the drinks, subjects completed additional trials of the video game. The dependent variables were lane changes, cars passed, and amount of time at maximum speed. Results showed that high sensation seekers were more likely to score above the median on lane changes and cars passed. Low sensation seekers were more likely to score below the median on these variables. Alcohol consumption did not have a statistically significant effect on lane changes or cars passed. High sensation seekers who thought they had consumed alcohol tended to have more scores above the median on lane changes and cars passed than high sensation seekers who thought they had not consumed alcohol. The amount of time at maximum speed was not related to sensation seeking, alcohol received, or alcohol expected.

Apparently few published studies have examined the relationship between personality factors such as attention deficit/hyperactivity disorder (ADHD) and conduct disorder (CD) and risky driving. This is puzzling in light of the long term predictions that children identified with conduct disorder are likely to engage in drunk driving as adults (Kazden, 1987). Barkely and his colleagues (1993) compared adolescents who had been previously diagnosed with behavioral problems to a control group in terms of parental report of driving, driving citations, and crashes. Over three-quarters of the experimental group had a diagnosis of ADHD; however, over half of them also had a diagnosis of Conduct Disorder and Oppositional Defiant Disorder. A small minority of those in the experimental group had a diagnosis of CD or ODD without another diagnosis. Results showed that the experimental group was more likely than the control group to experience the following: driving without a license, multiple crashes as the driver, crash involvement in which they were at fault, and more than three citations. Parental ratings of their children's driving were lower for the experimental group, while reports of impaired driving were more frequent. In addition, the experimental group received more speeding tickets, and more citations for failing to stop when appropriate.

Poorer driving records among persons diagnosed with ADHD also appear in results of a study conducted for NHTSA (Lambert, 1995). The study utilized a longitudinal database to assess the relationship of early (childhood) diagnosis of ADHD to later driving performance. Pervasive and severe ADHD was found to correspond with a greater likelihood that subjects had specific types of moving violations on their driving records (through age 25), including sign and signal, speeding, roadway markings, following too closely, and passing. Several non-moving violations also were more likely to surface among the severe ADHDs. The nature of some of the latter offenses suggested that ADHD subjects experience compounded problems when charged with moving violations because they are more prone not to follow through the required process (failure to pay; failure to appear).

Lavery and her colleagues (1993) showed that greater perception of risks was associated with less involvement in risky behavior, with the exception of vehicle-related risks (motor vehicle and motorcycle), in a sample of youths diagnosed with affective or conduct disorder. Involvement 
in vehicle-related risks, drug-related risks, status-offence risks, and criminal behavior risks corresponded to a diagnosis of conduct disorder.

"Extra motives," a class of behaviors that while not clinically meaningful in the strictest sense, allude to possible underlying reasons for engaging in risky driving. Competitiveness, sense of power and control, or more generally the pursuit of sensual pleasure for its own sake, have been referred to as "extra motives" (Naatanen \& Summala, 1976). Evans (1991) believes that "extra motives" play an important role in the elevated crash rates for younger drivers. There is a paucity of research examining the relationship of extra motives to crash rates. However, in one study, 47 percent of tenth grade students reported that the automobile made them feel like an adult. The same percentage reported using the automobile as a means for being alone. Students also reported that the automobile increased their popularity, and males reported that automobiles gave them a sense of power (Farrow \& Brissing, 1990).

It is difficult to discover a body of work addressing each hypothesis specified in the beginning of this section. For example, to our knowledge, there is little empirical data addressing motor vehicle crashes as a method of suicide among youths. One study examining suicide among children and youths younger than 19 years of age showed that the most prevalent method is firearms, followed by hanging, poisoning, ingestion, and falls. Only 1 percent of the suicides involved motor vehicles (Hoberman \& Garfinkel, 1988). Given the increasing numbers of suicides among adolescents and the difficulty of linking motor vehicle crashes with specific causes, it is conceivable that this rate is higher. 


\section{IMPAIRED DRIVING}

Enormous efforts have been undertaken to combat the serious problem of youthful impaired driving. This section provides a brief overview of some of the salient issues related to the goals of this project.

\subsection{Demographics}

\subsubsection{Crash Statistics}

Despite enactment of age 21 minimum drinking age (MDA) laws across the states, alcohol persists as a major highway safety problem for youth. In 1993, 34 percent of drivers ages 16 through 20 who were killed in motor vehicle crashes had alcohol in their systems; totaling 1,056 cases. Seventy-three percent of these alcohol fatalities were at blood alcohol concentration (BAC) levels that met or exceeded most legal definitions of driving while intoxicated, measuring 0.10 or greater. Among driver crash fatalities ages 21 through 24,53 percent $(1,525$ cases $)$ had been drinking alcohol. More than 80 percent of these alcohol fatalities had a BAC of 0.10 or greater (NHTSA, 1994b).

Drivers who consume alcohol pose a threat not only to themselves but to others. It's therefore instructive to look at driver involvement in fatal crashes, whether or not that driver was killed. Table 6 shows substantial decline over the past 10 years in the percentage of young drivers involved in fatal crashes who had been drinking. Across all age groups, reduction in this measure of alcohol involvement has been greatest among persons ages 16 through 20, thanks in part to enactment in many states of age $21 \mathrm{MDA}$ laws at this time. Still, about 1,800 drivers under the age of 21 who were involved in fatal crashes during 1993 had measurable alcohol in their systems, as did another 2,500 drivers ages 21 through 24 . Most were legally intoxicated. That same year, alcohol involvement was reported for more than 50,000 drivers younger than age 25 who were involved in nonfatal injury crashes, 22,000 of whom were under the age of 21.

\subsubsection{Gender}

Males are more likely than females to report drinking-and-driving regardless of age (NHTSA, 1993c). They also compose a disproportionately large share of driver alcohol fatalities. Among 1993 crash victims ages 16 through 20, males accounted for 85 percent of all driver fatalities where the driver was found to have been drinking alcohol. In the 21 through 24 age group, they accounted for 87 percent (NHTSA, 1993b). 
Table 6. Drivers in Fatal Crashes by Blood Alcohol Concentration (BAC) and Age $1982-1993$

\begin{tabular}{|c|c|c|c|c|c|c|c|c|c|}
\hline \multirow[b]{4}{*}{ Year } & \multicolumn{9}{|c|}{ Age } \\
\hline & \multicolumn{3}{|c|}{$<16$ Years } & \multicolumn{3}{|c|}{ 16-20 Years } & \multicolumn{3}{|c|}{ 21-24 Years } \\
\hline & \multirow[b]{2}{*}{ Total } & \multicolumn{2}{|c|}{ Percent } & \multirow[b]{2}{*}{ Total } & \multicolumn{2}{|c|}{ Percent } & \multirow[b]{2}{*}{ Total } & \multicolumn{2}{|c|}{ Percent } \\
\hline & & $\begin{array}{l}\text { *Alcohol } \\
\text { Involved }\end{array}$ & $\begin{array}{l}\text { * *Legally } \\
\text { Intoxicated }\end{array}$ & & $\begin{array}{l}\text { Alcohol } \\
\text { Involved }\end{array}$ & $\begin{array}{c}\text { Legally } \\
\text { intoxicated }\end{array}$ & & $\begin{array}{l}\text { Alcohol } \\
\text { Involved }\end{array}$ & $\begin{array}{c}\text { Legally } \\
\text { Intoxicated }\end{array}$ \\
\hline 1982 & 412 & 13.4 & 8.2 & 9,858 & 44.0 & 31.1 & 9,018 & 51.6 & 40.0 \\
\hline 1983 & 416 & 12.2 & 7.4 & 9,334 & 42.2 & 29.7 & 8,432 & 50.7 & 39.1 \\
\hline 1984 & 446 & 14.7 & 7.5 & 9,804 & 39.6 & 26.6 & 8,963 & 49.0 & 37.3 \\
\hline 1985 & 479 & 15.5 & 8.8 & 9,386 & 35.5 & 23.9 & 9,046 & 45.9 & 35.3 \\
\hline 1986 & 504 & 15.3 & 8.1 & 10,163 & 36.5 & 23.7 & 9,129 & 47.3 & 36.1 \\
\hline 1987 & 469 & 15.8 & 7.9 & 9,910 & 33.3 & 21.0 & 8,808 & 45.4 & 34.1 \\
\hline 1988 & 448 & 13.6 & 6.0 & 10,171 & 32.3 & 20.7 & 8,555 & 46.1 & 35.2 \\
\hline 1989 & 402 & 10.8 & 6.0 & 9,442 & 29.9 & 19.5 & 7,723 & 45.0 & 34.5 \\
\hline 1990 & 409 & 12.4 & 5.9 & 8,821 & 31.7 & 21.1 & 7,195 & 44.8 & 34.7 \\
\hline 1991 & 364 & 14.0 & 5.4 & 8,002 & 29.8 & 20.0 & 6,748 & 44.5 & 33.8 \\
\hline 1992 & 350 & 11.9 & 4.4 & 7,192 & 26.8 & 17.6 & 6,323 & 41.0 & 30.7 \\
\hline 1993 & 380 & 9.6 & 3.5 & 7,245 & 24.6 & 16.2 & 6,395 & 39.4 & 30.7 \\
\hline
\end{tabular}

- $B A C=0.01+$

* BAC $=0.10+$

Taken from Traffic Safety Facts 1993 (National Highway Traffic Safety Administration, 1994b).

Data also show that males and females differ in the proportion of their fatalities involving alcohol, indicating that males' greater share of the alcohol crash fatality problem is not simply a reflection of their greater involvement in all fatal crashes. For example, 39 percent of male drivers ages 16 through 20 who died in crashes in 1993 had a positive BAC compared to 20 percent of comparably aged female driver fatalities. Among victims in the 21 to 24 age range, 58 percent of the male drivers and 34 percent of the female drivers had been drinking. Most male and female alcohol fatalities involved BAC levels of 0.10 or greater, with the percentages only slightly higher for the males (NHTSA, 1993b).

Gender disparities persist when switching from fatalities to (fatal) crash-involvement. Among drivers below age 21 involved in fatal crashes in 1993, 28 percent of the males and 13 percent of the females had alcohol in their systems. The percentages increased to 44 percent of males and 24 percent of females for the 21 through 24 age group (NHTSA, 1993b). 


\subsection{Unequal Effects of Alcohol on Crash Risk}

Youth are at a greater relative risk of a crash than older drivers at all levels of BAC (Mayhew, Beirness, Donelson, \& Simpson 1986). Even at the lower BAC levels youths have a high relative risk of an alcohol-related crash. At a BAC level of 0.05, 16- to 19-year-olds have been found to have the identical relative risk of a fatal crash as drivers age 55 and older at a BAC of 0.10 (NHTSA, 1990). This heightened risk has often been attributed to combined inexperience with both drinking and driving, though direct empirical evidence is lacking.

Studies also suggest that alcohol has an unequal impact on the crash risk of males and females. Zador (1989) found the relative risk of fatal crash involvement for young female drivers to be almost twice as high as that for young males at BACs in the 0.05-0.14 range.

\subsection{Factors Contributing to the Risk of a Crash}

Several hypotheses have been put forth in the literature as to why young drivers are overrepresented in fatal crashes involving alcohol. It has been proposed that young drivers have a special sensitivity to alcohol (Beirness \& Simpson, 1987). Another proposition is that alcohol may impair automatized skills to a lesser degree than newly acquired skills (Elander, West \& French, 1993). It has also been suggested that youthful overinvolvement in alcohol-related crashes can be attributed to the disinhibiting effects of alcohol, perhaps inducing a greater willingness to accept risk (Elander, West, \& French, 1993). Others have attributed the problem to personal and social characteristics of youth (Vegega \& Klitzner, 1988). Mayhew and his colleagues (1986) stated that the causes of the high proportions of alcohol-related crashes have not been identified. Specifically, there are still questions about "which factors (e.g., agespecific, person-specific, alcohol-specific, driving-related) contribute most to observed differences and, once the relative importance of factors has been determined, (2) how (or even if) key factors can be addressed effectively" (Mayhew et al., 1986).

\subsubsection{Personality Factors}

As mentioned earlier, the relationship between sensation seeking and risky driving has been examined in a number of studies. According to research by Zuckerman (1979), young males who are likely to engage in risky driving (including drunk driving) are often characterized by legal difficulties, poor academic performance, and high scores on the Thrill and Adventure Seeking, Disinhibition, and Boredom Susceptibility subscales of Zuckerman's Sensation Seeking Scales (Zuckerman, 1979). Arnett (1990b) similarly found that drunk driving is associated with high scores on the Boredom Susceptibility Subscale. A study conducted by Farrow (1987a), while not directly examining sensation seeking, obtained corroborating results. He found that young DWI offenders appeared to be more likely to counteract boredom by being with friends, consuming alcohol, and drinking before driving.

Farrow (1988) investigated the relationship of anger, hostility, powerlessness, and life events to impaired driving in three groups: (1) high school students without DWI convictions, (2) 16- 
to 21-year-old DWI offenders, and (3) juvenile offenders without DWI convictions. Results showed DWI offenders and delinquents endorsing assaultive behavior and feelings of hatred towards others. Overall anger/hostility scores were higher for the DWI and juvenile offender groups. There were no differences on items relating to powerlessness (internal-external locus of control) among the groups. The DWI offenders and juvenile offenders experienced more negative life events than the high school students (e.g., moving to a new home, attending a new school, losing a close friend, losing a job, etc.). DWI offenders and juvenile offenders reported more often than the nonoffender students that alcohol made them loud, unafraid, daring, and aggressive. The author argued that these personality variables are important predictors of impaired driving in the youngest drivers, as the research has shown them to be with adults.

Previous sections of this report discussed interrelationships between psychosocial characteristics and problem behaviors drawn from Problem Behavior Theory (see page 74). Klepp and Perry (1990) used environmental, behavioral, and personality factors from Problem Behavior Theory (Jessor \& Jessor, 1977) to determine predictors of impaired driving in 10th and 11th graders. Students prone to impaired driving reported more involvement in the following: intentions to drink and drive; experiences riding with an impaired driver; marijuana use; and problems with parents, friends, or school because of drinking. Moreover, students who had cars available to them, and females who felt pressure from peers to drink and drive, were more likely to drink and drive than those who did not. Those who perceived that they could safely drive after drinking were more likely to tolerate riding with an impaired driver. Finally, those who reported a lack of self-confidence in avoiding an impaired driving situation were more likely to drink and drive.

\subsubsection{Social Factors}

Peer influence has been found to be related to impaired driving (Cameron, 1982; Farrow, 1987a; Vegega \& Klitzner, 1989; DiBlasio, 1986; Klepp \& Perry, 1990) and was empirically tested in a study by Oei and Kerschbaumer (1990). Subjects were given alcohol in either one of two conditions. The two conditions differed in the attitude towards impaired driving portrayed by a confederate. In one condition, the confederate acted positively towards impaired driving and in the other condition s/he acted negatively towards impaired driving. Results showed that subjects were influenced by the confederate's position regarding impaired driving. The subjects who were in the pro-drunk driving condition were more likely to believe they could "drive better than usual after drinking alcohol." The drivers in the against condition showed less desire to be in a drunk driving situation. The subjects in the pro-drunk driving condition drove faster in a simulator as alcohol consumption increased, while drivers in the against condition remained at approximately the same speed. In the pro-drunk driving condition subjects also made significantly more errors than the against subjects. This performance was not consistent with their beliefs about driving abilities. These subjects felt that they could drive better than usual; however, this was not the case. Performance was more consistent for the against subjects; they correctly believed their driving was worse as they drank more. Thus, perception of behavior and actual performance were mismatched in the pro-drunk driving condition, whereas subjects in the against condition had perceptions that matched their true performance. 
PART III: INTERVENTIONS 


\section{INTRODUCTION/COMMON THEMES}

In Part III of this report, we provide an overview of major components of interventions aimed at behaviors addressed in Part II. There are similarities in approaches to interventions across domains of risk taking behaviors. These approaches include the following: (1) teaching about the negative consequences of risk taking behavior, (2) enhancing self-esteem and self-concept, (3) teaching communication and decision-making skills, and (4) providing opportunities for leisure-time activities. This section provides a selective overview of interventions. The goal was to present examples of different types of interventions in each domain of risky behavior. 


\section{INTERVENTIONS: SUBSTANCE USE}

Intervention/prevention programs tend to target specific unhealthy behaviors or else a cluster of risk taking behaviors. Meta-analysis ${ }^{1}$ of secondary school drug prevention programs by Tobler (1986) showed "Peer Programs" superior to other program modalities in affecting drug-specific knowledge, attitudes, substance use, and avoidance-related skills among average problem-free teens. These programs expose youth to "positive peer influences" while building competencies and skills important to resisting drugs. For adolescents exhibiting serious problems such as delinquency or substance use, the meta-analysis identified "Alternatives" programs as an effective modality for building skills and changing behavior. Here, at-risk youth undergo compensatory and other activities tailored towards their special needs. Programming is intensive, and costs can be relatively high. Tobler found remaining modalities to be largely unsuccessful in influencing substance use -- those providing information only, those providing "affective" education only (e.g., building self-esteem; clarifying values), or those which combine the preceding knowledge and affective approaches.

In a review by Hansen (1992) of 35 school-based alcohol prevention programs, the 14 that were found to be successful in lowering alcohol consumption used social influences approaches. Successful programs included some elements of normative beliefs, information, personal commitment, and resistance skills. In another review article, Hansen (1993) indicated that school-based alcohol prevention programs that employ "normative beliefs" strategies may "play a critical role in effective school-based alcohol use prevention programs." Hansen and Graham (1991) found that attacking "normative beliefs" about substance use in a school-based prevention program successfully lowered alcohol use among 7th graders. "Normative beliefs" refer to the perception of how much peers use substances. For instance, when 6th graders were asked what proportion of 6th graders drink alcohol, the average answer was about 50 percent. In fact, 20 percent was the accurate figure. The authors said that students who overestimate the proportion of their peers who drink alcohol were more likely to drink themselves in comparison to those who had accurate appraisals. A "normative beliefs" approach tries to correct students' perceptions by "debating the issues regarding the appropriateness of alcohol and other drug use." Other school-based prevention programs using a "normative beliefs" component have also been effective in reducing alcohol use among youths (MacKinnon et al., 1991; Botvin \& Botvin 1992).

Following is a limited review of selected intervention programs.

${ }^{1}$ Meta-analyses combine results from many studies to compute the strength of the relationships among variables. 


\subsection{Social Influence Models}

\subsubsection{Project Model Health}

Project Model Health (PMH) is an intensive 32-hour school-based health curriculum designed for eighth graders whose approach is based on social learning theory. From a social learning theory perspective, substance abuse is viewed as a "learned, personally and socially functional behavior."

PMH targets multiple health behaviors in the following areas: (1) nutrition - eating less salt, sugar, fat, and increasing amount of fiber and calcium in the diet; (2) sexuality - postponement of the onset of sexual intercourse or for those who are sexually active, use of birth control; (3) marijuana - students will not use marijuana, but those who are already experimenting will reduce or cease usage; (4) drinking and driving - non acceptance of rides offered by those whose ability to drive has been impaired by drinking alcohol; and (5) tobacco - avoidance or cessation of using tobacco products. The seven major strategies employed in the program are:

(1) the use of instructors who are positive, high status role models for the students, (2) focus on understanding and interpreting media messages about the targeted behaviors,

(3) practice of peer refusal skills,

(4) use of information on peer norms for the targeted health risk behaviors,

(5) emphasis on short-term effects rather than effects in some indeterminate future,

(6) use of students' public commitment to change their behavior, and

(7) students advocating healthy behaviors in their school and community.

Moberg \& Piper (1990) conducted an evaluation of the program. The experimental group was composed of 115 eighth graders who were taught by college-age "role models." Both a prior year's cohort and students from a similar untreated school were used as comparisons. The immediate post-test outcome showed inconsistent results. A 20-month follow-up produced mixed results. A clear positive program outcome was measurable only for cigarette smoking and improved food choice. There was improved knowledge regarding drug use, drinking-driving, nutrition, and sexual risk taking behaviors in the intervention group but these differences were not statistically significant. Evaluation of the program implementation showed that it was uneven across the curriculum units. The tobacco and sexuality units were successfully implemented. However, implementation of the nutrition unit was not consistent with the stated methods despite its success. The marijuana unit was brief and used a cognitive approach, while the alcohol unit focused on drinking and driving rather than on delaying the onset of drinking. The use of college-age instructors was much more labor intensive than using regular teachers in terms of recruitment, training, lesson preparation, and supervision. In terms of costeffectiveness, the curriculum may be more efficiently delivered using seasoned teachers. The concept of role modeling was also problematic. The actual role fulfilled by the instructors was that of a teacher, although a younger and more informal one. There were questions about 
whether the instructors spent enough time with the students to be "true role models." Students almost never observed the instructors' health-related behaviors.

\subsubsection{Project ALERT}

Project ALERT, also based on a social-influences model, is a school-based prevention program designed for the seventh and eighth grades which targets cigarette, alcohol, and marijuana use. It uses question and answer techniques, small group exercises, role modeling, and repeated skills practice. Students receive eight lessons during grade 7 and three booster lessons in grade 8 . The program is designed to build the motivation and skills needed for effective resistance to pressure to use drugs. The program focuses on "pressures from inside yourself," as well as external pressures.

Ellickson and Bell (1990) evaluated Project ALERT in middle schools located in California and Oregon. The schools were situated in communities reflecting diverse socioeconomic status and racial and ethnic composition. They were assigned to either a control group or two experimental groups. In one experimental group, the program was taught by an adult health educator, while in the other, it was taught by an adult health educator and a "teen leader" from a local high school.

After initiation of the program, a modest but short-lived reduction in alcohol use was found for those who were categorized at baseline as either nonusers, experimenters, or habitual users. For nonusers, the measure of success was not reduction in use per se but initiation and subsequent use in comparison to the control group.

Significant reductions in cigarette use were seen for baseline experimenters, with the program stimulating some subjects to quit. These results tended to emerge after the booster sessions in the eighth grade. Yet while reductions among baseline experiments were sustained over a period of time, the program failed to reduce smoking among those who were regularly smoking at the start of the program, and even showed a counter-productive "boomerang" effect for them. Specifically, at 12 months, baseline users' smoking increased by 20 percent and increased to almost 30 percent after exposure to the booster sessions. This "boomerang" effect is similar to that seen in other programs that have an integrated alcohol-and-other-drugs prevention curricula (Bagnall, 1990).

For nonusers of cigarettes or marijuana at baseline, initiation of marijuana use was lower by 30 percent and current use was lower by approximately 60 percent in comparison to controls. For experimenters and users, there also was a lesser use of marijuana. However, the differences were not statistically significant.

The use of teen leaders in addition to health educators did not result in greater reductions of use. However, the booster sessions were a particularly effective means of reducing use. The authors believed that providing booster sessions during the junior and senior high school years when 
students are exposed to a broader peer group and increased drug use by friends may help maintain early prevention effects.

\subsection{Skills Training Models}

These approaches contain components of the social-influences model as well as emphasize acquiring generic personal and social skills (Botvin \& Botvin, 1992). The programs usually include two or more types of skills training. The focus is on building skills for resisting negative social influences, increasing self-control and self-esteem, reducing stress and anxiety, and enhancing interpersonal and assertive skills. Skills are taught using a combination of instruction, demonstration, feedback, reinforcement, and exercises. The goal of these programs is to teach skills that have broad application. However, specific programs aimed at reducing substance use/abuse utilize this approach (Botvin \& Botvin, 1992).

\subsubsection{Life Skills Training Program (LST)}

The Life Skills Training Program (LST), which uses a cognitive-behavioral skills training approach to drug abuse prevention, was implemented in seventh grade classes in New York State. Botvin et al. (1990) reported significant prevention effects for cigarette smoking as early as the first two years of the study, while prevention effects in marijuana use and immoderate alcohol use were noted at the end of the third year. Positive changes were also found in normative expectations and knowledge concerning substance use, as well as enhanced interpersonal skills and communication skills. Previous studies that tested the efficacy of this intervention found that the program was implemented with varying degrees of completeness, and that program effects were stronger among those individuals receiving a more complete implementation of the prevention program. The authors recommended focusing future research on strategies for increasing completion of the program. One suggestion was to produce training videos for teachers which would provide more tools for implementing the program. This may result in higher implementation rates (Botvin et al., 1990).

\subsection{School-Based Programs}

Flynn et al. (1992) conducted a longitudinal study that compared two similar school-based antismoking programs, one of which was supplemented by a mass media intervention. The study was conducted in the Northeastern United States and in Montana. Results showed the school and media program superior to the school-only program, with a relative difference ranging from 34 percent to 41 percent for different measures. For example, in the fifth year, the school and media group reported smoking an average of 2.6 cigarettes per week compared with 4.4 cigarettes per week for the school-only group, a relative difference of 41 percent. Measurement of non-targeted risk taking behaviors such as smokeless tobacco use and alcohol use showed no program effects. The authors concluded that this school-based educational program was more effective, and sustained its impact longer, when it was supported by mass media (Flynn et al., 1992). 
Project DARE (Drug Abuse Resistance Education), a school-based program, was created in 1983 by the Los Angeles Police Department and the Los Angeles Unified School District. It is used now by approximately 50 percent of local school districts nationally. Taught by law enforcement officers, Project Dare was originally produced for elementary schools, but recently expanded to junior and senior high schools (Ennett, Tobler, Ringwalt, \& Flewelling, 1994).

Project DARE's core curriculum includes 17 one-hour lessons. The focus of the program is on teaching pupils the skills needed to "recognize and resist social pressures to use drugs." The elements of the program include providing information about drugs, teaching decision-making skills, building self-esteem, and choosing healthy alternatives to drug use. A variety of teaching strategies are used, such as lectures, group discussions, question and answer sessions, audiovisual material, workbook exercises, and role-playing. Law enforcement officers receive 80 hours of instruction before leading the program.

Ennet and her colleagues (1994) performed a meta-analysis evaluating the short-term effects of project DARE in elementary schools. Results showed that DARE's core curriculum effect on drug use (compared to control schools) was minimal. The authors offered several reasons for the small effect size: (1) low usage of drugs in elementary school, (2) the effects of the program may be delayed, (3) combining the use of interactive and noninteractive techniques may have diluted the effectiveness of the program (interactive techniques have been shown to be more effective than noninteractives ones), and (4) use of law enforcement officers to teach the program rather than teachers who have more training.

\subsection{Communications and Mass Media Based Programs}

Schilling and McAlister (1990) reviewed the strengths and weaknesses of mass media interventions designed to prevent substance use by adolescents. Two of the strengths discussed were cost and family access. Unlike other intervention strategies, the cost per receiver is relatively low. The authors also stated that watching TV is one of the few remaining family activities. Prevention messages have the potential of stimulating family discussions.

One of the weaknesses of mass media interventions is that there is little evidence showing that mass media has effects on behavior over a long period of time. Another is that several features of mass media campaigns have not been evaluated. The authors perceived major benefits to rigorous evaluation of messages during development, with the research results disseminated to assist in the development of effective communications. They also concluded that mass media interventions should not be viewed as a main prevention strategy. However, mass media can reinforce other types of prevention strategies. It can effectively target high-risk groups who may not be accessible through other types of interventions. The authors also recommended applying principles of social learning theory and cognition to mass media campaigns. 


\subsubsection{Public Service Announcements (PSAs)}

The majority of drug prevention messages on the airwaves are public service announcements (PSAs) which are typically 30 seconds or less (Schilling \& McAlister, 1990). Most PSAs use principles of product marketing, which may not be applicable to substance use prevention. Schilling and McAlister (1990) stated that, "The series of perceptual, cognitive, and behavioral events that lead from product awareness to purchase is quite different from, and probably less complex than, the steps involved in drug exposure, experimentation, and habituation" (p. 418).

An example of how to develop messages is provided by The Centers for Disease Control (CDC), which sponsors PSAs aimed at preventing youths from smoking and at motivating those who are experimenting with cigarettes to stop smoking (McKenna \& Williams, 1993). In 1991, as the first step in planning a new mass media campaign, CDC's Office of Smoking and Health (OSH) conducted focus groups across the country. The goal of the focus groups was to determine adolescents' knowledge and attitudes towards smoking, to investigate adolescents' insights into their own smoking, and to evaluate specific messages. The findings revealed that adolescents had an indepth knowledge of the negative consequences of smoking. The participants tended to see issues as "black or white." Also, they believed their experiences or those of their friends or family members to be the "truth." Participants preferred messages that were factual, informative, and nonjudgmental. In May of 1992, OSH conducted interviews with adolescents to test a TV spot and print ads. The theme of industry manipulation was used in the messages. Results showed that the materials did not effectively communicate the intended message to the target audience. The authors concluded that there is great value in testing health communication messages before they are produced and widely distributed. 


\section{INTERVENTIONS: RISKY ADOLESCENT SEXUAL BEHAVIOR}

Sexual risk taking is one of the costliest risk taking behaviors among adolescents (Kirby 1991). To be successful, intervention programs should consider the situations in which adolescent sex takes place and be attentive to the influence of family, peers, and schools, as well as cultural influences (Brooks-Gunn \& Paikoff, 1993). Intervention programs include: school-based clinics, school-based curricula, and community-wide/multicomponent programs (Dryfoos, 1990). One objective of intervention is pregnancy prevention. Dryfoos (1990) notes that the objectives of a good pregnancy prevention program should be to promote responsible decision-making, to increase contraception use, and to prevent unwanted pregnancy. In addition, pregnancy prevention programs should begin early (no later than middle school), and provide comprehensive, multicomponent services including school, community, and parental input.

\subsection{School-Based Curricula}

School-based curricula involving sex education courses provide youths with information on reproduction, sexuality, and contraception. It is estimated that 94 percent of sex education courses teach rational and informed decision making, while 74 percent focus on information and reproduction (Katchadourian 1990). Sex education courses tend to be short and are usually integrated into other classes such as health or physical education (Katchadourian 1990). However, research on the impact of sex education courses has found mixed results. Dryfoos (1990) cites evidence reported by Kirby (1984) finding no change in contraceptive use or the rate of pregnancy following sex education. Katchadourian, on the other hand (1990), cites evidence from Furstenberg and Brooks-Gunn (1985) and Zelnick and Kim (1982) reporting that among sexually active teens, sex education is related to lower pregnancy rates.

\subsubsection{Reducing the Risk}

Kirby et al. (1991), examined a risk-reduction program entitled "Reducing the Risk" (RTR). RTR is a sex education program based on social learning theory, social inoculation theory, and cognitive-behavioral theory. The emphasis of the program is on the avoidance of unprotected sex through either abstinence or contraception. RTR attempts as well to facilitate parent-child discussions of both abstinence and birth control.

The RTR program was implemented in 13 urban and rural California high school classrooms. Students in the RTR classes were compared with general health education classes on three separate occasions: when the study began; 6 months after completion; and again 18 months after the program's completion. An increase in contraceptive knowledge was found among both groups of students. However, RTR students had an 18 percent increase in knowledge as compared with a 9 percent increase in the health education group. There was no significant difference in the rate of pregnancy between the two groups. When comparing students who had never had intercourse, RTR students were less likely than the comparison group to initiate sexual 
intercourse. No differences were found in the intention to avoid unprotected coitus or in contraception use overall. However, among students who had not had sex at pretest, differences in social activity and contraceptive use were found. Eighteen months after the study's completion, only 13 percent of the RTR subgroup had engaged in unprotected coitus as compared with 23 percent of the comparison subgroup. The RTR curriculum was also reported to be effective in fostering parent-child discussion on birth control and abstinence. The program was not, however, successful at fostering communication on related topics such as pregnancy and STDs.

\subsubsection{Postponing Sexual Involvement}

Postponing Sexual Involvement, developed at the Grady Memorial Hospital in Atlanta, GA, is an intervention program stressing abstinence as opposed to increasing sexual knowledge (Whitehead, 1994). This program stresses societal norms and teaches teens to resist pressures to have sex. The program is taught by older, popular teens and involves role playing aimed at reinforcing socially desirable behaviors. However, this is more directive or structured roleplaying than the traditional kind, as each skit must end in a rebuff of some sort of sexual advance.

The program was reported to be useful in helping adolescents postpone sexual activity. By the end of the ninth grade, 24 percent of the program participants had engaged in sex, as compared with $39 \%$ of the non-program youths. Additionally, of the program participants who later had sex, one-half had protected intercourse as compared with one-third of the non-program participants.

\subsubsection{Family-Life Education}

In 1980, New Jersey issued a state-wide mandate for "family-life education" calling for a comprehensive sex education program (Whitehead, 1994). The family-life program provides adolescents with knowledge about sex and reproduction as well as training in decision making skills and self- esteem. By teaching children about sex at an early age, program planners hoped that they would become more comfortable with the terminology and be able to discuss sex openly with adults and each other. The idea is that if children understand the concepts of sex at an early age, as adolescents, they will be well-prepared to deal with sex responsibly.

Programs such as this one have received a good deal of support from sex education advocates. Unfortunately, results on the New Jersey program are not yet available, although results from programs designed to increase knowledge have generally been successful in meeting this objective (Whitehead, 1994). However, although such programs have been successful in educating youths about sex, this increased knowledge has not translated into a reduction of risk taking behavior (Whitehead, 1994). In fact, there is little evidence supporting the idea that knowledge and communication about sex will have the desired effect of changing risk taking behavior as was hoped (Whitehead, 1994). 


\subsection{School-Based Clinics}

The objective of school-based clinics is to provide adolescents with both primary and preventive health services. Preliminary evaluations of school-based clinics demonstrate these clinics are widely used by adolescents and for a variety of health-related reasons (Dryfoos, 1990). Additionally, examination of several school-based clinics has found a decrease in birth rates (Dryfoos, 1990).

Zabin et al. (1986) conducted a pregnancy prevention program for inner-city adolescent teens. The program was designed to provide both education and intervention with adolescents. The program's design was based on the authors' previous research which found that adolescents are at a high risk of pregnancy during the first few months after first intercourse, and when sexual intercourse was initiated in early adolescence. Research also indicates adolescents tend to delay visiting a clinic by more than 16 months after first coitus. Adolescents report a desire for facilities which are confidential and convenient to their usual hang-outs.

One junior and one senior high participated in the study. A facility providing both educational and medical services was opened exclusively for these students. The clinic was located adjacent to one school and within a few blocks of the other. Students were predominantly black innercity youths, many from low income, single-parent homes. The program took place over two years, during which time measures of sexual knowledge, attitudes, and behavior were taken. To encourage participation in the program, both classroom and group discussions were used.

Baseline measures indicate many youths were sexually active when the program began. Nearly 13.3 percent of the sexually active junior high school girls and 21.1 percent of the sexually active senior high girls reported having had at least one pregnancy when the study began. Contraception use among the sample was also high, with 90 percent of the senior high students reporting past contraception use, although not on a regular basis. However, knowledge about specific contraceptive methods was quite low, especially among junior high school students. Junior high school students were also less likely to have visited a clinic at the outset of the program.

By the end of the program's second year, 40.8 percent of the sexually active junior high, and 57.6 percent of the sexually active senior high school girls had registered with the clinic. The program was effective in improving teens' knowledge of contraception, as well as their understanding of the risks of pregnancy. Additionally, recognition of teen pregnancy as a problem increased among all girls, especially among those in junior high school. There was an increase in the perception that contraception is the responsibility of both partners, with junior high students again showing the most change. The use of contraceptives also increased, with reported use at last intercourse increasing among all students. Between the beginning and the end of the program, there was an increase of almost 61 percent in the use of medical methods of contraception among junior high girls and an increase of 34 percent among senior high girls. The program was also effective in reducing the time interval between first coitus and the first clinic visit among girls, a factor important in reducing pregnancy. The number of sexually 
active girls who visited the clinic for the first time also increased. The program was not, however, found to affect the proportion of youths attending the clinic pre-coitus. The authors suggested this may be attributable to the high incidence of sexual activity at the program's start. The authors further noted that it was difficult to evaluate the program's effectiveness at reducing pregnancy rates because of the inability to gain accurate reporting of abortion and the limited program length.

Kirby (1991) examined six school-based clinics in order to evaluate their effectiveness in pregnancy prevention. The clinics were located in different parts of the country, in both rural and urban areas, and served mainly minorities. Each clinic was located on the campus of the school and provided primary health care to the students. However, clinics differed in their philosophies, staffing, budgets, services provided, and characteristics of their student body.

The results of the study indicated the clinics were perceived favorably and were widely used by students of all backgrounds. Over the course of a year, four of the clinics reported between 60 percent to 80 percent of the students as using the clinic. At the remaining two sites, approximately one- quarter of the students were reported to have used the clinic. Variations in clinic use were partially a function of clinic size, staff size, and length of existence.

The clinics did not affect the initiation or the frequency of sexual intercourse. The rate of pregnancy was also not found to decrease. Additionally, schools with clinics were not found to have a lower incidence of unprotected sex when compared with other schools or with the same schools two years later.

\subsection{Community-Based/Multicomponent}

In an examination of multicomponent/multicommunity pregnancy prevention programs, Dryfoos (1990) summarized the results of a program based in rural South Carolina called the School/Community Program for Sexual Risk Reduction among Teens. The objectives of the program were to delay the start of sexual intercourse; to promote contraception use; to teach decision making skills; as well as to increase interpersonal communication, knowledge, and selfesteem. The program was implemented in grades $\mathrm{K}$ through 10 and integrated into classes such as biology, science, and social studies. In preparation, teachers were provided with graduate level courses and training in sex education. Parents, clergy, and church leaders were also invited to attend mini-courses designed to increase knowledge. The program utilized media and community awareness, and sponsored activities such as the National Family Sexuality Week. The results of the program were positive. During the period from 1981 to 1985 , the rate of pregnancy among 14- to 17-year-olds decreased from 61 to 25 per 1,000. In neighboring areas during the same time period, pregnancy rates rose from approximately 35 to 50 per 1000 . The program's success was attributed to parental and community involvement, as well as the availability of professional staff. 


\section{INTERVENTIONS: RISKY DRIVING}

\subsection{Overview of Countermeasures}

This section provides an overview of major findings and opinion concerning interventions related to driving, based on review of key sources and expert contacts. The intent is to identify important issues to consider in developing state-of-the-art countermeasures.

\subsubsection{Graduated Licensing}

The purpose of a graduated licensing system is to gradually integrate novice drivers into the traffic environment in a manner that enables them to gain knowledge, skill, and experience over a period of time under controlled conditions (American Association of Motor Vehicle Administrators and NHTSA, 1995). The system divides the licensing process into a series of discrete stages, with the final stage being the issuance of a regular state operating permit. Novice operators must spend a minimum amount of time in all stages preceding acquisition of the regular license. They also are required to adhere to stipulations attached to each stage intended to reduce risk and prevent injury. Young novices progress from one stage to the next by demonstrating responsible driving behavior and being crash and conviction free. Strictures attached to the stages become less limiting as drivers advance in the system. Thus novices "graduate" to progressively more difficult experiences after practicing, and mastering, driving skills under less demanding conditions.

Graduated licensing systems impose requirements for novice operators that can be protective, motivational, and/or educational. Protective components in a multi-staged system may include night-time driving restrictions, lower legal blood alcohol concentration (BAC) limits, requirements for adult supervision when driving, mandatory use of safety restraints by all vehicle occupants, and limits on the number of passengers in the vehicle. Motivational components for safe driving revolve around making acquisition of the regular drivers license contingent on demonstrated safe driving performance (e.g., crash-and conviction free record). As one of the more prized possessions for youth, the regular operators permit is a powerful "carrot" to influence behavior. Penalties for unsafe driving that delay full licensure provide strong incentive for responsible driving. Additional positive motivation may come from learners and provisional driving permits that are distinctive in appearance from the regular license. Lastly, the system may seek to better prepare the novice operator through expanded educational components.

The NHTSA and the American Association of Motor Vehicle Administrators (AAMVA) have jointly proposed a model graduated licensing system comprised of three licensing stages: a learning period under total supervision, an intermediary or provisional period, and full licensing (American Association of Motor Vehicle Administrators and NHTSA, 1995). Under the model system, novices first obtain a learners permit after passing a rules-of-the-road test and vision screening test. Provisions attached to the learners permit require that: 
- A licensed adult (at least 21 years of age) be in the vehicle at all times;

- All occupants of the vehicle use safety belts;

- The applicant remain crash and conviction free for at least six months;

- The permit be cancelled if the applicant is convicted of any alcohol-related offense, with a mandatory minimum six-month waiting period (or age 18, whichever is later) prior to reapplication for another permit; and

- The permit be distinctly different in appearance from the provisional and regular license.

Drivers graduate to the next step in the model licensing system by satisfactorily completing the learners permit stage, passing a road test, and meeting a minimum age requirement of 16 years. Youth entering this intermediary stage receive a provisional license that is governed by another set of requirements. Recommended requirements attached to vehicle operation with a provisional license are:

- Supervision by a licensed adult, who is at least 21 years of age, during night-time hours;

- Use of safety belts by all occupants of the vehicle;

- Crash- and conviction-free record by the applicant for at least twelve consecutive months;

- Initiation of driver improvement actions at a lower level than for regular drivers;

- Revocation of the provisional license for a minimum of six months or until the applicant reaches age 21, whichever is longer, if the applicant is convicted of any alcohol-related offense; and

- A provisional license distinctly different in appearance from the learners permit and regular license.

To date, no state has implemented a graduated licensing system containing all the components recommended by the NHTSA and the AAMVA. However, partial systems have been implemented and found to be effective. For example, Maryland requires a provisional licensing stage for minors under which provisional licensees are prohibited from driving during specified nighttime hours (presently 12:00 midnight until 6:00 a.m.) unless accompanied by an adult, and must maintain a violation-free record to become eligible for a regular license. Evaluation of the Maryland system showed a coinciding reduction in both crashes and traffic convictions. The fact that the decrease in crashes occurred principally during daytime hours suggested that the requirement for a violation-free record motivated provisional licensees to drive more safely (American Association of Motor Vehicle Administrators and NHTSA, 1995; McKnight, Hyle, \& Albrecht, 1983). It bears noting that the curfew at the time of the Maryland evaluation was 
1:00 a.m. to 6:00 a.m. Data from various states suggests some beneficial effects from a curfew as long as it is not confined to early morning hours when young persons would not be driving anyway (McKnight, 1989).

Other support for graduated licensing systems comes from evaluation of programs in Oregon and California. Components of the Oregon Provisional Licensing Program include expanded driver knowledge testing, zero tolerance of alcohol, suspension for major traffic violations, and a driver improvement program that takes progressively more severe action in response to additional traffic violations by the novice operator. Assessment of the provisional program provided evidence that it was effective in reducing crash rates among 16 and 17 year old male drivers. California's graduated licensing program includes a minimum period for holding an instruction permit, a parent/adult participation component, special reading materials for adolescents, and mandatory adult supervision for one month after a second traffic violation. Initial results suggested that the program prevented what otherwise would have been an increase in fatal and injury crash rates among 15 to 17 year old drivers. Subsequent analysis linked the licensing program to a five percent reduction in crash rates for that age group (American Association of Motor Vehicle Administrators and NHTSA, 1995).

\subsubsection{Other Licensing Issues}

Not allowing youngsters to get any license until they are older (e.g., 18 years of age) is an easy, but probably unacceptable, solution to young driver crashes. However, as indicated above, states can establish learner and provisional requirements that effectively delay full licensure until some maturation in driving experience has occurred.

In a study addressing adolescent licensing issues, Preusser (1988) collected survey data from high school students in seven states that differed in age and other requirements for full licensure. He found that "summed across all students, licensed and unlicensed . . . . students from those states where teenagers typically get licensed at an early age reported more driving, risky driving, crashes, and violations than students in states that didn't typically license until the teenager was somewhat older." Preusser concluded that delayed licensure can be a potent highway safety countermeasure for adolescent drivers.

Another licensing issue concerns the use of license suspensions as a motivator to encourage safe driving. Jones and Lacey (1991) examined the effectiveness of such sanctions in their review of literature on countermeasures for alcohol-impaired driving. Although the studies were not restricted to youth their overall findings are worth noting. In general, the authors found imposition of license sanctions for alcohol violations to be effective in reducing crashes, DWI (driving while intoxicated) convictions, and other traffic violations.

\subsubsection{Driver Education}

The premise that instruction aids the acquisition of driving skills dates to the early age of the automobile (Smith, 1994). The first documented novice driver education program appeared in 
1916. By the 1930's, driver education was beginning to be taught in high schools, and colleges began preparing teachers in traffic safety. A generally accepted standard for the apportionment of instruction did not emerge until the late 1940s. At that time, the first National Conference on High School Driver Education recommended that courses consist of 30 hours of classroom instruction and another 6 hours of instruction behind-the-wheel. Many current driver education programs continue to follow this formula today.

The popularity of driver education increased dramatically during the 1950s and 1960s as it was widely promoted as a means for teaching driving skills, spurred by positive results obtained in several evaluation studies. Further motivation for receiving driver education derived from discounts that insurance companies began offering to drivers who had completed a training program. Enrollment in driver education grew to more than 2 million teenagers per year (about 70 percent of those eligible) during the late 1960s and early 1970s.

This expansion did not occur without growing pains. The rapid rise in demand for driver education exceeded the availability of trained instructors. As a result, teachers from other disciplines were "borrowed" to teach driver education part time, often after receiving little to no relevant training. This potentially affected the quality of instruction, and made driver education seem less important than other parts of the school curriculum. With this general lack of stature, there was little impetus on improving driver education by the schools.

Re-examination of earlier evaluation studies of driver education called into question their findings of program effectiveness. Serious flaws in methodological design were uncovered, raising the specter that crash reductions formerly ascribed to driver education could alternatively have been caused by other factors. Thus by the close of the 1960s, the effectiveness of driver education as a crash reduction countermeasure was largely unknown despite its wide-scale popularity.

Beginning in the late 1960s, NHTSA initiated a program to develop and evaluate a performancebased driver education curriculum. The objectives were to document that a quality high school driver education (HSDE) program could significantly reduce crash involvement among persons exposed to it, and to stimulate improvements in existing HSDE programs.

The project began with the identification of behaviors necessary to operate a passenger vehicle, plus an assessment of how critical each of the behaviors is to driving (McKnight \& Adams, 1970). Task descriptions generated from this analysis were used to develop instructional objectives. This was followed by development of curriculum specifications, and development of the curriculum and performance measures (NHTSA, 1975).

A demonstration evaluation was initiated in the DeKalb County (Georgia) public school system in September 1976. Students were randomly assigned to the Safe Performance Curriculum (SPC); to an abbreviated curriculum, Pre-Driver Licensing (PDL); or to a control group given no formal driver education in the secondary school. By the end of March 1981, more than 16,000 students had been assigned to one of the three groups. 
The SPC provided approximately 80 hours of training using classroom instruction, simulation, range and on-street practice, independent study, and parent participation. The curriculum addressed vehicle control skills, environmental factors, complex perceptual skills, driver impairments, emergency situations, and personal readiness. The PDL had approximately 30 hours of instruction and was a condensed version of the SPC. Instructors were highly trained and taught both versions to minimize instructor influence.

Results were disappointing. During the initial evaluation, no substantial impact on crashes and convictions was discerned for those students assigned to training after the first two years of driving. Although some positive effects from training were found for the six-month period following driver licensing, the effect quickly diminished over time (Stock, et al., 1983). One problem with the evaluation was that the majority of students had minimal driving experience, in many cases less than a year. A follow-up evaluation of the demonstration project, using up to six years of driving experience, showed no significant impact on crashes from the SPC but a small significant reduction in crashes among the PDL students as compared to the control group (Smith, 1994).

The percentage of eligible adolescents receiving high school driver education has declined since the peak years of a quarter century ago, though exact numbers are not available. Today, fewer than half the teenagers may be receiving some type of formal high school driver education training (Smith, 1994). A confluence of factors is probably responsible. For example, the large level of financial support provided high school driver education by states during its boom years could not be maintained in many jurisdictions when reductions occurred from governmental funding sources. Also proponents of driver education lacked a strong empirical foundation upon which to base their arguments.

There remains a sense that novice driver education can be effective in reducing crashes involving youth. Determining how best to instruct novice operators is a complex task. Presently, the NHTSA is initiating efforts to develop an improved driver education program that is an integral part of a graduated licensing system. The strategy is to divide driver education into two phases linked to the stages of graduated licensing. The first phase consists of instruction in basic handling skills to be administered during the learners permit stage. The second phase in the educational process is to improve decision making to reduce risk taking. This phase will be administered during the restricted license stage.

\subsubsection{Use of Media}

Interviews with experts conducted for the Pennsylvania Department of Transportation (Pennsylvania Transportation Institute, 1992) addressed mass media approaches to presenting driver safety information. Television was thought to be the best medium for conveying messages to youths. The experts believed that TV spots should be visually stimulating and "shocking." Other methods of delivering messages on TV were talk shows and special programs. Radio public service announcements (PSAs) were thought to be a less effective means for communicating with young people. The experts also mentioned newspapers, which 
may be more effective in rural areas. Other public awareness methods mentioned were short films, school-related programs, pamphlets, handouts, comic books, posters, and roadside billboards. The experts argued that the most effective public locations to use for communicating with young drivers are schools, movie theaters, and shopping malls. Unfortunately, the experts concluded that it is very difficult to measure the effectiveness of these kinds of countermeasures.

Evans (1991) suggested that media have a potential for facilitating profound changes in behavior. He cited a dramatic example of how media influenced normative changes in thinking about traffic safety. In Japan, a young mother transporting her young children to school on a twowheeled vehicle was hit by a truck and all three were killed. The crash received wide media attention and as a result there were changes in truck design, and changes in safety awareness of the general public.

Atkin (1989) argued that there is little empirical evidence on the effects of TV on risky driving by adolescents, but "there's ample basis for speculation." After reviewing theories of socialization, performing content analysis on ads, and analyzing audience response data, he concluded:

... the socializing influence of this powerful medium is rather modest in magnitude and mixed in directionality: alcohol commercials seem to slightly increase the incidence of drunk driving, certain fictional role modeling portrayals stimulate drunk driving intervention intentions while other entertainment depictions apparently teach reckless driving patterns, and the incidental safety belt usage increasingly depicted in programs and ads probably promotes buckling to a limited degree. At this point, however, any conclusions remain tentative pending the implementation of a systematic research program to explore and chart the dimensions of television's impact in the important domain of risky driving (Atkin, 1989, p. 11).

\subsubsection{Summary}

Over the years educators, policy makers, traffic safety experts, and researchers have made numerous suggestions on how to improve current driver education programs. Among the findings and recommendations of the experts interviewed for the Pennsylvania Department of Transportation were: (1) there is little consensus on the approach of driver safety programs; (2) the aim of driver education should be to prepare drivers mentally and physically to handle driving; (3) driver education should also raise the awareness of drivers to laws and other drivers; (4) local campaigns using local spokespersons tend to be the most successful in raising awareness; (5) parents should be encouraged to promote safe driving to their children; and (6) driving safety messages should also be targeted to the pre-driving group. Others have suggested that driver education include training in hazard perception, extensive practice with simulators (including recent proposals for virtual reality simulations), more on-the-road practice, and finally, more coordination between educational and administrative components of government. 


\subsection{DRINKING AND DRIVING}

Many types of countermeasures exist to combat drunk driving. Several are described below.

\subsubsection{Minimum Drinking Age Laws}

Perhaps the most rigorously studied countermeasure employed to deter youth drinking and driving has been the minimum drinking age (MDA) laws. The General Accounting Office (U. S. General Accounting Office, 1987) reviewed existing evaluations of drinking age laws to determine the extent to which they provided empirical support for federal and state initiatives to change the legal drinking age. The analysis indicated that "raising the drinking age has a direct effect on reducing alcohol-related traffic crashes among youths affected by the laws, on average, across the states." The GAO also found that raising the purchase age reduced alcohol consumption and the incidence of driving after drinking by the age groups affected, although caution was advised in generalizing these findings because of limitations in quantity and quality of studies showing these outcomes ( U.S. General Accounting Office, 1987). Efforts have been made to quantify the impact of the drinking age laws. The Transportation Systems Center (Skinner \& Hoxie, 1989) determined that the average effect of raising the minimum drinking age from 18 to 21 in any state during the 1975-1987 time period was a 10.3 percent reduction in fatalities involving 18- to 20-year-old drivers. The average effect of a one or two year change was proportionately less. No evidence was found that raising the minimum drinking age postponed fatalities, as the fatality rate among persons ages 21 to 23 did not increase when the members of this age group had no legal experience consuming alcohol before age 21 (Skinner \& Hoxie, 1989). Based on analysis of 1975-1986 data for thirteen states, a NHTSA report concluded that minimum drinking age laws were responsible for a 12 percent reduction in fatal crash involvements. This report updated an earlier NHTSA analysis that had found a 13 percent reduction in fatal crash involvements among affected drivers (Womble, 1989).

"Sting" programs to enforce MDA laws have been aimed at vendors in a number of communities. In Denver, police cadets younger than twenty-one years of age were sent into 88 stores to buy beer. They were successful on 59 percent of their attempts. Following the "sting" operation a press conference was held to publicize the effort to reduce sales of alcohol to minors. The "sting" operation was also covered by the media. Beer outlets in Denver were sent letters. Those who sold beer to the cadets were sent a warning letter indicating that they would be prosecuted the next time. Those who did not sell beer to the cadets were sent a letter of thank you and told that they might be visited again by an underage cadet. The same stores were visited again. This time only 32 percent of the stores sold alcohol to the underage cadets. Those businesses who had sold beer to the cadets on both occasions had their licenses suspended. On the third "sting" operation another sample of stores was visited. At this time the rate was reduced to 26 percent (Insurance Institute for Highway Safety, 1992). 


\subsubsection{Lowering Blood Alcohol Concentration (BAC) limits.}

Recent data illustrate that lowering the BAC limit for younger drivers contributes to a reduction in crashes (Hingson, Heeren, \& Winter, 1994; Kedjidjian, 1993). Hingson and his colleagues (1994) compared single-vehicle nighttime crash rates between states that had, and had not, lowered the BAC limit for youth below the limit for adults. Single-vehicle nighttime crashes were used as an outcome measure because, according to Hingson and his colleagues (1994), this type of crash for youths tends to involve alcohol. Results showed that, for the age range targeted by such laws, there was a reduction in single-vehicle nighttime crashes. The rate declined 16 percent in the states in which the BAC limit was lowered compared to an increase of 1 percent for that age range in comparison states where it was not lowered. Additional analyses showed that states with the lowest BAC limit had the greatest reduction in single-vehicle nighttime crashes for young drivers. For instance, states with a .00 limit for youth had a 22 percent reduction in single-vehicle crashes at night, while there was a 2 percent decline in comparison states. In states with a $.02 \mathrm{BAC}$ limit for youth, there was a 17 percent decline in single-vehicle crashes at night, while the rate increased 4 percent in comparison states. Although states in which the BAC limit was .04 to .06 showed a reduction of single-vehicle crashes at night, the decrease was statistically nonsignificant.

Blomberg (1992) detected enhanced safety benefits from lowered BAC limits when they were accompanied by public information and education (PI\&E) emphasizing the penalties for violating the law. Maryland enacted a 0.02 BAC sanction for youth in July 1988, with the restriction going into effect the following January. Analyses showed the sanction to be associated with a statewide reduction of crash-involved drivers under age 21 judged by police to have been drinking (HBD). As part of the study, a PI\&E campaign related to the law was implemented in six Maryland counties during early 1990. The PI\&E consisted of radio and tv public service announcements that utilized local police officials as spokespersons, plus pamphlets and posters supporting the broadcast media. The primary theme of the campaign was that if you are under 21, you will be fined or your license will be suspended if you are caught driving after having as little as one drink. Blomberg found that the campaign corresponded with an additional step reduction in the numbers of crash-involved under $21 \mathrm{HBD}$ drivers in the six PI\&E counties.

\subsubsection{Enforcement of DWI Laws}

Enforcement of DWI laws is an important countermeasure employed to combat impaired driving. However, data show youth being arrested for DWI less frequently than would be expected based on their incidence in alcohol-related crashes. Police, prosecutors, and others participating in a NHTSA study identified several obstacles to enforcing DWI laws among youth that were thought to contribute to the low arrest rates (Preusser, Ulmer, and Preusser, 1992). Prominent among these were obstacles related to differences between youth and older drivers in drinking and driving practices, with current enforcement methods geared more to adult behavior. For example, police typically monitor for DWI by patrolling along roadways leading to bars and other traditional drinking establishments. Yet youthful drinking tends not to occur at these places because of laws proscribing alcohol consumption by persons under age 21. Instead, youth 
tend to drink in parks, beaches, and private homes; away from where DWI enforcement resources usually are deployed. Youthful impaired driving also is more concentrated in time than is impaired driving by older drivers (clustering at $10 \mathrm{pm}$ to 1 or $2 \mathrm{am}$ on Friday and Saturday evenings). This affects the chances of detecting and arresting DWIs as the time frame during which police are likely to encounter youthful DWIs is narrowed, while other factors (e.g., competing demands; off road time for processing DWI arrests) limit DWI patrol time during the high risk periods. Large congregations of drinking youths such as occurs at keg parties present further challenges to police in enforcing alcohol laws. Often only one or two officers are available to respond, and the drinkers may scatter when they arrive.

Other enforcement obstacles revolve around uncertainties over the relationship between behavior and impairment among youth. Behavioral cues for detecting DWI are well established for the adult population. However, differences in impaired driving behavior between youth and older motorists make the traditionally used cues problematic for younger drivers. Police described youthful impaired driving behavior as more "erratic . . . impulsive . . . aggressive" compared to older adults. These terms may also apply to youthful driving in general. With the effects of impairment on youthful driving behavior not yet well understood, youth-specific detection cues for identifying impaired driving have yet to be firmly established and accepted within the DWI processing system. Thus observed erratic behavior by youth may not invoke probable cause for a DWI investigation; the system lacking validated methods to distinguish impaired driving by youth from their driving behavior in general (Preusser, Ulmer, \& Preusser, 1992).

Additionally, there may be disincentives in the DWI processing system for pursuing charges against persons with BAC levels typical of younger drinking drivers. Youth who drink and drive tend to do so at lower BACs compared to older drivers. Yet jurisdictional policies or messages sent by the judicial system may discourage prosecution at the relatively low BACs they exhibit (Preusser, Ulmer, \& Preusser, 1992).

Discussions with law enforcement personnel in states showing the highest DWI arrest rates for youth suggested "essential characteristics" for successful enforcement programs. These included command support for proactive DWI enforcement, training for officers, procedures to limit processing burdens, and educational outreach to the community (Preusser, Ulmer, \& Preusser, 1992).

\subsubsection{Developing Planning Strategies}

The importance of prior planning in averting drinking and driving is illustrated in data collected for the National Highway Traffic Safety Administration. Youths and adults age 16 and older were surveyed about the last time they drove to a location where they then consumed alcohol. In 11 percent of these situations, respondents reported that they drank too much to drive safely. Whether or not they subsequently drove (impaired) from the location related to their adoption of precautionary measures prior to the event. Those who avoided driving impaired were more likely to have taken earlier steps to avoid driving problems, such as having a designated driver or making sure they drove with someone else. Yet this did not mean that avoiders had 
alternative means of getting home while nonavoiders did not. Most of those who drove impaired reported that they could have gotten home easily if they had chosen not to drive. Thus, the impact of planning extended beyond the determination of safe alternatives; perhaps reflecting a predisposition or adopted mental framework (NHTSA, 1991a).

As with older adults, impaired driving among youth in the survey occurred most often when there was an absence of prior planning. Youth displayed vulnerability to lack of planning in that they appeared to be poorer than other age groups in anticipating ahead of time that they would be consuming alcohol. Whether this stemmed from a true lack of recognition, denial, or some other mechanism was unclear. However, if respondents did expect beforehand that they would be drinking alcohol, the survey detected a greater tendency among adolescents than older adults to report taking precautionary measures to avoid impaired driving (most often having a designated driver or planning to spend the night). This suggested receptivity to planning strategies by youth, provided a danger is perceived and the strategy is accepted (NHTSA, 1991a).

One of the most widely promoted strategies for avoiding impaired driving is use of a designated driver. Designated driver programs (DDPs) encourage selection of one person from among a group of drinkers to stay "alcohol-free" during outings where alcohol is consumed by others in the group. The designated driver agrees to refrain from drinking any alcohol, and to assume responsibility for transporting the drinkers safely home. DDPs may be server-based, where the idea for using a designated driver is introduced to drinkers by the server in an establishment that sells alcohol. Alternatively they may be drinker-based, a less formal situation where the drinkers themselves decide to designate a nondrinking driver (NHTSA, 1994a). Some controversy surrounds the designated driver approach, particularly as it relates to youth. Critics charge that it may communicate to adolescents that it is alright for them to drink as long as they have a designated driver, even though they are below the legal drinking age.

\subsubsection{Mass Media Campaigns.}

The media play a large part in how young drivers view driving, drinking, and drinking and driving (Atkin, DeJong, \& Wallack, 1992). For example, a mass media campaign focusing on raising awareness about drunk driving laws was conducted in Australia (NHTSA 1991b). Commercials directed towards young males between the ages of 18 and 30 years were aired on television. It was found that after airing the commercials there was an increased awareness of the probability of apprehension by the police than before the campaign. Additionally, reductions in the incidence of drunk driving were observed for males between the ages of 21 and 24 .

\subsubsection{Educational Campaigns.}

Klitzner, Vegega, \& Grunewald (1988) examined underlying assumptions of programs aimed at driving while intoxicated (DWI) and riding with an intoxicated driver (RWID). They identified five assumptions from a national sample of youth DWI prevention programs. The first, "alternative-related" factors, assumes that youth are not aware of alternatives to DWI and 
RWID or find them unacceptable. Programs based on this assumption employ strategies that encourage youths to use alternative means of getting from one location to another when they are intoxicated. The second, "personal-competency-related" factors, believes that youth who DWI or RWID lack certain life skills. These programs stress teaching decision-making skills. They also teach effective means of communicating, and employ methods for strengthening participants' self-concept. The third, "information-related" factors, believes that youth engage in DWI or RWID because they lack information about the effects of alcohol. Programs based on this assumption teach information about traffic safety. The fourth, "peer pressure-related" factors, believes that a major factor in youth DWI and RWID is such pressure. Participants are taught skills to fend off peer pressure. Finally, the fifth assumption, "normative" factors, assumes that DWI/RWID is a result of a belief that these behaviors are not deviant. Programs based on this assumption try to change perceptions of norms or change existing norms.

The researchers assessed the validity of the above assumptions by testing whether there was a significant relationship between these stable risk factors and youth DWI or RWID. Few significant relationships were found. Results of the analysis suggested to the researchers that DWI was largely a function of drinking practices and normative beliefs about DWI (i.e., perceiving DWI as not deviant). If any of the other factors influenced DWI, they did so indirectly through their impact on drinking practices. Face-to-face interviews were conducted with youths to determine the influence of situational factors on DWI. Drinking emerged as the most important situational variable in youth DWI, as not only had drivers been drinking but passengers often had been drinking as well. DWI drivers frequently reported that they drove because they felt they were the least impaired of the group. Another key situational factor was the need to get somewhere (usually home) or to get a passenger somewhere. Overall, findings from the surveys and interviews suggested that youth "DWI and RWID seem to be largely a function of the role alcohol plays in the youth culture."

The authors recommended targeting interventions at three points in the progression of alcoholrelated crash risk. The first point is the progression from no drinking to drinking. Here, strategies would aim at preventing youth from drinking, such as teaching skills to reduce peer pressure. Interventions would also include those that minimize alcohol availability. The second point is the evolution from drinking to drinking and driving. At this juncture, strategies would involve disassociating drinking from driving, such as designated driver programs. The third point is the evolution from drinking and driving to alcohol-related motor vehicle injuries and fatalities. In this final stage, strategies would involve reducing morbidity and mortality by employing vehicle-related technologies, improvements in highway design, and passive restraints.

After performing site visits to 12 anti-drunk driving programs across the country, Vegega and Klitzner (1988) identified several factors they believed contributed to the success of programs. First, different types of programs appealed to males and females. Males were more receptive to information about enforcement, while girls were more interested in learning about the influence of drinking on relationships. Second, groups in which participants had different levels of alcohol use were more successful than programs that segregated participants into groups 
according to level of alcohol use. Finally, the authors concluded that broad-based community support facilitates the effectiveness of prevention programs (Vegega \& Klitzner, 1988). 


\section{REFERENCES}

Adams, J. G. U. (1988). Risk homeostasis and the purpose of self regulation. Ergonomics, 31(4), 407-428.

Alan Guttmacher Institute (1994). Sex and America's teens. New York: The Alan Guttmacher Institute.

American Association of Motor Vehicle Administrators and National Highway Traffic Safety Administration (1995). An improved driver license entry system for novice drivers and riders. Draft Manual - Under Review. Washington, D.C.

Arnett, J. (1990a). Contraceptive use, sensation seeking, and adolescent egocentrism. Journal of Youth and Adolescence, 19(2), 171-180.

Arnett, J. (1990b). Drunk driving, sensation seeking and egocentrism among adolescents. Personality and Individual Differences, 11 (6), 541-546.

Arnett, J. (1992). Reckless behavior in adolescence: a developmental perspective. Developmental Review, 12, 339-373.

Atkin, C. K. (1989). Television socialization and risk driving by teenagers. Alcohol, Drugs, and Driving, $\underline{5}(1), 1-11$.

Atkin, C. K., DeJong, W., \& Wallack, L. (1992). The influence of responsible drinking TV spots and automobile commercials on young drivers. Washington, D.C.: AAA Foundation for Traffic Safety.

Bagnall, G. (1990). Alcohol education for 13 year olds - does it work? Results from a controlled evaluation. British Journal of Addiction, 85, 89-96.

Bailey, G. W. (1989). Current perspectives on substance abuse in youth. Journal of the American Academy of Child and Adolescent Psychiatry, 28 (2), 151-162.

Baker, S., O'Neill, B., Ginsburg, M. J., \& Li, G. (1992). The injury fact book. New York: The Oxford University Press.

Baldwin, J., \& Baldwin, J. (1988). Factors affecting aids-related sexual risk-taking behavior among college students. The Journal of Sex Research, 25(2), 181-196.

Barjonet, P. (1989). Understanding driver behaviour: sociological theories and surveys. Traffic Safety Theory and Research Methods. Institute for Road Safety Research. 
Barkely, R.A., Guevremont, D.C., Anastopoulos, A.D., DuPaul, G.J., \& Shelton, T.L. (1993). Driving-related risks and outcomes of attention deficit hyperactivity disorder in adolescents and young adults: A 3- to 5-year follow-up survey. Pediatrics, 92(2), 212218.

Barnes, G.M., \& Welte, J.W. (1986). Patterns and predictors of alcohol use among 7-12th grade students in New York State. Journal of Studies on Alcohol, 47(1), 53-61.

Basen-Engquist, K., \& Parcel, G. (1992). Attitudes, norms, and self-efficacy: A model of adolescents' HIV-related sexual risk behavior. Health Education Quarterly, 19(2), 263-277.

Baumrind, D. (1987). A developmental perspective on adolescent risk taking in contemporary America. In C. E. Irwin (Ed.). Adolescent social behavior and health. New directions for child development, No. 37. San Francisco: Jossey-Bass.

Baumrind, D. (1991). The influence of parenting style on adolescent competence and substance use. Journal of Early Adolescence, 11, 56-95.

Beauvais, F. (1992). An integrated model for prevention and treatment of drug abuse among American Indian youth. Journal of Addictive Diseases, 11(3), 63-80.

Beirness, D. S., \& Simpson, H. M. (1987). Alcohol use and lifestyle factors as correlates of road crash involvement amongst youth. In Benjamin, T. (Ed.), Young drivers impaired by alcohol and other drugs (pp 141-148). London: Royal Society of Medicine Services.

Beirness, D. S., \& Simpson, H. M. (1988). Lifestyle correlates of risky driving and accident involvement among youth. Alcohol, Drugs, and Driving, 4,(3-4), 193-204.

Bentler, P. M. (1992). Etiologies and consequences of adolescent drug use: Implications for prevention. Journal of Addictive Diseases, 11(3), 47-61.

Bergeron, J. (1991, February). Behavioral, attitudinal and physiological characteristics of young drivers in simulated driving tasks as a function of past accidents and violations. Paper presented at New to the Road Symposium, Halifax, Nova Scotia.

Beyth-Marom, R., Fischhoff B., Quadrel M.J., \& Furby, L. (1991) Teaching adolescents decision making. In J. Baron and R. Brown (Eds.), Teaching decision making to adolescents (pp. 19-58). Hillsdale, New Jersey: Erlbaum.

Biglan, A., Metzler, C., Wirt, R., Ary, D., Noell, J., Ochs, L., French, C., \& Hood, D. (1990). Social and behavioral factors associated with high -risk sexual behavior among adolescents. Journal of Behavioral Medicine, 13(3), 245-261. 
Billy J.O. \& Udry, J. R. (1985). Patterns of adolescent friendship and effects on sexual behavior. Social Psychology Quarterly, 48(1), 27-41.

Blomberg, R. D. (1992). Lower BAC limits for youth: Evaluation of the Maryland .02 law. DOT HS 807860 . Washington, D.C.: U. S. Department of Transportation, National Highway Traffic Safety Administration.

Blomquist, G. (1986). A utility maximization model of driver traffic safety behavior. Accident Analysis and Prevention, 18(5), 371-375.

Botvin, G. J., Baker, E., Dusenbury, L., Tortu, S. \& Botvin, E. M. (1990). Preventing adolescent drug abuse through a multimodal cognitive-behavioral approach: Results of a 3-year study. Journal of Consulting and Clinical Psychology, 58, 437-446.

Botvin, G. J., \& Botvin, E. M. (1992). Adolescent tobacco, alcohol, and drug abuse prevention strategies, empirical findings and assessment issues. Developmental and Behavioral Pediatrics, 13(4), 290-301.

Boyer, C. B., \& Kegeles, S. M. (1991). AIDS risk and prevention among adolescents. Social Science and Medicine, 33(1), 11-23.

Boyle, A. J., \& Wright, C. C. (1984). Accident "migration" after remedial treatment at accident blackspots. Traffic Engineering Control, 25, 260-267.

Bragg, W.E., \& Finn, P. (1985). Influence of safety belt usage on perception of the risk of an accident. Accident Analysis, \& Prevention, 17(1), 15-23.

Brooks-Gunn, J., \& Paikoff, L.P. (1993). "Sex is a gamble, kissing is a game: adolescent sexuality and health promotion. In S.G. Millstein, A.C. Petersen, E.O. Nightingale 1993 (Eds.), Promoting the health of adolescents (pp. 180-208). New York: Oxford University Press.

Brorsson, B., Rydgren, H., \& Ifver, J. (1993). Single-vehicle accidents in Sweden: A comparative study of risk and risk factors by age. Journal of Safety Research, 24, 5565 .

Brown, I. D. (1982). Exposure and experience are a confounded nuisance in research on driver behaviour. Accident Analysis \& Prevention, 14(5), 345-352.

Brown, I. D., \& Groeger, J. A. (1988). Risk perception and decision taking during the transition between novice and experienced driver status. Ergonomics, $\underline{31}$ (4), 585-597.

Brown, L. K., DiClemente, R. J., \& Park, T. (1992). Predictors of condom use in sexually active adolescents. Joumal of Adolescent Health, 13, 651-657. 
Burger, J. M., \& Inderbitzen, G. M. (1985). Predicting contraceptive behavior among college students: The role of communication, knowledge, sexual anxiety, and self-esteem. Archives of Sexual Behavior, 14, 343-350.

Cairney, P.T. (1982). An exploratory study of risk estimates of driving situations. Proceedings of the ARRP Conference, 11 (5), 233-240.

Cameron, T. (1982). Drinking and driving among American youth: Beliefs and behaviors. Drug and Alcohol Dependence, 10, 1-33.

Casper, L. M. (1990). Does family interaction prevent adolescent pregnancy? Family Planning Perspectives, 22(3), 109-114.

Catania, J. A., Kegeles, S. M., \& Coates, T. J. (1990). Towards an understanding of risk behavior: An AIDS risk reduction model (ARRM). Health Education Quarterly, 17(1), 53-72.

Chassin, L., Presson, C. C., \& Sherman, S. J. (1989). "Constructive" vs. "destructive" deviance in adolescent health-related behaviors. Journal of Youth and Adolescence, 18(3), 245-262.

Chatman, L. M., Billups, M. D., Bell, C. C., \& Priest, M. L. (1991). Injury: A new perspective on an old problem. Joumal of the National Medical Association, $\underline{83}(43-48)$.

Clark, D., Sommerfeldt, L., Schwarz, M., Hedeker, D., \& Watel, L. (1990). Physical recklessness in adolescence. The Journal of Nervous and Mental Disease, 178(7), 423-433.

Clement, R., \& Jonah, B. (1984). Field dependence, sensation seeking and driving behavior. Personality and Individual Differences, $\underline{5}(1), 87-93$.

Collins, J. \& Schlenger, W. E. (1988). Acute and chronic effects of alcohol use on violence. Journal of Studies on Alcohol, 49 , 516-521.

Datta, T. K., \& Guzek, P. (1992). Restraint system use in 19 U.S. cities: 1991 Annual Report. DOT HS 808 148. Washington, D.C.: U.S. Department of Transportation, National Highway Traffic Safety Administration.

Dawson, D. A. (1986). The effects of sex education on adolescent behavior. Family Planning Perspectives, 18(4), 162-170.

DeJoy, D. M. (1989). The optimism bias and traffic accident risk perception. Accident Analysis and Prevention, 21 (4), 333-340. 
DeJoy, D. M. (1992). An examination of gender differences in traffic accident risk perception. Accident Analysis and Prevention, 24(3), 237-246.

Dekker, D.K., Kotwal, B.M., \& Lerner, N.D. (1994). Understanding driver performance variability and perception of risk. Technical Report for Federal Highway Administration.

DiBlasio, F. (1986). Predriving riders and drinking drivers. Journal of Studies on Alcohol, $\underline{49}(1), 11-15$.

DiClemente, R. J., Brown, L. K., Beausoleil, N. I., \& Lodico, M. (1993). Comparison of AIDS knowledge and HIV-related sexual risk behaviors among adolescents in low and high AIDS prevalence communities. Journal of Adolescent Health, 14(3), 231-236.

Dielman, T. E., Butchart, A. T., Shope, J. T., \& Miller, M. (1990-1991). Environmental correlates of adolescent substance use and misuse: implications for prevention programs. International Journal of the Addictions, 25(7A \& 7B), 855-880.

Dinges, M. M., \& Octting, E. R. (1993). Similarity in drug use patterns between adolescents and their friends. Adolescence, $\underline{28}(110), 253-266$.

Donohue, W. A. (1988). Issues of risk in adult and teen safety belt use. Alcohol, Drugs and Driving, 4 (3-4), 297-304.

Donovan, J. E., \& Jessor, R. (1978). Adolescent problem drinking: Psychosocial correlates in a national sample study. Journal of Studies on Alcohol, $\underline{39}(9), 1506-1523$.

Donovan, J. E., \& Jessor, R. (1985). The structure of problem behavior in adolescence and young adulthood. Journal of Consulting and Clinical Psychology, 53, 890-904.

Donovan, J. E., Jessor, R., \& Costa, F. (1991). Adolescent health behavior and conventionality-unconventionality: An extension of problem-behavior theory. Health Psychology, 10(1), 52-61.

Donovan, J. E., Jessor, R., \& Jessor, L. (1983). Problem drinking in adolescence and young adulthood. A follow-up study. Journal of Studies on Alcohol, 44,(1), 109-137.

Dryfoos, J.G. (1990). Adolescents at risk. New York: Oxford University Press.

DuRant, R. H., Jay, S., \& Seymore, C. (1990). Contraceptive and sexual behavior of black female adolescents: A test of a social-psychological theoretical model. Journal of Adolescent Health Care, 11(4), 326-334. 
DuRant, R. H., Rickert, V. I., Ashworth, C. S., Newman, C., \& Slavens, G. (1993). Use of multiple drugs among adolescents who use anabolic steroids. The New England Journal of Medicine, $\underline{328(13), 922-925 .}$

DuRant, R. H., \& Sanders, J. M. (1989). Sexual behavior and contraceptive risk taking among sexually active adolescent females. Journal of Adolescent Health Care. 10(1), 1-9.

Earls, F., \& Powell, J. (1988). Patterns of substance use and abuse in inner-city adolescent medical patients. The Yale Journal of Biology and Medicine, 61, 233-242.

Elander, J., West, R., \& French, D. (1993). Behavioral correlates of individual differences in road-traffic crash risk: An examination of methods and findings. Psychological Bulletin, $\underline{113}(2), 279-294$.

Elkind, D. (1967). Egocentrism in adolescence. Child Development, $\underline{38}$, 1025-1034.

Elkind, D. (1985). Egocentrism redux. Developmental Review, $\underline{5}, 218-226$.

Ellickson, P. L., \& Bell, R. M. (1990). Drug prevention in junior high: A multi-site longitudinal test. Science, 247, 1299-1305.

Ellickson, P. L., \& Hays, R. D. (1992). On becoming involved with drugs: modeling adolescent drug use over time. Health Psychology, 11(16), 377-385.

Elliot, D. S. (1993). Health-enhancing and health-compromising lifestyles. In S. Millstein, A. C. Petersen, \& E. O. Nightingale (Eds). Promoting the health of adolescents (pp. 119327). New York: Oxford University Press.

Emler, N. P., Winton, M., \& Heather, N. (1977). Moral reasoning and delinquency: Some limitations of Kohlberg's theory. Bulletin of the British Psychological Society, 30, 181.

Ennett, S. T., Tobler, N. S., Ringwalt, C. L., \& Flewelling, R. L. (1994). How effective is drug abuse resistance education? A meta-analysis of project DARE outcome evaluations. American Journal of Public Health, $\underline{84}(9), 1394-1401$.

Ensminger, M.E. (1990). Sexual activity and problem behaviors among black, urban adolescents. Child Development, 61, 2032-2046.

Evans, L. (1985). Human behavior feedback and traffic safety. Human Factors, 27(5), 555576.

Evans, L. (1986). Comments on Wilde's notes on "Risk homeostasis theory and traffic accident data." isk Analysis, $\underline{6}(1), 103-107$. 
Evans, L. (1991). Traffic safety and the driver. New York: Van Nostrand Reinhold.

Evans, L., \& Wasielewski, P. (1983). Risky driving related to driver and vehicle characteristics. Accident Analysis and Prevention, 15(2), 121-136.

Farrell, A. D., Danish, S. J., \& Howard, C. W. (1992a). Risk factors for drug use in urban adolescents: Identification and cross-validation. American Joumal of Community Psychology, 20(3), 263-285.

Farrell, A. D., Danish, S. J., \& Howard, C. W. (1992b). Relationship between drug use and other problem behaviors in urban adolescents. Journal of Consulting and Clinical Psychology, 60(5), 705-712.

Farrow, J. A. (1987a). The use of vignette analysis of dangerous driving situations involving alcohol to differentiate adolescent DWI offenders and high school drivers. American Journal of Drug and Alcohol Abuse, 13(1\&2), 157-174.

Farrow, J. A. (1987b). Young driver risk taking: A description of dangerous driving situations among 16- to 19-year old drivers. The International Journal of the Addictions, 22, 12551267.

Farrow, J. A. (1988). Personality factors associated with driving while intoxicated: A comparison study of adolescent drivers. Journal of Alcohol and Drug Education, $\underline{34}(2)$, 21-32.

Farrow, J., \& Brissing, P. (1990). Risk for DWI: A new look at gender differences in drinking and driving influences, experiences, and attitudes among new adolescent drivers. Health Education Quarterly, 17(2), 213-221.

Faulkenberry, J. R., Vincent, M., \& James, A. (1987). Coital behaviors, attitudes and knowledge of students who experience early coitus. Adolescence, $\underline{86}, 321-332$.

Fingerhut, L. A. (1993). Firearm mortality among children, youth and young adults one-tothirty-four years of age, trends and current status: United States, 1985-1990. Advanced Data from Vital Health Statistics: 231. Hyattsville, MD: National Center for Health Statistics.

Fingerhut, L. A., Jones, C. \& Makuc, D. M. (1994). National Center for Health Statistics. Centers for Disease Control and Prevention. Advance Data, 242.

Finn, P., \& Bragg, W. E. (1986). Perception of the risk of an accident by young and older drivers. Accident Analysis and Prevention, 18(4), 289-298. 
Finn, P., Hodgdon, J., Beauregard, M., Shapiro, E., Zaman, S., \& Stein, M. (1985). Risk taking and safety restraint usage of young drivers: Technical report of experimental study. (Report No. DOT-HS 806-811). Washington, D.C.: U. S. Department of Transportation, National Highway Traffic Safety Administration.

Flynn, B. S., Worden, J. K., Secker-Walker, R. H., Badger, G. J., Geller, B. M., \& Costanza, M. C. (1992). Prevention of cigarette smoking through mass media intervention and school program. American Journal of Public Health, 82(6), 827-834.

Fuller, R. (1984). A conceptualization of driving behaviour as threat avoidance. Ergonomics, 27(11), 1139-1155.

Fuller, R. (1988). On learning to make risky decisions. Ergonomics, $\underline{31(4), 519-526 .}$

Furby, L. \& Beyth-Marom, R., (1992). Risk taking in adolescence: A decision-making perspective. Developmental Review, 12(1), 1-44.

Furstenberg, F. F., Jr., \& Brooks-Gunn, J. (1985). Adolescent fertility: Causes, consequences, and remedies. In L. Aiken \& D. Mechanic (Eds.), Applications of social science to clinical medicine and health policy. New Brunswick, NJ: Rutgers University Press.

Galavotti, C., \& Lovick, S. R. (1989). School-based clinic use and other factors affecting adolescent contraceptive behavior. Journal of Adolescent Health Care, 10, 506-512.

Gardner W. (1993). A lifespan rational choice theory of taking risk. In N. J. Bell and R. W. Bell (Eds.), Adolescent risk taking (pp. 66-83). Newbury Park, CA: Sage.

Gibbons, S., Wylie, M. L., Echterling, L., \& French, J. (1986). Situational factors related to rural adolescent alcohol use. International Journal of the Addictions, 21(11), 1183-1195.

Gibbs, J. C. (1991). Sociomoral developmental delay and cognitive distortion: Implications for the treatment of antisocial youth. In W. M. Kurtines \& J. C. Gewirtz (Eds.), Handbook of moral behavior and development (pp. 95-110). Hillsdale, NJ: Lawrence Erlbaum.

Goodman, E., \& Cohall, A. T. (1989). Acquired immunodeficiency syndrome and adolescents: Knowledge, attitudes, beliefs, and behaviors in a New York City adolescent minority population. Pediatrics, $\underline{84}(1), 36-42$.

Groeger, J. A., \& Brown, I. D. (1989). Assessing one's own and others' driving ability: Influences of sex, age, and experience. Accident Analysis, \& Prevention, 21(2), 155-168. 
Gross, J., \& McCaul M.E. (1991). A comparison of drug use and adjustment in urban adolescent children of substance abusers. The International Journal of the Addictions, $\underline{25}(4 \mathrm{~A}), 495-511$.

Haight, F. (1986). Risk, especially risk of traffic accident. Accident Analysis \& Prevention, 18(5), 359-366.

Halebsky, M. A. (1987). Adolescent alcohol and substance abuse: Parent and peer effects. Adolescence, 22(88), 961-967.

Handler, A. (1990). The correlates of the initiation of sexual intercourse among young urban black females. Journal of Youth and Adolescence, 19(2), 159-170.

Hansen, W. B. (1992). School-based substance abuse prevention: A review of the state of the art in curriculum 1980-1990. Health Education Research, 7, 403-430.

Hansen, W. B. (1993). School-based alcohol prevention programs. Alcohol, Health, and Research World, 17(1), 54-60.

Hansen, W. B. \& Graham, J. W. (1991). Preventing alcohol, marijuana, and cigarette use among adolescents: Peer pressure resistance training versus establishing conservative norms. Preventive Medicine, 20(3), 414-430.

Hanson, S. L., Myers, D. E., \& Ginsburg, A. L. (1987). The role of responsibility and knowledge in reducing teenage out-of-wedlock childbearing. Joumal of Marriage and the Family, 49, 241-251.

Harman S.M. (1978). Clinical aspects of aging of the male reproductive system. In E.L. Schneider (Ed.). New York: The Aging Reproductive System, New York: Raven Press.

Hart, B., \& Hilton, I. (1988). Dimensions of personality organization as predictors of teenage

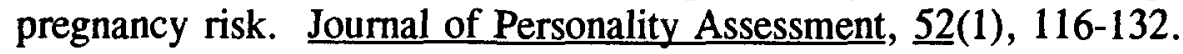

Hayes, C.D. (1987). Risking the future: Adolescent sexuality, pregnancy, and childbearing. Washington, D.C.: National Academy Press.

Heath, L., Kruttschnitt, C., \& Ward, D. (1986). Television and violent criminal behavior: Beyond the bobo doll. Victims and Violence, 1, 177-190.

Hernandez, J. T., Lodico, M., \& DiClemente, R. H. (1993). The effects of child abuse and race on risk taking in male adolescents. Journal of the National Medical Association, 85, 593-597. 
Hingson, R., Hereen, T., \& Winter, M. (1994, January). Lower legal blood alcohol limits for young driver. Paper presented at the annual meeting of the Transportation Research Board, Washington, D.C.

Hoberman, H. M., \& Garfinkel, B. D. (1988). Completed suicide in children and adolescents. Journal of the American Academy of Child and Adolescent Psychiatry, 689-695.

Hogan, D. P., \& Kitagawa, E. M. (1985). The impact of social status, family structure, and neighborhood on the fertility of black adolescents. American Journal of Sociology, 90(4), 825-855.

Hovarth, P., \& Zuckerman M. (1993). Sensation seeking, risk appraisal and risky behavior. Personality Individual Differences, $14,41-52$.

Howarth, C. I. (1988). The relationship between objective risk, subjective risk and behaviour. Ergonomics, 31 (4), 527-535.

Hoyes, T. W., \& Glendon, A. I. (1993). Risk homeostasis: Issues for future research. Safety Science, 16, 19-33.

Huizinga, D., Loeber, R., Thornberry, T. P. (1993). Longitudinal study of delinquency, drug use, sexual activity, and pregnancy among children and youth in three cities. Public Health Reports, 108(Supp. 1), 90-96.

Insurance Institute for Highway Safety. (1992, November). Status report, 27(4). Arlington, VA: Insurance Institute for Highway Safety.

Irwin C. E. (1990). The theoretical concept of at-risk adolescents. Adolescent Medicine: State of the Art Reviews, 1, 1-14.

Irwin C. E. (1993). Adolescence and risk taking: How are they related? In N. Bell and R. Bell (Eds.), Adolescent risk taking (pp.7-28). Newbury Park, CA: Sage Publications.

Irwin, C. E., \& Millstein, S. G. (1986). Biopsychosocial correlates of risk taking behaviors during adolescence. Journal of Adolescent Health Care, $7(6), 82-96$.

Irwin, C. E., \& Millstein, S.G. (1987). The meaning of alcohol use in early adolescents. Pediatric Research, 21, 175-178.

Jack, M. S. (1989). Personal fable: a potential explanation for risk-taking behavior in adolescents. Journal of Pediatric Nursing, 4(5), 334-338.

Jackson, D.N. (1968). Personality research form. Goshen, NY: Research Psychologists Press. 
Janssen, W. (1990). The economy of risk; or, what do I get for my error? Ergonomics, $33(10 / 11), 1333-1348$.

Jessor, R. (1987). Risky driving and adolescent problem behavior: An extension of problem-behavior theory. Alcohol, Drugs and Driving, $\underline{3}(3-4), 1-11$.

Jessor, R. (1992). Risk behavior in adolescence: A psychosocial framework for understanding and action. Developmental Review 12(4), 374-390.

Jessor R. (1993). Successful adolescent development among youth in high risk settings. American Psychologist, 48(2), 117-126.

Jessor, R., \& Jessor, S. L. (1975). Adolescent development and the onset of drinking. Journal of Studies on Alcohol, $\underline{36}, 27-51$.

Jessor, R., \& Jessor, S. L. (1977). Problem behavior and psychosocial development: A longitudinal study of youth. New York: Academic Press.

Johnston, L. D., O'Malley, P. M., \& Bachman, J. G. (1994). National survey results on drug use from the monitoring the future study, 1975-1992, (Vol. II). Rockville, MD.: U. S. Department of Health and Human Services.

Jonah, B. (1986). Accident risk and risk-taking behavior among young drivers. Accident Analysis and Prevention, 18(4), 255-271.

Jonah, B. (1990). Age differences in risky driving. Health Education Research, $\underline{5}(2), 139-149$.

Jones, R. K., \& Lacey, J. H. (1991). Review of the literature evaluating the effect of countermeasures to reduce alcohol impaired driving (1980-1989). Final Report: Volume I - Synthesis. DOT HS 808 023. Washington, D.C.: U.S. Department of Transportation, National Highway Traffic Safety Administration.

Jorgensen, S.R. \& Sonstegard, J. S. (1984). Predicting adolescent sexual and contraceptive behavior: An application and test of the Fishbein model. Journal of Marriage and the Family, 46, 43-55.

Kahneman D., \& Tversky A. (1972). Subject probability: A judgement of representativeness. Cognitive Psychology, 3 , 430-454.

Kandel, D.B. (1982). Epidemiological and psychosocial perspectives on adolescent drug use. Journal of American Academy of Child Psychiatry, 21 , 328-344. 
Kasperson, R., Renn, O., Slovic, P., Brown, H., Emel, J., Goble, R., Kasperson, J., \& Taick, S. (1988). The social amplification of risk: A conceptual framework. Risk Analysis, $\underline{8}(2), 177-187$.

Katchadourian, H. (1990). Sexuality. In S.S. Feldman, G.R. Elliott 1990 (Ed.) At the threshold (pp. 330-351). Cambridge, MA: Harvard University Press.

Kazden, A. E., (1987). Conduct disorder in childhood and adolescence. Newbury Park, CA: Sage Publications.

Keasey, C. B. (1971). Social participation as a factor in the moral development of preadolescents. Developmental Psychology, , 216-220.

Kedjidjian, C. B. (1993). Get young drivers BAC to zero. Traffic Safety, 16-18.

Kegeles, S. M., Adler, N. E., \& Irwin, C. E. (1988). Sexually active adolescents and condoms: Changes over one year in knowledge, attitudes and use. American Journal of Public Health, $\underline{78(4), 460-461 .}$

Kegeles, S. M., Adler, N. E., \& Irwin, C. E. (1989). Adolescents and condoms: Associations of beliefs with intentions to use. American Journal of Diseases of Children, 143(8), 911-915.

Keller, S. E., Bartlett, J. A., Schleifer, S. J., Johnson, R. L., Pinner, E., \& Delaney, B. (1991). HIV-relevant sexual behavior among a healthy inner-city heterosexual adolescent population in an endemic area of HIV. Journal of Adolescent Health, 12(1), 44-47.

Kingery, P. M., Pruitt, B. E., \& Hurley, R. S. (1992). Violence and illegal drug use among adolescents: Evidence from the U.S. national adolescent student health survey. International Journal of Addictions, 27, 1445-1462.

Kirby, D. (1984). Sexuality education: An evaluation of programs and their effect. Santa Cruz, CA: Network.

Kirby, D. (1991). School-based clinics: research results and their implications for future research methods. Evaluation and Program Planning. 14, 35-47.

Kirby, D., Barth, R. P., Leland, N., \& Fetro, J. V. (1991). Reducing the risk: Impact of a new curriculum on sexual risk taking. Family Planning Perspectives, 23(6), 253-263.

Klepp, K. I., \& Perry, C. L., (1990). Adolescents, drinking and driving: Who does it and why? In J. Wilson and R. E. Mann, (Eds.), Drinking and driving: advances in research and prevention (pp. 42-67). New York: Guilford Press. 
Klitzner, M., Vegega, M., \& Gruenewald, P. (1988). An empirical examination of the assumptions underlying youth drinking/driving prevention programs. Evaluation and Program Planning, 11, 219-235.

Kohlberg, L. (1978). The cognitive-developmental approach to behavioral disorders: A study of the development of moral reasoning in delinquents. In G. Serban (Ed.), Cognitive defects in the development of mental illness. New York: Brunner/Mazel.

Labouvie, E. W., \& McGee, C. R. (1986). Relation of personality to alcohol and drug use in adolescence. Journal of Consulting and Clinical Psychology, 54(3), 289-293.

Lalonde, K.G. (1979). The grande record study of motor vehicle collisions in Ontario. Ontario: Ontario Ministry of Transportation and Communications.

Lambert, N. (1995). Analysis of driving histories of ADHD subjects. (Cooperative Agreement No. DTNH22-94-H-05320). Unpublished report. Washington, D.C.: U.S. Department of Transportation, National Highway Traffic Safety Administration.

Langer, L. M., Zimmerman, R. S., Warheit, G. J., \& Duncan, R. C. (1993). Decision-making orientation and AIDS-related knowledge, attitudes and behaviors of Hispanic, African-American, and white adolescents. Health Psychology, 12(3), 227-34.

Lavery, B., Siegel, A., Cousins, J. \& Rubovits, D. S. (1993). Adolescent risk-taking: An analysis of problem behaviors in problem children. Journal of Experimental Child Psychology, 55, 227-294.

Lerner, N., Williams, A., \& Sedney, C. (1988). Risk perception in highway driving. (Contract No. DTFH61-85-C-00143). Washington, DC. U.S. Department of Transportation, Federal Highway Administration.

Luce, R. D., \& Raiffa, H. (1957). Games and decisions: Introduction and critical survey. New York: Wiley.

Lyng, S. (1990). Edgework: A social psychological analysis of voluntary risk taking. American Journal of Sociology, 95, 851-856.

Lyng, S. (1993). Dysfunctional risk taking: Criminal behavior as edgework. In N. Bell and R. Bell (Eds.), Adolescent Risk Taking (pp. 107-130). Newbury Park, CA: Sage Publications.

MacDonald, N. E., Wells, G. A., Fisher, W. A., Warren, W. K., King, M. A., Doherty, J. A., \& Bowie, W. R. (1990). High-risk STD/HIV behavior among college students. Journal of the American Medical Association, 263(23), 3155-3159. 
MacKinnon, D. A., Johnson, C. A., Pentz, M. A., Hansen, W. B., Flay, B. R., \& Yang, Y. F. I. (1991). Mechanisms in a school-based drug prevention program: First year effects of the Midwestern Prevention Project. Health Psychology, 10, 164-172.

Magnusson, D., Stattin, H., \& Allen, V. L. (1985). Biological maturation and social development: A longitudinal study of some adjustment processes from mid-adolescence to adulthood. Journal of Youth and Adolescence, 14, 267-283.

Mahalel, D., \& Szternfeld, Z. (1986). Safety improvements and driver perception. Accident Analysis and Prevention, 18(1), 37-42.

Maher, M. J. (1987). Accident migration-a statistical explanation? Traffic Engineering and Control, 28 (9), 480-483.

Maher, M. J. (1990). A bivariate negative binomial model to explain traffic accident migration. Accident Analysis and Prevention, 22(5), 487-498.

Maiuro, R. D., \& Eberle, J. A. (1989). New developments in research on aggression: An international report. Violence and Victims, 4, 3-15.

Marsiglio, W., \& Mott, F. (1986). The impact of sex education on sexual activity, contraception use and premarital pregnancy among American teenagers. Family Planning Perspectives, $\underline{18}(4), 151-161$.

Mason, M. G., \& Gibbs, J. C. (1993). Social perspective talking and moral judgment among college students. Journal of Adolescent Research, 8(1), 109-123.

Matthews, M. (1986). Aging and the perception of driving risk and ability. Proceedings of the Human Factors Society -- 30th Annual Meeting, 1159-1163.

Matthews, M., \& Moran, A. (1986). Age differences in male drivers' perception of accident risk: The role of perceived driving ability. Accident Analysis and Prevention, 18(4), 229- 313.

Mayhew, D. R., Donelson, A. C., Beirness, D. J., \& Simpson, H. M. (1986). Youth, alcohol, and relative risk of crash involvement. Accident Analysis, and Prevention, 18(4), 273287.

McKenna, J. W., \& Williams, K. N. (1993). Crafting effective tobacco counteradvertisements: Lessons from a failed campaign directed at teenagers. Public Health Reports, 108(1), 85-89. 
McKnight, A. J. (1989). Safety effects of provisional driver licensing programs. In Provisional licensing programs for young drivers -- topical papers by licensing experts, including an annotated bibliography. DOT HS 807 375. Washington, D.C.: U. S. Department of Transportation, National Highway Traffic Safety Administration.

McKnight, A. J., \& Adams, B. B. (1970). Driver education task analysis. Volume II: Task analysis methods. DOT HS 800 368. Washington, D.C.: U. S. Department of Transportation, National Highway Safety Bureau.

McKnight, A.J., Hyle, P., \& Albrecht, L. (1983). Youth license control demonstration project. DOT-HS-7-01765. Washington, D.C.: U. S. Department of Transportation, National Highway Traffic Safety Administration.

McKnight, J., \& Resnick, J. (1993, August). Youthful driver at risk workshop: Background issue paper. In workshop to identify training requirements designed to reduce young driver risk taking and improve decision making skills. DOT HS 808066 . Washington, D.C.: U. S. Department of Transportation, National Highway Traffic Safety Administration.

McMillen, D., Smith, S., \& Wells-Parker, E. (1989). The effects of alcohol, expectancy, and sensation seeking on driving risk taking. Addictive Behaviors, 14, 477-483.

Michon, J. (1985). A critical view of driver behavior models: What do we know, what should we do? In Evans, L. and Schwing, R. C. (Eds.), Human behavior and traffic safety. New York: Plenum Press.

Moberg, P. D., \& Piper, D. L. (1990). An outcome evaluation of project model health: A middle school health promotion program. Health Education Quarterly, 17(1), 37-51.

Moncher, M. S., Holden, G. W., \& Schinke, S. P. (1991). Psychosocial correlates of adolescent substance use: a review of current etiological constructs. The International Journal of the Addictions, 26(4), 377-414.

Moncher, M. S., Holden, G. W., \& Trimble, J. E. (1990). Substance abuse among Native-American youth. Journal of Consulting and Clinical Psychology, $\underline{58(4), 408-415 . ~}$

Morash, M. (1981). Cognitive developmental theory: A basis for juvenile correctional reform? Criminology, 10, 360-371.

Morash, M. (1983). An explanation of juvenile delinquency: The integration of moralreasoning theory and sociological knowledge. In W. S. Laufer \& J. M. Day (Eds.), Personality theory, moral development, and criminal behavior (pp. 385-403). New York: Lexington Books. 
Muss, R. E. (1988). Theories of adolescence (5th ed). New York: McGraw-Hill.

Naatanen, R., \& Summala, H. (1976). Road-user behavior and traffic accidents. Amsterdam, Netherlands: North-Holland.

Namerow, P. B., Lawton, A. I., \& Philliber, S. G. (1987). Teenagers' perceived and actual probabilities of pregnancy. Adolescence, $\underline{22}(86), 475-485$.

National Highway Traffic Safety Administration (1975). The driver education evaluation program (DEEP) study. A report to the Congress. DOT HS 801 766. Washington, D.C.: U. S. Department of Transportation, National Highway Traffic Safety Administration.

National Highway Traffic Safety Administration (1990). Alcohol and highway safety 1989: A review of the state of knowledge. DOT HS 807 557. Washington, D.C.: U.S. Department of Transportation, National Highway Traffic Safety Administration.

National Highway Traffic Safety Administration (1991a). National survey of drinking and driving decision making. Unpublished 1991 data. DTNH22-90-C-07004. Washington, D.C.: U. S. Department of Transportation, National Highway Traffic Safety Administration.

National Highway Traffic Safety Administration (1991b). Review of the literature evaluating the effect of countermeasures to reduce alcohol impaired driving (1980-1989). Final Report, Volume II -- Individual Analyses and Assessments. DOT HS 808024. Washington, D.C.: U. S. Department of Transportation, National Highway Traffic Safety Administration.

National Highway Traffic Safety Administration (1993a). Addressing the safety issues related to younger and older drivers. A report to Congress January 19, 1993 on the research agenda of the National Highway Traffic Safety Administration. DOT HS 807957. Washington, D.C.: U. S. Department of Transportation, National Highway Traffic Safety Administration.

National Highway Traffic Safety Administration (1993b). Fatal accident reporting system. Unpublished 1993 data. Washington, D.C.: U. S. Department of Transportation, National Highway Traffic Safety Administration.

National Highway Traffic Safety Administration (1993c). National survey of drinking and driving attitudes and behavior. Unpublished 1993 data. Washington, D.C.: U. S. Department of Transportation, National Highway Traffic Safety Administration. 
National Highway Traffic Safety Administration (1994a). A guide to developing a communitybased designated driver program. DOT HS 808 137. Washington, D.C.: U. S. Department of Transportation, National Highway Traffic Safety Administration.

National Highway Traffic Safety Administration (1994b). Traffic safety facts 1993. DOT HS 808 169. Washington, D.C.: U. S. Department of Transportation, National Highway Traffic Safety Administration.

Newcomb, M. D., \& Bentler, P. M. (1989). Substance use and abuse among children and teenagers. American Psychologist, 44(2), 242-248.

Newcomer, S. F., \& Udry, J. R. (1985). Parent-child communication and adolescent sexual behavior. Family Planning and Perspective, 17, 169-174.

Newcomer, S.F., \& Udry, J. R. (1987). Parental marital status effects on adolescent sexual behavior. Journal of Marriage and the Family, 49(2), 235-240.

Newell, A., \& Simon, H.A. (1972). Human problem solving. New York: Plenum Press.

Norris, A. E., \& Ford, K. (1994). Condom beliefs in urban, low income, African American and Hispanic Youth. Health Education Quarterly, 21, 39-53.

Oei, T. P. S., \& Kerschbaumer, D. M. (1990). Peer attitudes, sex, and the effects of alcohol on simulated driving performance. American Journal of Drug and Alcohol Abuse, 16(1\&2), 135-146.

Ogden, K. W. (1990). Human factors in traffic engineering. ITE Journal, 41-46.

Olweus, D. (1980). Familial and temperamental determinants of aggressive behavior in adolescent boys: A causal analysis. Developmental Psychology, 16, 644-660.

O'Neill, B. (1977). A decision-theory model of danger compensation. Accident Analysis and Prevention, 9, 157-165.

Oppe, S. (1988). The concept of risk: A decision theoretic approach. Ergonomics, $\underline{31}$ (4), 435-440.

Organization for Economic Cooperation and Development (1975). Young driver accidents. Paris, France: Road Research Program.

Osgood, D. W., Johnston, L. D., O'Malley, P. M., \& Bachman, J. G. (1988). The generality of deviance in late adolescence and early adulthood. American Sociological Review, 49, 711-725. 
Parker, D., Manstead, A. S. R., Stradling, S. G., \& Reason, J. T. (1992). Determinants of intention to commit driving violations. Accident Analysis and Prevention, 24(2), 117-31.

Pelz, D. C., \& Schuman, S. H. (1971). Are young drivers really more dangerous after controlling for exposure and experience? Joumal of Safety Research, $\underline{3}, 68-79$.

Pendergrast, R. A., DuRant, R. H., \& Gaillard, G. L. (1992). Attitudinal and behavioral correlates of condom use in urban adolescent males. Journal of Adolescent Health, 13(2), 133-139.

Pennsylvania Transportation Institute (1992). Further promotion of safe driving strategies. University Park, PA: Pennsylvania Transportation Institute.

Persaud, B. (1987). "Migration" of accident risk after remedial blackspot treatment. Traffic Engineering and Control, 28(1), 23- 24.

Petersen, A. C., Compas, B. E., \& Brooks-Gunn, J. (1992). Depression in adolescence: Current knowledge, research directions, and implications for program policy. Washington, D.C.: The Carnegie Corporation.

Pleck, J. H., Sonenstein, F. L., \& Leighton, C. K. (1990). Contraceptive attitudes and intention to use condoms in sexually experienced and inexperienced adolescent males. Journal of Family Issues, 11(3), 294-312.

Popkin, C. L. \& Council, F. M. (1991, October). DWI and alcohol-related crash trends of non-white North Carolina drivers. Paper presented at the annual meeting of the Association for the Advancement of Automotive Medicine, Toronto, Canada.

Preusser, D. F. (1988). Delaying teenage licensure. Alcohol, Drugs, and Driving, 4(3-4), 283295.

Preusser, D. F., Ulmer, R. G., \& Preusser, C. W. (1992). Obstacles to enforcement of youthful (under 21) impaired driving. Washington, D.C.: U.S. Department of Transportation, National Highway Traffic Safety Administration.

Quadrel, M. J., Fischhoff, B., \& Davis, W. (1993). Adolescent (in)vulnerability. American Psychologist, $\underline{48(2), 001-0015 .}$

Quimby, A. R., \& Watts, G. R. (1981). Human factors and driving performance. TRRL Report 1004. Crowthorne, England: Transport and Research Laboratory.

Ranney, T. (1994). Models of driving behavior: A review of their evolution. Accident Analysis and Prevention, 26(6), 733-750. 
Reis, J., \& Herz, E. (1989). An examination of young adolescents' knowledge of and attitude toward sexuality according to perceived contraceptive responsibility. Journal of Applied Social Psychology, 19(3), 231-50.

Rickert, V. I., Jay, M. S., Gottlieb, A., \& Bridges, C. (1989). Adolescents and AIDS: Female's attitudes and behaviors toward condom purchase and use. Journal of Adolescent Health Care, 10(4), 313-316.

Rothe, P. (1992). Traffic sociology: Social patterns of risk. International Journal of Adolescent Medicine and Health, 5 (3-4), 187-197.

Runyan, C. W., \& Gerken, E. A. (1991). Injuries. In W. Hendee (Ed.), The health of adolescents (pp 302-333). San Francisco: Jossey-Bass.

Santrock, J. (1993). Adolescence: An introduction. Madison, WI: Brown \& Benchmark.

Schilling, R. F., \& McAlister, A. L. (1990). Preventing drug use in adolescents through media interventions. Journal of Consulting and Clinical Psychology, 58(4), 416-424.

Shafer, M., \& Boyer, C. B. (1991). Psychosocial and behavioral factors associated with risk of sexually transmitted diseases, including human immunodefienciency virus infection, among urban high school students. The Journal of Pediatrics, 119(5), 826-833.

Shedler, J., \& Block, J. (1990). Adolescent drug use and psychological health: A longitudinal inquiry. American Psychologist, 45(5), 612-630.

Singer, D. (1985). Does violent television produce aggressive children? Pediatric Annals, $\underline{14},(12), 804-810$.

Singer, S. I. (1986). Victims of serious violence and their criminal behavior: Subcultural theory and beyond. Victims and Violence, 1, 61-70.

Sivak, M., Soler, J., Trankle, U., \& Spagnhol, J. M. (1989). Cross-cultural differences in driver risk-perception. Accident Analysis \& Prevention, 21(4), 355-362.

Skinner, D., \& Hoxie, P. (1989). Effects of minimum drinking age laws on highway fatalities. DOT TSC HS970 PM 89 1. Washington, D.C.: U. S. Department of Transportation, Transportation Systems Center.

Slovic, P. (1987). Perception of risk. Science, 236(4799), 280- 285.

Smith, E. A., Udry, J. R., Morris, N. M. (1985). Pubertal development and friends: A biosocial explanation of adolescent sexual behavior. Journal of Health and Social Behavior, 26, 183-192. 
Smith, M. (1994). Research agenda for an improved novice driver education program: Report to Congress. Washington, D.C.: U. S. Department of Transportation, National Highway Traffic Safety Administration.

Smith, R., \& Lovegrove, A. (1983). Danger compensation effects of stop signs at intersections. Accident Analysis \& Prevention, 15 (2), 95-104.

Soliday, S. M. (1974). Relationship between age and hazard perception in automobile drivers. Perceptual and Motor Skills, 39, 335-338.

Stanton, B. F., Aronson, R., Borgatti, S., Galbraith, J., \& Feigelman, S. (1993). Urban adolescent high risk sexual behavior: Corroboration of focus group discussions through pile-sorting. The AIDS Youth Research Team. AIDS Education and Prevention, $\underline{5}(2)$, 162-174.

Staplin, L., \& Lyles, R.W. (1991). Age differences in motor perception and specific traffic maneuver problems. Transportation Research Record, 1325, 23-33.

Stern, M., Northman, J. E., \& Van Slyck, M. R. (1984). Father absence and adolescent "Problem Behaviors": Alcohol consumption, drug use and sexual activity. Adolescence, 19(74), 301-312.

Stock, J. R., Weaver, J. K., Ray, H. W., Brink, J. R., \& Sadof, M. G. (1983). Evaluation of safe performance secondary school driver education curriculum demonstration project. DOT-HS-806-568. Washington, D.C.: United States Department of Transportation, National Highway Traffic Safety Administration.

Streff, F., \& Geller, E. S. (1988). An experimental test of risk compensation: Between-subject versus within-subject analyses. Accident Analysis \& Prevention, 20(4), 277-287.

Strunin, L., \& Hingson, R. (1992). Alcohol, drugs, and adolescent sexual behavior. The International Journal of the Addictions, 27(2), 129-146.

Studer, M., \& Thornton, A. (1987). Adolescent religiosity and contraceptive use. Journal of Marriage and the Family, 49 (1), 117-128.

Summala, H. (1987). Young driver accidents: Risk taking or failure of skills? Alcohol, Drugs, and Driving, $\underline{3}(3-4), 79-91$.

Summala, H. (1988). Risk control is not risk adjustment: The zero-risk theory of driver behaviour and its implications. Ergonomics, $\underline{31}(4), 491-506$. 
Tobler, N.S. (1986). Meta-analysis of 143 adolescent drug prevention programs: Quantitative outcome results of program participants compared to a control or comparison group. Journal of Drug Issues, $\underline{16}, 537-568$.

Tonkin, R.S. (1987). Adolescent risk taking behavior. Journal of Adolescent Health Care, $\underline{8}$, 213-220.

Towberman, D. B., \& McDonald, R. M. (1993). Dimensions of adolescent drug-avoidant attitude. Journal of Substance Abuse Treatment, 10(1), 45-52.

Traffic Injury Research Foundation of Canada (1991). New to the road. Ottawa: Traffic Injury Research Foundation of Canada.

Trankle, U., Gelau, C., \& Metker, T. (1990). Risk perception and age-specific accidents of young drivers. Accident Analysis and Prevention, 22(2), 119-125.

Tsuang, M. T., Boor, M., \& Fleming, J. A. (1985). Psychiatric aspects of traffic accidents. American Journal of Psychiatry, 142(5), 538-546.

Turner, R. A., \& Irwin, C. E., Tschann, J. M., \& Millstein, S. G. (1993). Autonomy, relatedness, and the initiation of health risk behaviors in early adolescence. Health Psychology, 12(3), 200-208.

United States Department of Health and Human Services (1993). Eighth special report to the U.S. Congress on alcohol and health. Washington, D.C.: U.S. Department of Health and Human Services.

United States Department of Health and Human Services. (1994). Preliminary Estimates from the 1993 National Household Study on Drug Abuse. Washington, D.C.: U. S. Department of Health and Human Services, Substance Abuse and Mental Health Services Administration, Office of Applied Studies.

United States Department of Justice (1992). Uniform Crime Reports for the United States 1992. Washington, D.C.: U.S. Department of Justice, Federal Bureau of Investigation.

United States General Accounting Office (1987). Drinking-age laws: An evaluation synthesis of their impact on highway safety. GAO/PEMD-87-10. Report to the Chairman, Subcommittee on Investigations and Oversight, Committee on Public Works and Transportation, House of Representatives.

Valois, R. F., Vincent, M. L., McKeown, R. E., Garrison, C. Z., \& Kirby, S. D. (1993). Adolescent risk behavior and the potential for violence: a look at what's coming to campus. Journal of American College Health, 41, 141-147. 
Van Der Colk, H. (1988). Risky behaviour resulting from bounded rationality. Ergonomics, 31(4), 485-490.

Van Der Molen, H., \& Botticher, A. (1988). A hierarchical risk model for traffic participants. Ergonomics, $\underline{31(4), 537-535 .}$

Vegega, M., \& Klitzner, M. (1988). What have we learned about youth anti-drinking-driving programs? Evaluation and Program Planning, 11, 203-217.

Vegega, M., \& Klitzner, M. (1989). Drinking and driving among youth: A study of situational risk factors. Health Education Quarterly, 16(3), 373-388.

Von Winterfeldt, D., \& Edwards, W. (1986). Decision making and behavioral research. New York: Cambridge University Press.

Walter, H. J., Vaughan, R. D., \& Cohall, A. T. (1993). Comparison of three theoretical models of substance use among urban minority high school students. Journal of the American Academy of Child and Adolescent Psychiatry, 32(5), 975-981.

Warren, R.A., \& Simpson, H.M. (1976). The young driver paradox. Ottawa: Traffic Injury Foundation of Canada.

Wasielewski, P. (1984). Speed as a measure of driver risk: Observed speeds versus driver and vehicle characteristics. Accident Analysis and Prevention, 16(2), 89-103.

Weinstein, N. D. (1980). Unrealistic optimism about future life events. Journal of Personality and Social Psychology, $\underline{39}, 800-820$.

Welford, A.T. (1980). Relationships between reaction time, fatigue, stress, age, and sex. In A.T. Welford (Ed.), Reaction time (pp. 321-354). London: Academic Press.

White, H. R., Hansell, S., \& Brick, J. (1992). Alcohol use and aggression among youth. Alcohol Health and Research World, 14-16.

Whitehead, B.D. (1994). The failure of sex education. The Atlantic Monthly, 274(4), 55-80.

Widom, C. S. (1989). Does violence beget violence? A critical examination of the literature. Psychological Bulletin, 106, 13-28.

Wilde, G. (1982). The theory of risk-homeostasis: Implications for safety and health. New York: Van Nostrand Reinhold.

Wilde, G. (1984). Evidence refuting the theory of risk homeostasis? A rejoinder to Frank McKenna. Ergonomics, 27(3), 297-304. 
Wilde, G. (1985). Assumptions necessary and unnecessary to risk homeostasis. Ergonomics, 28(11), 1531-1538.

Wilde, G. (1986a). Beyond the concept of risk homeostasis: Suggestions for research and application towards the prevention of accidents and lifestyle-related disease. Accident Analysis \& Prevention, 18(5), 377-401.

Wilde, G. (1986b). Notes on the interpretation of traffic accident data and of risk homeostasis theory: A reply to L. Evans. isk Analysis, $\underline{6}(1), 95-101$.

Wilson, R. J., \& Jonah, B. A. (1988). The application of problem behavior theory to the understanding of risky driving. Alcohol, Drugs, and Driving, 4(3-4), 173-191.

Womble, K. (1989). The impact of minimum drinking age laws on fatal crash involvements: An update of the NHTSA analyses. DOT HS 807 349. Washington, D.C.: U. S. Department of Transportation, National Highway Traffic Safety Administration.

Yates, J. F. (1992). Risk taking. New York: Wiley.

Zabin, L. S., Hardy, J. B., Smith, E. A., \& Hirsch, M. B. (1986). Substance use and its relation to sexual activity among inner-city adolescents. Journal of Adolescent Health Care, $7,320-31$.

Zabin, L.S., Hirsch, M.B., Smith, E.A., Streett, R., \& Hardy, J.B. (1986). Adolescent pregnancy-prevention program. Journal of Adolescent Health Care, $\underline{7}, 77-87$.

Zador, P. L. (1989). Alcohol-related relative risk of fatal driver injuries in relation to driver age and sex. Arlington, VA: Insurance Institute for Highway Safety.

Zelnick, M., \& Kim, Y. J. (1982). Sex education and its association with teenage sexual activity, pregnancy, and contraceptive use. Family Planning Perspectives, 14, 117-126.

Zimmerman, M. A., \& Maton, K. I. (1992). Life-style and substance use among male AfricanAmerican urban adolescents: A cluster analytic approach. American Journal of Community Psychology, 20(1), 121-138.

Zuckerman, M. (1979). Sensation seeking: Beyond the optimal level of arousal. Hillsdale, NJ: Erlbaum.

Zuckerman, M., Eyseneck, S. B. G., \& Eysenck, H. J. (1978). Sensation seeking in England and America: Cross cultural, age and sex comparisons. Journal of Consulting and Clinical Psychology, 46, 139-149. 
Zuckerman, M., \& Neeb, M. (1980). Demographic influences in sensation seeking and expressions of sensation seeking in religion, smoking, and driving habits. Personality and Individual Differences, $\underline{1}, 197-206$. 